\title{
Análise dos Programas de Residência para formação do médico de família no Estado do Ceará
}

Rita Erotildes Maranhão Mariano

Tese apresentada ao Programa de Pós-Graduação em Saúde Pública para obtenção do título de Doutor em Saúde Pública.

Área de Concentração: Serviços de Saúde Pública Orientador: Prof. Dr. Eurivaldo Sampaio de Almeida

São Paulo 
É expressamente proibida a comercialização deste documento, tanto na sua forma impressa como eletrônica. Sua reprodução total ou parcial é permitida exclusivamente para fins acadêmicos e científicos, desde que na reprodução figure a identificação do autor, título, instituição e ano da tese/dissertação. 


\title{
Análise dos programas de residência para a formação do médico de família no estado do - Ceará 2010.
}

\author{
Rita Erotildes Maranhão Mariano
}

Tese apresentada ao Programa de PósGraduação em Saúde Pública da Faculdade de Saúde Pública da Universidade de São Paulo para obtenção do título de Doutor em Saúde Pública, no Curso de Doutorado Interinstitucional em Saúde Pública, no Estado do Ceará, junto à Universidade Federal do Ceará, Universidade Estadual do Ceará e Escola de Saúde Pública do Ceará.

Área de Concentração:

Serviço de Saúde Pública

Orientador:

Prof. Titular Eurivaldo Sampaio de Almeida

\section{São Paulo}

2010

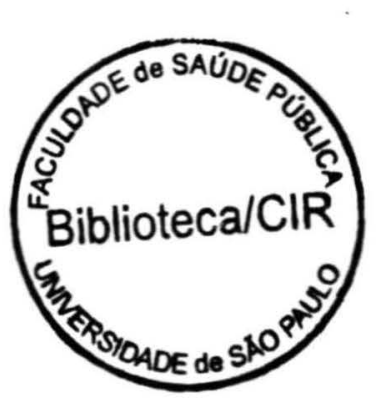




\section{AGRADECIMENTOS}

- À Deus, na pessoa de Jesus Cristo, razão de ser da minha existência, que sempre esteve ao meu lado e me conduziu ao longo desse trabalho, levando-me nos braços, nos momentos mais difíceis.

- Aos meus filhos Patrícia e Matheus, que tão bem souberam entender a minha divisão de tempo, renunciando aos períodos de lazer, durante a realização desse trabalho. Esse momento me fez amá-los de forma mais intensa e o meu reconhecimento pelo apoio não cabe em palavras.

- Ao Prof. Dr. Eurivaldo Sampaio de Almeida, orientador desse trabalho, pela segurança transmitida e pela paciência e apoio nos momentos de desânimo.

- Ao Doutorado em Saúde Pública da Faculdade de Saúde Pública (FSP) da Universidade de São Paulo (USP) e seu corpo docente, que transmitiram conhecimento e experiência com dedicação.

- À mais que amiga Virgínia Maria Costa de Oliveira que sempre esteve ao meu lado, pelos seus inestimáveis e permanentes apoio e incentivo e pela demonstração de amizade e carinho. 
- À grande amiga Jocileide Sales Campos, pelo incentivo constante desde o primeiro momento deste Doutorado, transformando em ações práticas a realização deste sonho.

- À Dra. Anamaria Cavalcante e Silva, ex-Superintendente da Escola de Saúde Pública do Ceará, por ser a responsável direta pela articulação de mais essa conquista para nós cearenses, e pela grande demonstração de carinho.

- Ao Dr. Osmar Vasconcelos, Coordenador local do Doutorado, pela sua amizade, carinho e por me permitir recorrer sempre nos momentos mais difíceis.

- À amiga Isabel Cristina Cavalcanti Carlo Diniz pelo seu apoio e incentivo, por providenciar as condições de seguir este trabalho.

- À Dra. Maria de Fátima Antero Sousa Machado pela inestimável ajuda nos caminhos da pesquisa qualitativa.

- Ao Dr. Alexandre de Lima Santos pelo apoio e disponibilidade em fornecer documentos que foram de grande valia.

- À Escola de Saúde Pública do Ceará, na pessoa de seu superintendente Haroldo Jorge de Carvalho Pontes, pela oportunidade dessa realização. 
- À Dra. Sílvia Mamede Studart Soares, ex-Superintendente da Escola de Saúde Pública do Ceará, exemplo de profissionalismo, desde os idos tempos do Distrito Sanitário I, da Secretaria da Saúde de Fortaleza, quando a conheci.

- A toda equipe do Centro de Desenvolvimento Educacional em Saúde (CEDES) da Escola de Saúde Pública do Ceará, Deusimar Ribeiro da Silva, José Batista Cisne Tomaz, Joselene Dutra Mota Silva, Núbia Maria Arruda Bastos pelo apoio e incentivo.

- A toda equipe dos outros cursos da Escola, a todos os outros funcionários, enfim a todos aqueles que fazem a ESP-CE, pelo apoio e torcida e pela alegria de poder compartilhar essa vitória.

- Aos colegas do curso, pela convivência e dificuldades que conseguimos vencer juntos.

- A toda a equipe da biblioteca da ESP-CE pela dedicação e ajuda na busca da bibliografia necessária.

- Aos coordenadores dos Programas de Residência em Medicina de Família e Comunidade, pela colaboração e por fomecer as informações e os documentos necessários à realização desta pesquisa. 
- Aos médicos residentes que tão gentilmente aceitaram participar deste estudo.

- À minha irmã Nilde e às minhas sobrinhas Larissa e a pequena Letícia, que mesmo sem saber foi minha grande fonte de inspiração.

- A todos aqueles que de algum modo colaboraram para a realização desse trabalho. 
"Feliz o homem que acha sabedoria, e o homem que adquire conhecimento; porque melhor é o lucro que ela dá do que o da prata, e melhor a sua renda do que o ouro mais fino.

Mais preciosa é do que pérolas, E tudo o que podes desejar Não é comparável a ela".

(Provérbios 3: 13-15) 


\section{RESUMO}

MARIANO, R. E. M. Análise dos programas de residência para formação do médico de família no estado do Ceará. [tese de doutorado]. São Paulo: Faculdade de Saúde Pública da Universidade de São Paulo. 2010

Introdução - A história das políticas de saúde no Brasil sempre esteve atrelada à necessidade de melhorar, quantitativa e qualitativamente, os recursos humanos responsáveis pelo desenvolvimento das ações de saúde. A criação do Sistema Único de Saúde (SUS) demandou um perfil de recursos humanos compatível com as exigências desse novo modelo. Para garantir a implementação e consolidação do SUS, em consonância com seus princípios, fez-se necessária a organização da Atenção Primária em Saúde como porta de entrada aos senviços de saúde. Para tanto, foi criado, pelo Ministério da Saúde, em 1994, a Estratégia Saúde da Família (SF). A partir da implantação da SF verificou-se a necessidade de formação dos profissionais de saúde, em especial, do médico de família, para exercer suas atividades neste campo de atuação. Assim, a Residência Médica, caracterizada como a interface entre as instituições de ensino formadoras do profissional médico e os serviços de saúde, tem buscado formar o médico de família, por meio de programas criados por diversas instituições. Objetivos - Caracterizar os Programas de Residência existentes no Estado do Ceará, para formação do médico de família. Métodos Pesquisa com abordagem qualitativa, de caráter descritivo, a partir da análise de fontes secundárias e documentais e da coleta de dados primários, mediante a realização de entrevistas em profundidade com informantes-chave, iniciada após prévia aprovação do Comitê de Ética em Pesquisa e assinatura do termo de consentimento livre e esclarecido pelos entrevistados. Os sujeitos são residentes das Residências em Medicina de Família e Comunidade. A análise do material seguiu os ensinamentos da Análise de Conteúdo de Bardin. Resultados - Os currículos dos Programas de Residência foram desenhados para utilizar metodologias ativas de aprendizagem, a fim de aproximar a teoria da prática e desenvolver competências para formar médicos de família. $\mathrm{Na}$ percepção dos entrevistados estes Programas contribuem para a formação dos médicos de família por serem orientados e baseados na comunidade e enfatizarem o trabalho em equipe. Conclusão - A Residência em Medicina de Família e Comunidade é a modalidade de ensino de excelência para formar o médico de família, por treiná-lo em senviço junto à comunidade e preencher as lacunas de conhecimentos da graduação. Existem alguns obstáculos para superar, como falta de infra-estrutura e capacitação da preceptoria. No entanto, estes Programas dependem de políticas efetivas de reconhecimento dos médicos de família e de legitimação da estratégia Saúde da Família, campo de trabalho desses profissionais, para evitar a evasão nos Programas de Residência em Medicina de Família e Comunidade.

Descritores: Capacitação de Recursos Humanos em Saúde, Educação de Pós-Graduação em Medicina, Internato e Residência, Programa Saúde da Família (Estratégia Saúde da Família). 


\section{ABSTRACT}

MARIANO, R. E. M. Análise dos programas de residência para formação do médico de família no estado do Ceará. /An analysis of residency programs to train family doctors in the state of Ceará, Brazil. [thesis]. São Paulo (BR): Faculdade de Saúde Pública da Universidade de São Paulo. 2010.

Introduction - The history of health policies in Brazil has always been linked to the need for qualitative and quantitative improvements in the human resources responsible for the development of health actions. The creation of the Unitary Health System (SUS) demanded a human resources profile that was compatible with this new model. To guarantee the implementation and consolidation of the SUS, according to its principles, it was necessary to organize Primary Health Care as the gateway to health services. For this, in 1994 the Ministry of Health created the Family Health Strategy (SF). When the SF was implemented the need for training health professionals was verified, especially the family doctor, to act in this field. Thus, the Medical Residency, characterized as the interface between medical training bodies and the health service, has sought to train family doctors, through programs created by several institutions. Objectives To characterize the Residency Programs in the state of Ceará which train family doctors. Methods - Qualitative research of a descriptive nature, using secondary and document sources and the collection of primary data by carrying out in-depth interviews with key informants. Research started after approval by the Research Ethics Committee and the informed signing of terms of consent by interviewees. The subjects are residents in Family and Community Health. The material was analyzed using the teachings of Bardin's Content Analysis. Results - The curricula of the residency Programs were designed to use active leaming methodologies to bring theory closer to practice and develop the competencies to train family doctors. In the perceptions of the interviewees these Programs contribute towards the training of family doctors because they are community based and emphasize team work. Conclusion - The Residency in Family and Community Medicine is a an excellent modality to instruct family doctors as the training is in-service with the community and it fills in gaps in knowledge at graduation. There are some obstacles to be overcome, such as the lack of infrastructure and the qualification of preceptors. However, these Programs depend on effective policies which recognize family doctors and legitimize the Family Health strategy, the area in which these professionals work, to avoid the flight of professionals from Family and Community Medicine Residency Programs.

Keywords: Training of Human Resources in Health, Postgraduate Medical Education, Internship and Residency, Family Health Program (Family Health Strategy) 


\section{ÍNDICE}

1 INTRODUÇÃO..................................................................................................... 17

1.1 A EDUCAÇÃO MÉDICA NO BRASIL ................................................... 31

1.2 SAÚDE PÚBLICA, MEDICINA SOCIAL E A EDUCAÇÃO MÉDICA...... 38

1.3 A RESIDÊNCIA MÉDICA......................................................................... 45

1.4 A EDUCAÇÃO PROFISSIONAL ATRAVÉS DA RESIDÊNCIA MÉDICA ..... 50

1.5 A ESTRATÉGIA SAÚdE DA FAMÍLIA E A QUALIFICAÇÃO DE SUAS EQUIPES............................................................................................................ 58

1.6 O PROGRAMA DE RESIDÊNCIA EM MEDICINA DE FAMÍLIA E COMUNIDADE 66

1.6.1 O Programa de Residência em Medicina de Família e Comunidade no Ceará 69

2 OBJETIVOS ............................................................................................. 73

2.1 GERAL.................................................................................................. 73

2.2 ESPECÍFICOS............................................................................................. 73

3 METODOLOGIA DO ESTUDO................................................................. 74

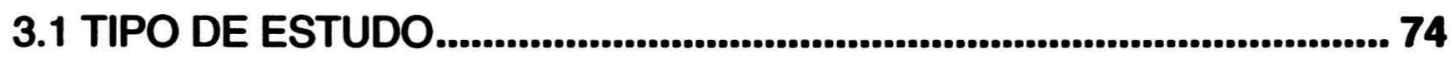

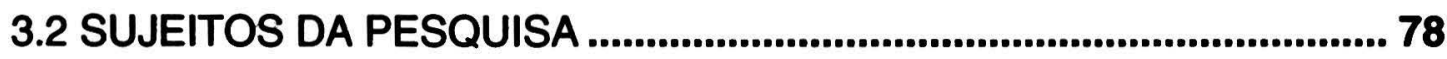

3.3 TÉCNICAS E INSTRUMENTOS PARA A COLETA DOS DADOS ........ 80

3.3.1 Estudo da Documentação Existente ............................................................ 80

3.3.2 Entrevista em Profundidade com Informantes-Chave............................ 82

3.4 PROCESSAMENTO E ANÁLISE DOS DADOS ....................................... 86

3.5 ASPECTOS ÉTICOS DA PESQUISA ..................................................... 90

4 RESULTADOS E DISCUSSÃO..................................................................... 93

4.1 OS PROGRAMAS DE RESIDÊNCIA EM MEDICINA DE FAMÍLIA E COMUNIDADE NO ESTADO DO CEARÁ. 
4.1.1 O Perfil dos Programas................................................................... 95

a) Programa A ..................................................................................................... 95

Categoria I. Construção do PRMFC ................................................................... 95

Categoria II. Desenho do Currículo......................................................................... 97

II.a) Competências a serem desenvolvidas .................................................. 99

II.b) Estrutura Curricular......................................................................................... 109

II.c) Sistema de Avaliação.................................................................................. 111

Categoria III. Preceptoria ........................................................................................ 114

b) Programa B ................................................................................................... 116

Categoria I. Construção do PRMFC ......................................................... 116

Categoria II. Desenho do Currículo.............................................................. 118

II.a) Competências a serem desenvolvidas ................................................ 119

II.b) Estrutura Curricular................................................................................... 120

II.c) Sistema de Avaliação.................................................................................... 124

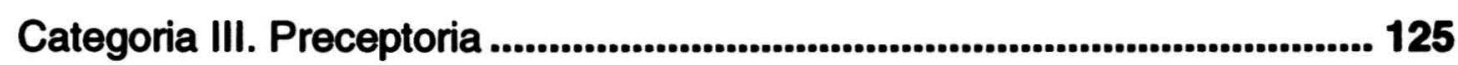

c) Programa C .................................................................................................. 127

Categoria I. Construção do PRMFC ........................................................... 127

Categoria II. Desenho do Currículo................................................................... 129

II.a) Competências a serem desenvolvidas ..................................................... 129

II.b) Estrutura Curricular.................................................................................. 138

II.c) Sistema de Avaliação............................................................................... 144

Categoria III. Preceptoria ............................................................................. 151

4.1.2 A Análise dos Programas de Residência ........................................... 154

Categoria I. Construção do PRMFC ................................................................. 156

Categoria II. Desenho do Currículo.................................................................. 163 
II.a) Competências a serem desenvolvidas .................................................. 166

II.b) Estrutura Curricular....................................................................................... 175

II. c) Sistema de Avaliação............................................................................... 179

Categoria III. Preceptoria ........................................................................... 182

4.2 A PERCEPÇÃO DOS RESIDENTES DOS PROGRAMAS DE RESIDÊNCIA EM MEDICINA DE FAMÍLIA E COMUNIDADE..................... 185

Categoria I. Organização e Execução do Programa de Residência em Medicina de Família e Comunidade....................................................................... 187

I.a) Pontos Positivos na Organização e Execução do Programa.................. 188

I.b) Dificuldades Percebidas na Organização e Execução do Programa... 194

Categoria II. Contribuição da Residência em Medicina de Família e Comunidade para a Prática do Médico de Família

Categoria III. Captação e Evasão da Residência em Medicina de Família e Comunidade: um dilema a ser enfrentado 216

5 CONCLUSÕES. 230

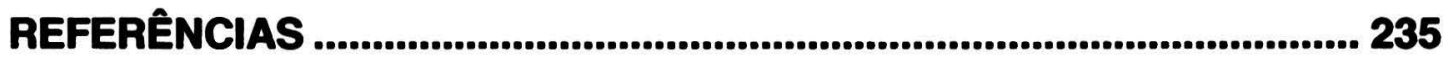

APÊNDICES

APÊNDICE I - Roteiro para entrevistas com os residentes e ex-residentes dos Programas de Residência em Medicina de Família e Comunidade.... 253

APÊNDICE II - Roteiro para entrevistas com os coordenadores dos Programas de Residência em Medicina de Família e Comunidade

APÊNDICE III - Termo de Consentimento Livre e Esclarecido para os médicos residentes

APÊNDICE IV - Termo de Consentimento Livre e Esclarecido para os coordenadores dos Programas de Residência 


\section{Lista de Siglas}

ABEM Associação Brasileira de Educação Médica AMB Associação Médica Brasileira ANMR Associação Nacional dos Médicos Residentes

APS. Atenção Primária em Saúde

ANMR . Associação Nacional de Médicos Residentes

BIRD Banco Intemacional para a Reconstrução e o Desenvolvimento

CERME Centro de Coordenação de Residência Médica CFM Conselho Federal de Medicina CNPq ......... Conselho Nacional de Desenvolvimento Científico e Tecnológico CNRM .Comissão Nacional de Residência Médica

CNS Conselho Nacional de Saúde

COEP Comitê de Ética em Pesquisa

CONASEMS Conselho Nacional de Secretários Municipais de Saúde CONASS .Conselho Nacional de Secretários Estaduais de Saúde COREME .Comissão de Residência Médica Estadual DAB Departamento de Atenção Básica DEREMDepartamento de Residência Médica e Projetos Especiais em Saúde DCN Diretrizes Curriculares Nacionais ESP-CE. Escola de Saúde Pública do Ceará FENAM .Federação Nacional dos Médicos FSP Faculdade de Saúde Pública FUSEC. .Fundação de Saúde do Estado do Ceará IDA Integração Docente Assistencial INAMPS Instituto Nacional de Assistência e Previdência Social LDB Lei de Diretrizes e Bases da Educação Nacional MEC Ministério de Educação MGC Medicina Geral Comunitária MS Ministério da Saúde NESCON Núcleo de Educação em Saúde Coletiva 
OPAS Organização Pan-Americana de Saúde PBL Problem-Based Learning

PITS Programa de Interiorização do Trabalho em Saúde

PNE Plano Nacional de Educação

PRM Programa de Residência Médica PRMFC Programas de Residência Médica em Medicina de Família e

Comunidade.

PROESF Projeto de Expansão e Consolidação da Saúde da Família Pró-Residência Programa Nacional de Apoio à Formação de Médicos Especialistas em Áreas Estratégicas para o SUS PSF Programa Saúde da Família RMFC Residência Médica em Medicina de Família e Comunidade

SAS Secretaria de Atenção à Saúde

SBMGC Sociedade Brasileira de Medicina Geral Comunitária SCNES. Sistema de Cadastro Nacional de Estabelecimento em Saúde SESA-CE Secretaria da Saúde do Estado do Ceará SESU Secretaria de Educação Superior SF estratégia Saúde da Família

SGTES Secretaria de Gestão do Trabalho e da Educação em Saúde SIAB Sistema de Informação da Atenção Básica SMSE Sistema Municipal de Saúde Escola

SSMA Secretaria de Saúde e do Meio Ambiente

SUS Sistema Único de Saúde

TCLE Termo de Consentimento Livre e Esclarecido UBASF Unidade Básica de Saúde da Família

UERJ Universidade Estadual do Rio de Janeiro UFC Universidade Federal do Ceará

UFMG Universidade Federal de Minas Gerais UFRGS Universidade Federal do Rio Grande do Sul UNI União com a Comunidade USP Universidade de São Paulo 


\section{INTRODUÇÃO}

A formação dos recursos humanos em saúde (profissionais e trabalhadores de saúde) no Brasil tem sido objeto de discussão há muitas décadas. A história das políticas de saúde sempre esteve atrelada à necessidade de melhorar, tanto quantitativa como qualitativamente, os recursos humanos responsáveis pelo desenvolvimento das ações de saúde, tornando-se ainda mais evidente a partir dos avanços alcançados com a Constituição de 1988, que assegurou "a saúde como direito do cidadão e dever do Estado", estipulando, como princípios fundamentais, o atendimento integral, a hierarquização, a universalidade, a resolutividade das ações de saúde e a participação popular nos serviços, o que demandou um perfil de recursos humanos capacitado para atender às exigências desse novo modelo assistencial (BRASIL, 1988).

De fato, o movimento de reformas sanitárias já atribuía uma relevância especial aos recursos humanos, entendendo que a sua capacitação, com características de "novo ator", seria fundamental para enfrentar os novos desafios advindos da reforma, colocando-o numa posição de agente de transformação. Como afirmaram SCHRAIBER e PEDUZZI (1993) à época:

“... espera-se que os recursos humanos, por sua importância como componente das práticas, atuem através de sua transformação, como "agente de mudança" da própria prática" (SCHRAIBER e PEDUZZI, 1993, p. 297). 
Desde então se observou um incremento das propostas de formação dos recursos humanos em saúde, para atender às necessidades dos serviços. Propostas estas que vinham sendo objeto de análise em vários encontros, inclusive por ocasião da VIII Conferência Nacional de Saúde, configurando-se, a partir da Constituição, como uma das quatro questões fundamentais para a implementação do Sistema Único de Saúde (SUS), além da descentralização, do financiamento e do controle social (BRASIL, 1988; TEIXEIRA et al., 1996; ALMEIDA, 1996; TEIXEIRA \& PAIM, 1996; MENDES, 2002).

Entretanto, segundo as considerações de SANTANA e GIRARDI (1993), ao analisarem o cenário daquele período, o que se observava era "uma completa inadequação entre as disponibilidades quantitativas e qualitativas dos recursos humanos e os objetivos e metas preconizados para o Sistema Único de Saúde (SUS)".

Quanto a essa perspectiva de capacitação, na busca de adequação dos recursos humanos às novas exigências dos serviços de saúde, GARRAFA (1996) foi categórico ao afirmar que:

"No momento em que o SUS configurou-se como um compromisso constitucional irreversivel, todo setor responsável pela formação de recursos humanos em saúde deveria ter sofrido uma imediata e profunda transformação no sentido de melhor enfrentar (e vencer) os desafios que Ihes foram colocados" (GARRAFA, 1996, p. 3).

Ressalte-se que a própria Constituição estabelece, em seu artigo 200, inciso III, ser competência do SUS, "ordenar a formação de recursos humanos na área da saúde", o que se observa, porém, ao longo dos anos, é 
que essas disposições não têm sido cumpridas, apesar, inclusive, de serem objeto de reivindicação nos diversos momentos de definição das políticas para o setor saúde (BRASIL, 1988; AMARAL, 1996; ALMEIDA e FERRAZ, 2008).

Nesse sentido, ALMEIDA e FERRAZ (2008) consideram que esse preceito institucional não se tem traduzido plenamente em ações práticas, pelo fato de que os instrumentos de poder e de articulação de que dispõe o sistema para orientar o processo de formação e a distribuição dos recursos humanos, não são suficientes, nem tampouco são utilizados na sua totalidade.

Para vários autores, a questão da organização dos recursos humanos passa pela elaboração e implementação de algumas medidas inovadoras, sendo necessárias "negociar novas bases legais e administrativas para a regulação profissional, educacional e das relações de trabalho para a saúde” (SANTANA e GIRARDI, 1993), consubstanciadas em: garantia de sua contratação formal, que assegure os seus direitos como trabalhador; cumprimento do que estabelece a legislação, quanto à responsabilidade do setor saúde, na formação dos recursos humanos, e nesse caso, participando da definição de criação de cursos e instalação de escolas universitárias; modernização dos processos gerenciais e o estabelecimento de compromissos com os profissionais que assegurem a oferta adequada dos senviços de saúde à população (NOGUEIRA, 1985; 1996; SANTANA e GIRARDI, 1993; BÓGUS et al., 1995; MEDICI e GIRARDI, 1996; CHRISTOFARO, 1999; ALMEIDA e FERRAZ, 2008).

Um outro aspecto a ser observado, diz respeito à própria conformação do sistema de saúde no Brasil a partir de 1988, que, a despeito 
de ser denominado de sistema único, assume notadamente um modelo segmentado, composto por três sistemas: o SUS, o Sistema de Atenção Médica Supletiva e o Sistema de Desembolso Direto, sendo o primeiro um sistema público e os outros dois, sistemas privados (MENDES, 2001).

Verifica-se, desse modo, a criação de dois mercados de trabalho distintos para os profissionais de saúde, tendo o setor privado, adepto ao modelo médico-assistencial privatista, maior poder de influência sobre a formulação e implementação dos currículos dos cursos de formação dos profissionais na área da saúde, o que promove a realimentação do modelo médico-hegemônico e dificulta o direcionamento dessa formação profissional para atender às necessidades do setor público.

De fato, o SUS em termos de objetivos e intencionalidade iria exigir profissionais com outro perfil, no entanto, o setor privado continua condicionando a linha de formação dos profissionais de saúde no país.

Além dessas considerações, outras reflexões precisam ser feitas, principalmente no que se refere à qualidade do sistema educacional de formação dos profissionais da saúde, e também quanto à repercussão que essa formação tem sobre a oferta dos senviços à população. Nesse aspecto, CHRISTOFARO (1999) chama a atenção de que:

\footnotetext{
'Se a formação do médico foi a 'origem' da formação dos demais profissionais de saúde de nível superior, quando da criação dos primeiros cursos, a reforma que se instalou com a LDB e com as Leis n. 5.540/68 e 5.692/71, toma como origem do conhecimento a ser ministrado nos cursos de nível médio, na área de saúde, as tarefas que o mercado de trabalho em saúde confia a estes trabalhadores. Isto denota, claramente, que as bases e diretrizes da formação na área de saúde não foram pensadas, em nenhum período, como
} 
forma de responder à complexidade, a especificidade e a interdependência exigidas pela natureza do processo de trabalho em saúde" (CHRISTOFARO, 1999, p. 20).

Corroborando com essa idéia, ALMEIDA e FERRAZ (2008) afirmam que, até agora, a lógica que tem orientado os movimentos educacionais no plano acadêmico "ainda está significativamente deslocada, tanto da realidade epidemiológica quanto dos propósitos assistenciais encetados pelo SUS" e que isso, na prática, influencia significativamente o ordenamento futuro dos profissionais de saúde, inferindo, a guisa de conclusão, que o processo de desenvolvimento dos recursos humanos na área da saúde ocorreu "de forma pontual, fragmentada, descontínua, não dando conta da integralidade da assistência".

E, nessa questão surge um grande desafio, pois para garantir a implementação e consolidação do SUS, e assegurar a observância de seus princípios fundamentais, em especial, o da integralidade da atenção à saúde, fez-se necessária a organização da Atenção Primária em Saúde (APS), como porta de entrada aos serviços de saúde. Para tanto, foi criado, pelo Ministério da Saúde (MS), em 1994, o Programa Saúde da Família (PSF), denominação recebida nos primeiros anos de sua criação, sendo que, posteriormente, em sua fase de consolidação, veio a ser chamada de estratégia Saúde da Família (SF); a qual tem se apresentado como uma estratégia fundamental para a organização da atenção básica (BRASIL, 1998; 2008).

Desde a sua criação, a SF vem sendo implantada, gradativamente, em todo o território nacional. Fato comprovado mediante a 
apresentação dos resultados da pesquisa "Saúde da Família no Brasil - uma análise de indicadores selecionados, 1998 a 2004", realizada pelo Ministério da Saúde, por meio da Secretaria de Atenção à Saúde (SAS), representada pelo Departamento de Atenção Básica (DAB), com o intuito de conhecer de maneira mais detalhada o perfil de expansão da estratégia Saúde da Família no país e a sua relação com alguns indicadores de saúde. Esses dados revelam um aumento progressivo da cobertura da SF, tanto no âmbito nacional como pelas regiões geográficas brasileiras, indicando que a proporção da população coberta em 1998 era de 6,55\% passando para 32,05\%, em 2002 e alcançando aproximadamente $40 \%$ em 2004 e 46,19\% em 2006. Essa evolução reflete um aumento em torno de $700 \%$ no período, considerando que a cobertura de 2006 foi de sete vezes a identificada em 1998, conforme demonstrado na Figura 1 (BRASIL, 2008; 2010a).

Figura 1 - Evolução da cobertura da estratégia Saúde da Família no Brasil, no período de 1998 a 2005/2006.

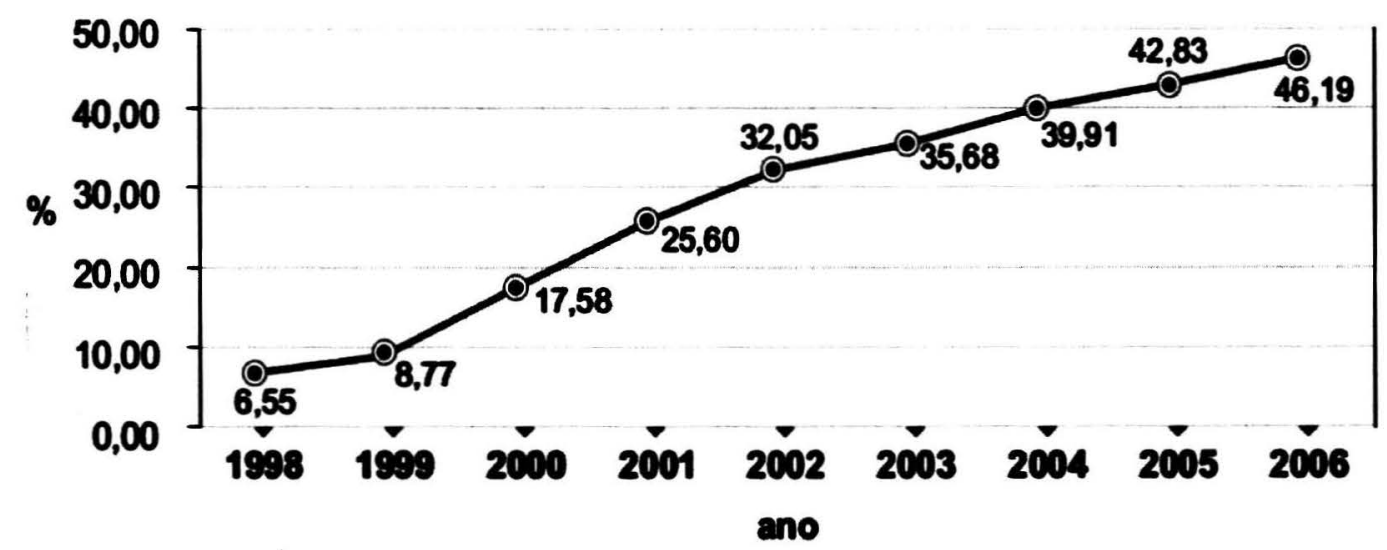

Extraído de: BRASIL. Ministério da Saúde. Saúde da família no Brasil: uma análise de indicadores selecionados: 1998-2005/2006. Secretaria de Atenção à Saúde, Departamento de Atenção Básica. 2. ed. Brasília: Ministério da Saúde, 2008. 200p. Disponível em: http://dab.saude.gov.br/docs/publicacoes/geral/saude_familia_no_brasil_uma_analise_indic adores_selecionados_1998_2006.pdf 
A análise dos dados desta pesquisa, ao comparar o desempenho de cobertura da estratégia de Saúde da Família entre as regiões geográficas do Brasil, nos anos de 1998, 2002 e 2006, demonstrou que a região Nordeste apresentou, no geral, as proporções mais elevadas de cobertura populacional, passando de 9,31\%, em 1998; para 45,40\%, em 2002 e alcançando a proporção de $67,20 \%$ da população nordestina beneficiada com a SF em 2006; como pode ser observado na Figura 2; denotando um aumento de cerca de sete vezes mais, apresentando uma evolução de cobertura semelhante à média de crescimento nacional, para esse intervalo de tempo pesquisado (BRASIL, 2008; 2010a).

Figura 2 - Evolução da cobertura da estratégia Saúde da Família na região Nordeste, no período de 1998 a 2005/2006.

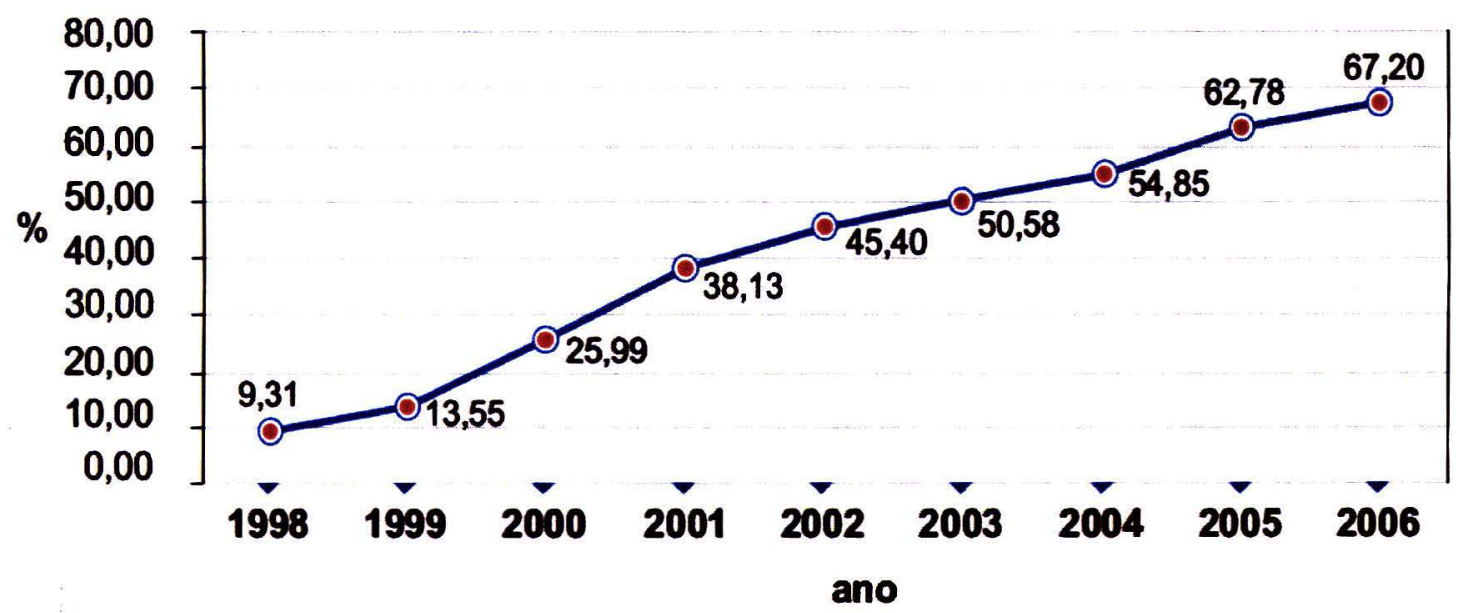

Extraído de: BRASIL. Ministério da Saúde. Saúde da família no Brasil: uma análise de indicadores selecionados: 1998-2005/2006. Secretaria de Atenção à Saúde, Departamento de Atenção Básica. 2. ed. Brasília: Ministério da Saúde, 2008. 200p. Disponível em: http://dab.saude.gov.br/docs/publicacoes/geral/saude_familia_no_brasil_uma_analise_indic adores_selecionados_1998_2006.pdf 
A Figura 3 indica a presença de desigualdades na evolução de cobertura entre as regiões. A região Sudeste apresentou cobertura de 4,94\% em 1998; 23,03\% em 2002 e 34,03\% em 2006, denotando uma evolução de cobertura análoga à região Nordeste. Mas, esta mesma região Sudeste, juntamente com a região Norte (4,82\% em 1998; $29,97 \%$ em 2002 e 41,85\% em 2006) exibiram as menores proporções de população coberta pela SF entre as regiões. Nas regiões Norte e Sul, esta última com 5,07\%, 30,65\% e $44,62 \%$, respectivamente, as proporções de cobertura cresceram, no período, mais do que $800 \%$, ou seja, acima do crescimento médio nacional. A região Centro-Oeste, apesar de registrar a maior cobertura inicial, 10,21\% em 1998, teve uma cobertura de 38,88\% em 2002 e 44,70\% em 2006, mostrando um perfil de evolução abaixo da média nacional, com uma cobertura de mais de quatro vezes durante o período (BRASIL, 2008; 2010a).

Figura 3 - Evolução da cobertura da estratégia Saúde da Família nas regiões geográficas do Brasil, no período de 1998 a 2005/2006.

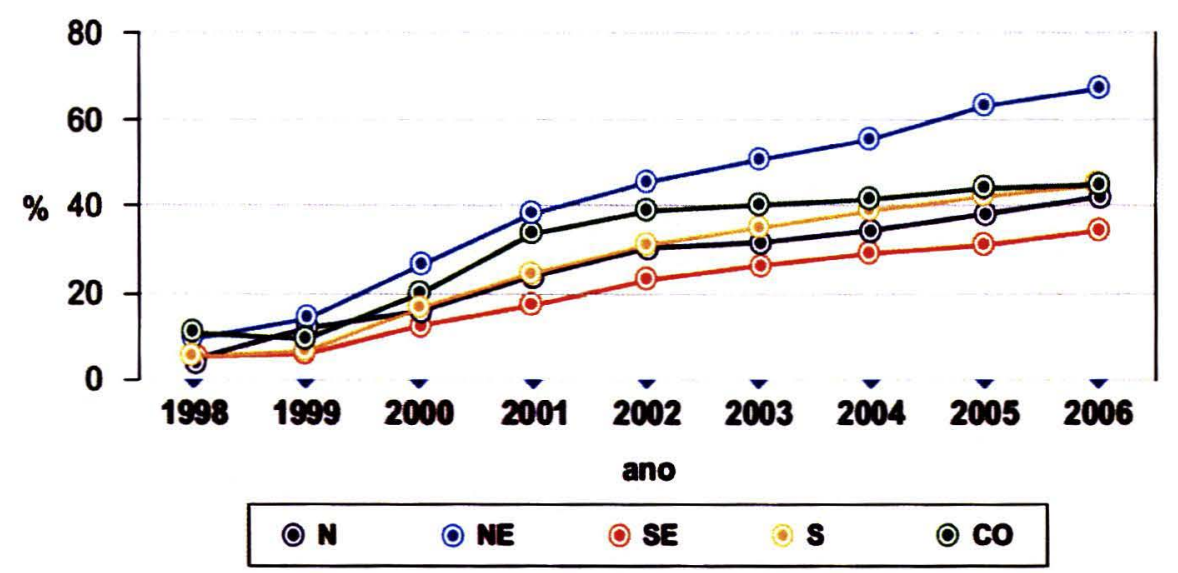

Extraído de: BRASIL. Ministério da Saúde. Saúde da família no Brasil: uma análise de indicadores selecionados: 1998-2005/2006. Secretaria de Atenção à Saúde, Departamento de Atenção Básica. 2. ed. Brasília: Ministério da Saúde, 2008. 200p. Disponível em: http://dab.saude.gov.br/docs/publicacoes/geral/saude_familia_no_brasil_uma_analise_indic adores_selecionados_1998_2006.pdf 
Dados provenientes de levantamentos do Sistema de Informação da Atenção Básica (SIAB) e do Sistema de Cadastro Nacional de Estabelecimento em Saúde (SCNES) revelaram que, em 2003, o Brasil contava com 19 mil Equipes de Saúde da Família implantadas, distribuídas num total de 4,4 mil municípios, perfazendo uma cobertura de $35,7 \%$ da população brasileira, correspondente a cerca de 62,3 milhões de pessoas. Em 2007, quatro anos depois, segundo as mesmas fontes, já havia um total de 27.324 Equipes de Saúde da Família implantadas, em 5.125 municípios, com uma cobertura populacional de $46,6 \%$ da população brasileira, o que corresponde a cerca de 87,7 milhões de pessoas (BRASIL, 2010a).

Informações mais recentes do SIAB e do SCNES indicam que, em fevereiro de 2010, já existem implantadas no Brasil, 30.603 Equipes de Saúde da Família, com a participação de 5.261 municípios. Atualmente, a estratégia Saúde da Família está presente em todos os 184 municípios cearenses e em quase todos os 5.564 municípios brasileiros, contando com um total de 235.768 Agentes Comunitários de Saúde, conforme apresentado na Figura 4 (BRASIL, 2010a). 
Figura 4 - Situação de implantação de equipes de saúde da família, saúde e agentes comunitários de saúde no território nacional, Brasil. Fevereiro, 2010.

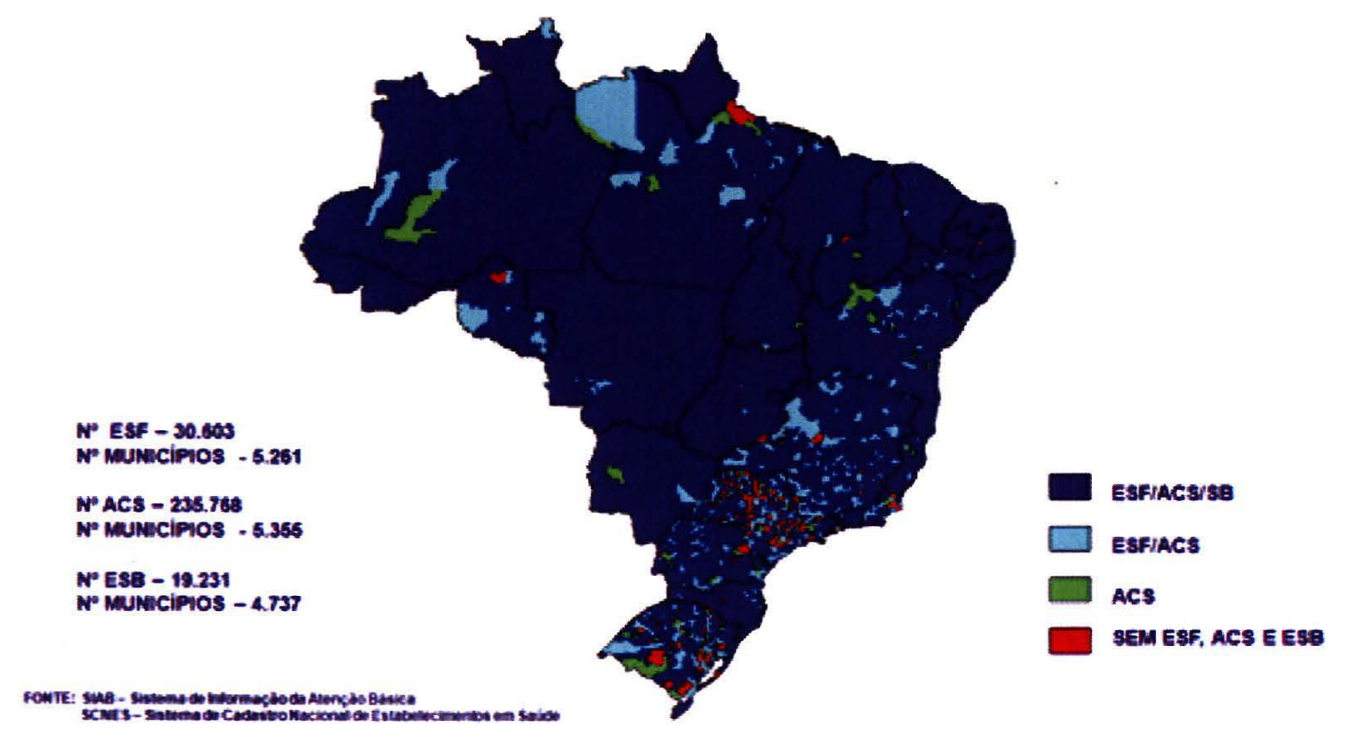

Fonte: Sistema de Informação da Atenção Básica (SIAB) e do Sistema de Cadastro Nacional de Estabelecimento em Saúde (SCNES), 2010.

Todos esses números indicam a grandiosidade do desafio a ser enfrentado, traduzido principalmente, pela crescente demanda por profissionais com o perfil adequado para atender às novas exigências desse modelo de saúde. Assim, as discussões em torno da identificação de formas apropriadas de formação e capacitação desses profissionais entraram na pauta da agenda da saúde no Brasil, buscando resposta para algumas questões, como: qual o perfil exigido para os profissionais do PSF, os quais teriam que atuar principalmente no interior do Estado, inseridos nas comunidades, trabalhando os problemas de saúde de acordo a realidade local? Os profissionais de saúde, em especial os médicos, estão tendo uma formação profissional adequada às necessidades dos serviços de saúde nos quais serão inseridos?

Vale aqui uma breve reflexão sobre a ênfase dada aos profissionais médicos neste estudo, que, por sinal, é corroborada em pesquisas realizadas por 
BLOCH, em 1985, e, posteriomente, por SCHRAIBER e PEDUZZl, em 1993, ambas constatando que, na grande maioria da produção científica sobre recursos humanos, o profissional médico aparece como "eixo do sistema de saúde, refletindo sua posição historicamente hegemônica no cenánio da saúde", e, portanto, sujeito principal das diversas proposições de melhorias do setor. Essa assertiva é confirmada por SCHRAIBER e NEMES (1996), que justificam sua escolha pelo estudo voltado para a categoria médica, afimando que:

“(..) a prática médica é a fundadora da técnica científica moderna e o núcleo original do qual outros trabalhos derivam, constituindo-se, por isso, prática dominante e hegemônica no conjunto das ações em saúde" (SCHRAIBER e NEMES, 1996, p. 109).

Da mesma forma, CARAPINHEIRO (1993) lembra que os médicos, por possuírem autoridade, mediante o domínio do processo diagnóstico-terapêutico, têm uma posição diferenciada na divisão do trabalho e um grande poder de influenciar e conformar as práticas de saúde.

Assim, essa ênfase dada ao profissional médico tem o tornado foco principal das discussões acerca da adequação do perfil requerido para - trabalho na estratégia Saúde da Família e quanto à necessidade deste profissional desenvolver um amplo espectro de competências, capazes de exercer um papel significativo na atenção básica, de modo que esta, com a participação dos demais membros da equipe, possa resolver até $90 \%$ dos problemas de saúde da comunidade.

Entretanto, no que se refere à formação desse profissional, como já referido anteriomente, existe um grande descompasso entre as necessidades 
requeridas pelo sistema público de saúde e o modelo de médico que de fato é reproduzido na graduação nas universidades. Várias tentativas de superação dessas divergências têm sido empreendidas, nas quais o govemo tem procurado estabelecer parcerias com as universidades, tais como: o Programa de Interiorização do Trabalho em Saúde (PITS), os cursos de Especialização em Saúde da Família, os Programas de Residência Médica em Medicina de Família e Comunidade (PRMFC), dentre outros (JANAUDIS et al., 2007).

No que se refere ao Programa de Interiorização do Trabalho em Saúde, este foi criado em 2001, pelo Ministério da Saúde, mediante Decreto Presidencial $\mathrm{N}^{\circ} 3.745$, de 5 de fevereiro de 2001, e regulamentado pelas Portarias Ministeriais $\mathrm{N}^{\circ} 227$, de 16 de fevereiro de 2001, e $\mathrm{N}^{\circ} 758$, de 16 de abril de 2002, substituída pela de № 1.695, de 24 de setembro de 2002.

As diretrizes gerais do PITS foram definidas em 2000, por um grupo de trabalho composto por representantes de entidades das áreas de medicina e enfermagem, representações estudantis, universidades, Conselho Nacional de Secretários Estaduais de Saúde (CONASS), Conselho Nacional de Secretários Municipais de Saúde (CONASEMS) e Organização Pan-americana de Saúde (OPAS) (BRASIL, 2001).

Este programa buscava impulsionar a reorganização da atenção básica à saúde e fortalecer o PSF. Nessa perspectiva, o PITS levava médicos e enfermeiros aos municípios que não dispunham de serviços de atenção à saúde e apresentavam dificuldades em atrair esses profissionais para atender à sua população, sendo implementado nos municípios do Nordeste, do Centro-Oeste e no norte de Minas Gerais, os quais 
apresentavam elevadas taxas de mortalidade infantil, malária, tuberculose e hanseniase. A meta era lotar médicos e enfermeiros em seus territórios, por meio da oferta de incentivos financeiros e de formação profissional aos participantes durante um ano, prorrogável por mais um. Tanto assim que, os profissionais que participavam desse programa faziam um Curso de Especialização em Saúde da Família em instituições de ensino superior, geralmente nos estados onde trabalhavam.

O Ministério da Saúde garantia o fomecimento de equipamentos e material de estudo e trabalho e tutoria para o acompanhamento dos trabalhos das equipes. Assim, cada médico recebia uma bolsa que variava entre $\mathrm{R} \$ 4$ mil e R $\$$ 4,5 mil por mês, concedida pelo Conselho Nacional de Desenvolvimento Científico e Tecnológico (CNPq) em convênio com MS. Esse valor era determinado pela distância e as condições de acesso entre a capital do estado e o município no qual o médico iria trabalhar. Além da bolsa, os profissionais de saúde também ganhavam seguro de vida e contra acidentes pessoais. Os municipios beneficiados entravam com a alimentação, a residência $e \quad 0$ transporte dos médicos. O PITS perdurou até o ano de 2004, quando foi substituido por outras iniciativas govemamentais (BRASIL, 2001; JANAUDIS et al., 2007; MACIEL FILHO e BRANCO, 2008; GIRARDI et al., 2010).

Ainda no sentido de incentivar a adesão dos médicos ao trabalho na Atenção Primária à Saúde e promover a sua capacitação para atuarem na estratégia Saúde da Família, o Ministério da Saúde, promulgou, em 2005, a Portaria $N^{\circ} 1.143$, que visa apoiar financeiramente os Programas de Residência Médica em Medicina de Família e Comunidade por meio do 
custeio de bolsas nas modalidades residente, preceptor, tutor e orientador de serviço, correspondentes do Programa de Bolsas para a Educação pelo Trabalho e demais custos decorrentes da implementação e organização dos programas de residência (BRASIL, 2005).

Assim, a Residência Médica vem se apresentando como a modalidade de eleição para a formação do médico de família, e, para tanto, verifica-se um movimento em busca de modelos e estratégias educacionais que possam torná-la mais efetiva.

De fato, no processo de formação do médico, a Residência Médica é atualmente parte integrante da Educação Médica, configurando-se como a interface entre as instituições de ensino formadoras do profissional médico e os serviços de saúde, nos quais serão inseridos posteriormente. Representa ainda o ingresso do profissional no mercado de trabalho, visto que alguns dos direitos trabalhistas são observados, e, para muitos, configura-se como o primeiro emprego de suas vidas profissionais (MARSIGLIA, 1995; MACHADO M et al., 1997; FEUERWERKER, 1998; 2002; FEUERWERKER e LIMA, 2002).

Oriunda de uma política de saúde voltada para atendimento individual e fragmentado, a Educação Médica, no Brasil, tem deixado lacunas, pelo que a Residência Médica surge como altemativa para complementar a formação profissional, embora não deve ser considera apenas como complemento da graduação, mas como um processo para assegurar especializações nas várias áreas que a Medicina vem se diversificando. 
Considerada como uma forma de treinamento em serviço, a Residência Médica proporciona uma diversidade de experiências práticas, configurando-se como "a porta de entrada" do recém-formado no exercício profissional (MARSIGLIA, 1995; MACHADO M et al., 1997).

Um programa de Residência Médica geralmente dura dois anos, a não ser em algumas especialidades, que exigem, como pré-requisito, a Residência em uma especialidade básica, antes de passar para uma outra de um nível de complexidade maior (MACHADO M et al., 1997; FEUERWERKER, 1998; 2002; FEUERWERKER e LIMA, 2002). Em todo Brasil, estima-se que $50 \%$ dos médicos que se formam têm acesso a uma Residência Médica.

Embora seja vinculada ao Ministério de Educação (MEC), a Residência Médica não é exclusiva da Universidade, podendo ser efetivada nos serviços de saúde ligados ou não a escolas médicas (MACHADO M et al., 1997; FEUERWERKER, 1998).

\subsection{A EDUCAÇÃO MÉDICA NO BRASIL}

O propósito da educação é criar condições que levem o aluno ao aprendizado, o qual uma vez adquirido provoca uma mudança no desempenho, na postura e, consequentemente, uma mudança de vida, fazendo com que as pessoas desenvolvam suas qualidades e habilidades e adquiram outras, ou seja, tornem-se mais aptas. 
Nos trabalhos apresentados por SCHRAIBER, em 1989 e em 1996, a autora chama a atenção sobre esse aspecto ao criticar a tendência de se reduzir o entendimento de Educação à educação escolar, e desta à simples transmissão do saber, pelo que afirma o seguinte:

"Educação significa ensino de saberes e introjeção de valores. Contudo, tem sido valorizada quase que exclusivamente quando se dispõe apenas como transmissão de informações ou adestramento de habilidades, qual seja, ensino de saberes. Esta características dos processos educacionais ocorre sobretudo na sua forma escolar (...) (SCHRAIBER, 1996, p. 45).

CHIAVENATO (1997) ensina que a Educação refere-se a toda influência que o ser humano recebe do ambiente social, durante a sua vida, com o propósito de adaptar-se "às normas e valores sociais vigentes e aceitos", ao passo que a Educação Profissional diz respeito à educação institucionalizada ou não, que objetiva preparar o ser humano para a vida profissional, ou ainda como menciona DE SETA (2000), "à preparação do indivíduo para o trabalho".

Para DUPRET (2000), é necessário, no entanto, ter cuidado para não "romper com aspectos de uma formação humanística, reduzindo a Educação ao atendimento às necessidades emergenciais do mercado, e não à formação do cidadão".

Didaticamente, CHIAVENATO (1997) subdivide Educação Profissional em: Formação Profissional, identificada como a educação profissional que visa preparar e formar o homem para o exercício de uma profissão; Aperfeiçoamento ou Desenvolvimento Profissional, como sendo a 
educação que objetiva ampliar, desenvolver e aperfeiçoar o homem para seu crescimento profissional; e Treinamento, referindo-se à educação profissional, que visa adaptar o homem para determinada tarefa. Uma definição mais ampla de Treinamento poderia ser compreendida como sendo o desenvolvimento sistemático do padrão de atitude, conhecimento, habilidade e conduta, requerido para que um indivíduo desempenhe, de forma adequada, uma determinada tarefa ou serviço (CHIAVENATO, 1997).

LIMA (2008) ressalta que no caso da educação médica, esta também não deve se restringir ao ambiente escolar, visto ter como "processo educativo fundamental as próprias práticas médicas, através das quais, qualifica tecnicamente e inculca os valores e concepções dominantes".

Para VUORI (1991), "a educação pode estar relacionada à qualidade dos serviços de saúde" tanto assegurando que o pessoal da saúde seja qualificado, como educando os prestadores para realizar avaliação de qualidade e utilizar os seus resultados.

SANTANA e CHRISTOFARO (2002) consideram que:

"As articulações entre o processo de formação de profissionais e trabalhadores de saúde e a produção de serviços do setor expressam particularidades da relação geral entre educação e trabalho na sociedade" (SANTANA e CHRISTOFARO, 2002, p. 3).

Já CECCIM e FEUERWERKER (2004, p. 47) propõem que a formação para a área da saúde deve ser uma articulação entre ensino, gestão, atenção e controle social, trazendo o conceito de quadrilátero, em 
que "cada face comporta uma convocação pedagógica, uma imagem de futuro, uma luta política $\Theta$ uma trama de conexões. Cada interseção resulta em trajetos formativos postos em ato".

Fato é que, quanto à formação dos profissionais de saúde, notadamente o médico, sabe-se que ensino da medicina tem origem bastante remota, sendo praticado desde a época primitiva, tendo em Hipócrates, no século V a.C. o grande precursor da medicina como ciência; sendo que sua evolução vem gradativamente acompanhando o desenvolvimento das sociedades contemporâneas em constante transformação, cujas inovações científicas e avanços tecnológicos influenciam fortemente a educação médica, dada as suas possibilidades de aplicação na prática médica (POLIGNANO, 2001; SEEGMÜLLER et al., 2008).

No Brasil, no período imperial, os serviços de saúde existentes se ressentiam de um número suficiente de profissionais médicos, tanto que, em 1789, a capital brasileira só contava com quatro médicos exercendo suas atividades profissionais, todos com formação na Europa. E, dada à carência desses profissionais, a atividade médica passou a ser exercida também pelos boticários, categoria profissional responsável pela manipulação das fórmulas farmacêuticas prescritas pelos médicos (POLIGNANO, 2001; SEEGMÜLLER et al., 2008).

As primeiras escolas médicas no Brasil foram criadas ainda no século XIX, quando, em 1808, D. João VI fundou na Bahia, o Colégio MédicoCinúrgico no Real Hospital Militar da cidade de Salvador, e, no mesmo ano, foi criada a Escola de Cirurgia do Rio de Janeiro, anexa ao Real Hospital Militar. 
Depois de quase um século, em 1898, criou-se a terceira escola médica, localizada em Porto Alegre. Durante o século XIX, a educação médica brasileira era influenciada pelo modelo de ensino europeu, notadamente da escola francesa (POLIGNANO, 2001, EDLER, 2001; SEEGMÜLLER et al., 2008).

No entanto, a partir do início do século $X X$, o modelo de saúde no Brasil e, consequentemente, o de ensino médico, sofreram a influência direta do Relatório Flexner (Medical Education in the United States and Canadá: A Report to the Carnegie Foundation for the Advancement of Teaching), publicado em 1910, nos Estados Unidos. Abraham Flexner, da Universidade John Hopkins, a convite da Fundação Carnegie, realiza uma avaliação da Educação Médica nas escolas médicas nos Estados Unidos e no Canadá, o que resultou no fechamento de 124 das 155 escolas de medicina norteamericanas e a dedicação de grande parte da carga horária do currículo às disciplinas básicas, privilegiando o estudo do corpo humano segundo órgãos e sistemas, com saberes e práticas estruturados em tomo das especialidades médicas. Por considerar que a aprendizagem deveria ser exclusivamente hospitalar, sendo os ambulatórios inadequados para o ensino, requeria a posse dos hospitais pelas escolas médicas, estimulava a docência em tempo integral, ficando os professores como chefes dos senviços desses hospitais. Dentro dessa lógica foram criados os hospitais universitários (SILVA, 2002; SEEGMÜLLER et al., 2008).

Vários autores descrevem o modelo flexneriano como sendo centrado na doença; devotado à tecnologia; com atendimento individualista, trabalho isolado e centrado no médico; voltado para o curativismo, desconsiderando o 
conjunto de fatores envolvidos no processo saúde-doença, e assim, de certo modo, reduzindo o entendimento e as práticas de promoção e prevenção, isso não significa reduzir a importância da assistência médica curativa, dentro de um processo integral de atenção à saúde (MENDES, 1995; 1996; RAGGIO e GIACOMINI, 1996; MACHADO J et al., 1997; SILVA, 2002).

A América Latina e o Brasil adotaram esse modelo, a partir das décadas de 1940 e 1950, justo no momento em que eram criadas novas escolas de Medicina e eram reestruturadas as escolas vigentes (NUNES, 1985; LAGUNA, 1992; MARSIGLIA, 1995; POLIGNANO, 2001; EDLER, 2001; SEEGMÜLLER et al., 2008).

Por isso, a reestruturação do ensino médico, no Brasil, nessa época, sofreu, conseqüentemente, a influência da reforma do ensino americano, que exerce, ainda hoje, grande influência na formação do médico e dos demais profissionais de saúde na América Latina (NUNES, 1985).

No entanto, a inadequação do modelo assistencial flexneriano, percebida à medida que a doença transmissível vem perdendo importância relativa, a expectativa de vida tem aumentado e que as doenças crônicas e as causas extemas vão ganhando força, e a conseqüente crise da saúde têm seus reflexos no sistema educacional médico e das demais áreas da saúde. Observa-se um distanciamento entre o ensino universitário e as necessidades dos serviços de saúde e da população usuária desses serviços, o que demanda a construção de novos modelos de formação e capacitação dos recursos humanos em saúde (MACHADO M. et al., 1997; MACHADO J. et al., 1997; POLIGNANO, 2001; EDLER, 2001; SEEGMÜLLER et al., 2008). 
O profissional médico em seu processo de formação, além de passar pelo curso de graduação regular em uma escola médica, busca aumentar sua qualificação em programas de pós-graduação, sendo os Programas de Residência Médica os mais requisitados pelos recémformados, por tratar-se de uma forma de especialização, caracterizada por treinamento em senviço. Entretanto, nem sempre a escolha desses profissionais recai nas especialidades médicas mais requeridas pelos sistemas de saúde vigentes, apresentando assim, um descompasso entre as necessidades dos serviços e os interesses da classe médica.

Assim, na perspectiva de formação desses profissionais, o Ministério da Saúde, diante da necessidade de consolidação da política nacional de saúde, desde 2003, vem implementando a Política de Educação Permanente para o SUS. Notadamente no que se refere à qualificação das equipes de saúde da família, tem efetuado ações articuladas com as instituições formadoras, de modo a adequar o ensino na graduação e pósgraduação às necessidades dos sistemas e serviços de saúde, e, no caso específico da estratégia saúde da família, responder aos desafios postos pela expansão e qualificação da atenção básica. 


\subsection{SAÚDE PÚBLICA, MEDICINA SOCIAL E A EDUCAÇÃO MÉDICA}

A modema Saúde Pública surgiu como uma ação social, por volta de 1800 a 1840, particularmente na Inglaterra, em decorrência da preocupação com as condições de vida da população, aglomerada nos grandes centros em busca dos empregos gerados pelo processo de industrialização crescente. Inicia-se, desde então, um processo de reforma sanitária e reorganização dos serviços de saúde, a partir da criação da Lei de Proteção aos Pobres, considerada a primeira legislação de saúde pública do mundo, e da publicação do relatório "The Sanitary Conditions of the Labouring Population of Great Britain", em 1842, pelo sanitarista Edwin Chadwick, no qual apresentava uma análise das condições sócio-econômicas e sanitárias da classe trabalhadora, e propunha ações para prevenir e controlar as enfermidades (MARSIGLIA, 1995; RAGGIO e GIACOMINI, 1996; NUNES, 2005).

Já o conceito de Medicina Social surge em 1848, cunhado pelo médico francês Jules Guérin, no texto denominado "Médicine Sociale", publicado no La Gazette Médicale de Paris, no dia 11 de março, no qual argumentava que os termos tais como polícia médica, saúde pública e medicina legal eram abordagens parciais e não coordenadas, os quais deveriam se juntar em um todo organizado sob a designação de Medicina Social. Segundo NUNES (2005), a institucionalização da Medicina Social ocorre tempos depois, em 1881, em Munique, com a criação do primeiro curso de Medicina Social, seguido dos cursos das Universidades de Harvard, 
em 1913 e de Johns Hopkins, em 1916; estes já no século XX, enfatizando assim, a corrente da determinação social das doenças (NUNES, 2005).

Posteriomente, no entanto, os avanços científicos, principalmente ao nível da microbiologia, na última fase do século $X I X$ e início do século $X X$, promoveram uma mudança na concepção do processo saúde-doença e criaram uma nova dimensão no campo da saúde pública, mudando-se o foco das ações de controle das epidemias, passando-se a combater o agente específico, seja através de medicamentos desenvolvidos e administrados ao paciente, seja pelo combate aos vetores, requerendo um potencial de ação organizada contra as doenças transmissíveis e demandando o aumento de conhecimentos nesta área, o que impulsionou o surgimento da medicina científica, que viria a caracterizar o modelo hegemônico de prestação de serviços de saúde no mundo ocidental, tendo como marco fundamental o Relatório Flexner, publicado em 1910 (NUNES, 2005).

Desse modo, a concepção de medicina científica, calcada no modelo flexneriano de ensino médico, provocou uma mudança na prática médica, que a partir de então passou a ser orientada por um conjunto de elementos estruturais complementares e sinérgicos entre si, representados pelo mecanicismo, segundo o qual o corpo humano é visto como uma máquina; o biologismo, originado a partir dos avanços da microbiologia; o individualismo, elegendo o indivíduo como seu objeto de atuação, distanciando-o de sua vida e dos aspectos sociais envolvidos no processo de adoecimento e cura; a especialização, uma vez que o mecanicismo induziu ao aprofundamento do conhecimento científico nas partes 
específicas do corpo, atenuando a visão holística do indivíduo; a tecnificação do ato médico, estruturando a engenharia biomédica; o curativismo, ao prestigiar os aspectos curativos, enfatizando o diagnóstico e a terapêutica; e à exclusão das práticas altemativas, sob o mito do conceito de eficácia a partir de práticas cientificamente comprovadas (MENDES, 1996, p. 239).

Em 1920, o ministro da saúde da Inglaterra, Bertrand Dawson, contrapondo-se ao modelo flexneriano, apresenta a Medicina Comunitária, como um modelo alternativo de assistência à saúde, e na publicação do Informe Dawson, preconizava a organização do sistema de saúde em três níveis: os centros primários de atenção à saúde, os centros secundários e os hospitais de ensino, descrevendo a função de cada nível de atenção e estabelecendo a base para o conceito de regionalização dos serviços; visando com isso favorecer uma coordenação das ações preventivas e curativas locais, além de se constituir em uma referência para a organização do modelo de atenção inglês, que à época apresentava custos elevados, crescente complexidade da atenção médica e baixa resolutividade. Para esse tipo de assistência, Dawson já preconizava um atendimento coordenado por médicos generalistas, com competência para atuarem nas comunidades e sobre o indivíduo (MARSIGLIA, 1995, MOROSINI, 2007).

Com relação ao ensino médico, Dawson propunha que as ações preventivas e curativas deveriam estar integradas no processo de formação dos futuros profissionais e enfatizava a atenção primária e as atividades coletivas de promoção e prevenção à saúde (MARSIGLIA, 1995). 
Não obstante, o modelo americano perdurou inalterado por quase meio século, e somente a partir dos anos 60 é que foram sendo criados os Departamentos de Medicina Preventiva nas escolas de medicina norteamericanas (MARSIGLIA, 1995; RAGGIO e GIACOMINI, 1996).

No Brasil, apesar da forte influência flexneriana, já na década de 20 foi criado o Laboratório de Higiene, junto à Faculdade de Medicina e Cirurgia, em São Paulo, em 1918, sendo oficializado pelo governo do estado, em 1924, o qual adquiriu autonomia, deixando de ser dependência direta da Faculdade de Medicina, sob a denominação de Instituto de Higiene de São Paulo, cujo objetivo era ministrar cursos para os estudantes de Medicina e formar sanitaristas. Posteriormente, foi denominado de Faculdade de Higiene e Saúde Pública de São Paulo, e depois Faculdade de Saúde Pública. (MARSIGLIA, 1995; NUNES, 2005).

Em 1950, foi criada a Escola Nacional de Saúde Pública no Rio de Janeiro (MARSIGLIA, 1995; MACHADO M. et al., 1997).

Duas décadas depois, em 1978, a Conferência Intemacional de Alma-Ata, sobre Cuidados Primários em Saúde, elegeu a Atenção Primária em Saúde como estratégia para alcançar a meta de "Saúde para Todos no Ano 2000", e teve grande influência nas novas políticas de saúde adotadas em todo o mundo, a partir de então, conseguindo, inclusive, a adesão das universidades, uma vez que reforçava a experiência dos Departamentos de Medicina Preventiva e as atividades além dos hospitais de ensino (OMS, 1978; MARSIGLIA, 1995; MENDES, 1995; 1996; FEUERWERKER e MARSIGLIA, 1996; MACHADO M. et al., 1997; FEUERWERKER, 1998; SILVA, 2002). 
No Brasil, o final da década de 1970 e o início dos anos 1980 foram marcados por uma profunda crise fiscal no Estado, com fortes repercussões na Previdência Social, dando vez a um grande movimento por reformas sociais, dentre elas a reforma sanitária, que culminam com a implantação do SUS (MARSIGLIA, 1995; MENDES, 1995; 1996; TEIXEIRA e PAIM, 1996; GALLO et al., 1996; MACHADO M. et al., 1997; FEUERWERKER, 1998; SILVA, 2002).

Tratava-se de um período de intensa discussão acerca das questões relacionadas à saúde e à formação dos profissionais de acordo com as necessidades dos serviços, em que era requerida uma maior integração entre os hospitais universitários e a rede de serviços, visando a garantia da continuidade da atenção e a diversificação das experiências práticas dos estudantes (MARSIGLIA, 1995; RODRIGUÉZ, 1995; FEUERWERKER, 1998).

É nesse contexto que desponta a proposta de Integração Docente Assistencial (IDA), representando um movimento que se estendeu por toda a América Latina, com apoio da OPAS e da Fundação W. K. Kellogg, sendo concebida, no Brasil, durante o processo de reforma sanitária, tornando-se depois política pública, incentivada por meio de iniciativas governamentais de variadas ordens (NOGUEIRA, 1985; ROVERE, 1994; MARSIGLIA, 1995; BELACIANO, 1996; GARRAFA, 1996; FEUERWERKER, 1998).

Na década de 1990, a Fundação W. K. Kellogg lança o Programa UNI - União com a Comunidade, tendo como base, principalmente, os resultados de uma série de estudos analíticos acerca das experiências de Integração Docente Assistencial. Este Programa representava um esforço de cooperação entre três componentes para a educação dos profissionais de 
saúde: as universidades, os senviços de saúde e as organizações comunitárias. Buscava-se, com isso, desenvolver, de forma integrada, modelos inovadores de ensino, de sistemas de saúde e de ação comunitária, a fim de intensificar o processo de mudança na formação desses profissionais (KISIL, 1996; CYRINO e CYRINO, 1997; MACHADO J. et al., 1997; FEUERWERKER, 2001a).

Como resultado do processo de amadurecimento das experiências desses dois projetos, IDA e UNI, surge a Rede UNIIDA, com o objetivo primordial de fortalecer a parceria entre os três elementos constitutivos desses projetos universidade, senviços de saúde e comunidade - tendo, principalmente, uma atuação na articulação política dos projetos (RANGEL e VILASBÔAS, 1996).

Para FEUERWERKER (1998), apesar das expectativas de que esses programas fossem capazes de produzir uma mudança mais profunda no ensino das profissões de saúde, poucas alterações ocorreram "no papel que a Universidade assume na educação permanente dos profissionais da saúde e na relação entre hospitais universitánios, escolas médicas e rede de serviços".

De acordo com MACHADO J. et al. (1997), o que se esperava das instituições de ensino superior era a adoção de um modelo de formação dos profissionais de saúde que reforçasse a formação acadêmica, em consonância com as práticas de ensino centradas no trabalho profissional, considerando, principalmente, os sistemas de saúde e as comunidades que seriam futuramente assistidas por esses profissionais. Pretendia-se, de igual forma, que os métodos de ensino-aprendizagem baseados no processo de memorização e centrados no professor, fossem substituídos por metodologias baseadas no auto-aprendizado e na educação permanente. 
Observa-se que todas as propostas de inovações nas práticas dos profissionais de saúde, como estratégia de favorecer a operacionalização do modelo de saúde, estabeleciam que a formação fosse baseada nas necessidades da comunidade e reforçavam a idéia de estabelecer um sistema de educação permanente desses profissionais (QUINTANA, et al., 1994; RIBEIRO e MOTTA, 1996).

Portanto, o objetivo de envolver as universidades no processo de educação permanente seria na perspectiva de se ter um amplo programa, em que as universidades seriam as organizadoras desse processo, por conta da sua estrutura e do domínio dos conhecimentos e da tecnologia na área da educação. Além disso, como já existia uma aproximação entre estas e os serviços de saúde, através dos convênios de Integração Docente Assistencial, esperava-se a ampliação desse convênio, de forma que envolvesse a Educação Permanente em Saúde e os Projetos IDA (PARKHOUSE, 1979; OMS, 1990; ROVERE, 1994).

Na busca de resolver esta questão, em 2004, o Ministério da Saúde, corroborando as deliberações do Conselho Nacional de Saúde, de setembro de 2003, instituiu, através da Portaria № 198/04, a Política Nacional de Educação Permanente em Saúde como estratégia do SUS para a formação e o desenvolvimento de trabalhadores para o setor, com a conseqüente aprovação da estratégia de Pólos ou Rodas de Educação Permanente em Saúde, "como instâncias locorregionais e interinstitucionais de gestão da Educação Permanente" (BRASIL, 2004a; 2004b). 
E destaca que a negociação entre os serviços de saúde e as instituições formadoras para a qualificação dos profissionais de saúde, "não admite a organização de um menu de cursos ou pacotes programáticos pontuais"; mas passa pelo debate e implementação da melhor e mais adequada proposta, inclusive com a definição dos conteúdos, formas, metodologias e responsáveis, a fim de garantir o impacto desta ação na resolução dos problemas identificados nos serviços de saúde, que geraram a demanda de capacitação (BRASIL, 2004a; 2004b).

\subsection{A RESIDÊNCIA MÉDICA}

A Residência Médica teve sua origem nos Estados Unidos, como um curso de pós-graduação, com a finalidade de formar recursos humanos na área médica, ainda no século XIX. Tratava-se de um sistema de instrução baseado no ensino clínico e no aproveitamento da rede hospitalar para 0 ensino médico, na modalidade de treinamento em serviço, formando especialistas (MACHADO M. et al., 1997; FEUERWERKER, 1998).

O princípio básico norteador dessa forma de ensino era da dedicação exclusiva, implicando o trabalho e envolvimento integral do profissional em treinamento com as atividades cotidianas do hospital em que estivesse sendo capacitado, passando o mesmo a residir no seu local de 
trabalho, a fim de propiciar a prática clínica (BLAISTEIN, 1993; MACHADO M. et al., 1997; FEUERWERKER, 1998).

No Brasil, as primeiras experiências de Residência Médica datam da década de 1940. O Hospital das Clínicas da Universidade de São Paulo e o Hospital dos Servidores do Estado, no Rio de Janeiro, foram os primeiros a implantar o programa de Residência Médica em 1944 e 1948, respectivamente (MACHADO M. et al., 1997; FEUERWERKER, 1998; ALVES, 2007); e somente em 1962, foi implantado o primeiro programa de Residência em Medicina Preventiva e Social, na Faculdade de Medicina de Ribeirão Preto, em São Paulo (CAMPOS e GIRARDI, 1984).

De início, a abrangência dos Programas de Residência Médica (PRM) era pequena, tanto que até meados da década de 1950, estes alcançaram um contingente muito reduzido de egressos das escolas médicas. A partir de então, o número de Programas de Residência Médica foi gradativamente aumentando, e, até o início dos anos 1960 ocorreu uma ampliação do número de PRM, notadamente em instituições oficiais, em virtude do interesse do corpo clínico ou pela procura dos recém-formados (FEUERWERKER, 1998; FEUERWERKER, 2001b; ALVES, 2007).

FEUERWERKER (2001b) destaca dois fatores que contribuíram para essa mudança:

"o impulso no processo de desenvolvimento tecnológico e científico na área médica, a partir do final de década de 50 , que estimulou a tendência de especialização; e, a partir da segunda metade da década de 60 , a multiplicação das vagas para Medicina na Universidade, através principalmente da 
criação de novas escolas e também da ampliação do número de vagas das já existentes" (FEUERWERKER, 2001b, p. 46)

No entanto, esse aumento crescente no número de PRM aconteceu de forma desordenada, levando os médicos residentes (principais interessados na organização e regulamentação da Residência Médica) a se unirem em busca de respostas às inúmeras demandas que se acumulavam, mediante a realização de Congressos Nacionais e da criação da Associação Nacional de Médicos Residentes (ANMR) (ALVES, 2007).

Assim, em resposta ao movimento encetado pelos médicos residentes, ocorreu a regulamentação da Residência Médica, por meio do Decreto $N^{\circ} 80.281$, de 5 de setembro de 1977, o qual criou também a Comissão Nacional de Residência Médica (CNRM), para disciplinar essa forma de capacitação (BRASIL, 1977; MACHADO M. et al., 1997).

$\mathrm{Na}$ conformidade do referido Decreto que regulamentou a Residência Médica, corroborado pela Lei № 6.932, de 07 de julho de 1981, esta é definida como:

"modalidade do ensino de pós-graduação destinada a médicos, sob a forma de curso de especialização, caracterizada por treinamento em serviço em regime de dedicação exclusiva, funcionando em Instituições de saúde, universitárias ou não, sob a orientação de profissionais médicos de elevada qualificação ética e profissional". (BRASIL, 1977; CNRM, 1981b).

Assim, um Programa de Residência Médica, quando cumprido integralmente dentro de uma determinada especialidade, confere ao médico residente o título de especialista. Ressalte-se, que a Residência Médica é 
considerada o "padrão-ouro" da especialização médica e, segundo as normas estabelecidas pela CNRM, a expressão "residência médica" só pode ser empregada para programas que sejam credenciados pela CNRM (CNRM, 1981b).

Quando da criação da CNRM, eram ofertados Programas de Residência Médica nas seguintes especialidades: Clínica Médica; Cirurgia Geral; Pediatria; Obstetrícia e Ginecologia e Medicina Preventiva e Social (BRASIL, 1977).

Entretanto, muito embora a CNRM tenha procurado normatizar o funcionamento da Residência Médica, esta não cumpriu com sua determinação de privilegiar a criação de programas nas áreas básicas; ao contrário, ocorreu uma multiplicação dos programas nas outras especialidades (FEUERWERKER, 1998). Atualmente, de acordo com a Resolução CNRM N 02/06 existem mais de 50 (cinqüenta) especialidades reconhecidas pela CNRM, sendo que 29 delas são de acesso direto e as demais exigem pré-requisito em áreas básicas para ingresso ao Programa de Residência Médica (CNRM, 2006).

A CNRM está vinculada ao Departamento de Residência Médica e Projetos Especiais em Saúde (DEREM), da Secretaria de Educação Superior (SESu) do Ministério da Educação (MEC), a qual é constituída por representantes do Ministério da Saúde, do Ministério da Educação, do Conselho Federal de Medicina (CFM), da Associação Médica Brasileira (AMB), da Associação Brasileira de Educação Médica (ABEM), da Federação Nacional dos Médicos (FENAM), da Associação Nacional dos 
Médicos Residentes (ANMR), como também pelos coordenadores regionais e estaduais dos Programas de Residência Médica em todo o país.

Embora vinculada ao Ministério da Educação, a CNRM não deixa clara quais as oportunidades de aprendizado que teriam os residentes, nem a qualidade dos preceptores e supervisores, visto que muito dos programas desenvolvem-se sem a mínima condição de funcionamento (FEUERWERKER, 1998).

Desde 1987, a CNRM criou as Comissões Estaduais de Residência Médica, sem, contudo promover a sua operacionalização, por falta de redistribuição dos recursos financeiros, definição de suas atribuições e transferência de poder decisório (FEUERWERKER, 1998).

No Ceará, os primeiros Programas de Residência Médica foram criados em 1962, no Hospital das Clínicas da Universidade Federal do Ceará, atualmente denominado de Hospital Universitário Walter Cantídio (HUWC), nas especialidades de Clínica Médica e Cirurgia Geral (SILVA, 2007).

Na década seguinte, o Hospital Geral Dr. César Cals (HGCC), pertencente à rede pública, iniciou os Programas de Residência Médica também em Clínica Médica e em Cirurgia Geral (SILVA, 2007).

Em 1976, o então Instituto Nacional de Assistência Médica e Previdência Social (INAMPS) passou a oferecer vagas para Residência Médica nas áreas Cirúrgicas e Clínicas no Hospital Geral de Fortaleza (HGF) e no Hospital de Messejana (SILVA, 2007).

A partir de 1978, os Programas de Residência Médica do serviço público estadual passaram a ser coordenados pela Fundação de Saúde do 
Estado do Ceará (FUSEC), sendo reconhecidos e credenciados pela CNRM somente em 1984 (SILVA, 2007).

Após a criação do SUS houve a fusão administrativa dos Programas de Residência Médica da FUSEC com os do INAMPS, ficando a coordenação desses Programas no SUS do Estado do Ceará sob a responsabilidade da Secretaria da Saúde do Estado do Ceará (SESA-CE). E, a partir de 1993, todos esses Programas de Residência Médica ficaram vinculados, funcional e administrativamente, à Escola de Saúde Pública do Ceará (ESP-CE) (SILVA, 1997; MARIANO e SILVA, 2001; 2002; 2006; SILVA, 2007).

\subsection{A EDUCAÇÃO PROFISSIONAL ATRAVÉS DA RESIDÊNCIA MÉDICA}

Para MACHADO M. et al. (1997), apesar de a formação médica ser concluída na graduação, a Residência Médica aparece como uma forma de aperfeiçoamento profissional; ou ainda no dizer de CIAMPO et al. (2003), esta representa uma complementação do processo de formação de recursos humanos na área médica.

Prefaciando a obra de FEUERWERKER (1998), Marcos Kisil observa que a Residência Médica surge como uma alternativa qualificadora para o ensino médico.

FEUERWERKER (1998), entretanto, questiona o papel formador da Residência Médica e em seu importante estudo a respeito das mudanças 
na Educação Médica e Residência Médica no Brasil, relata que participou, como consultora, de um projeto de avaliação dos programas de Residência Médica no Estado de São Paulo, tendo a oportunidade de observar, in loco, os problemas enfrentados pelos residentes. Como ela mesma narra,

\begin{abstract}
"difíceis condições de trabalho, falta de acompanhamento crítico do processo de formação dos residentes, ausência de relação entre instituições que formam os residentes e rede de serviços e, sobretudo, falta de definição acerca dos objetivos desse processo de especialização, pareceram ser problemas relevantes" (FEUERWERKER, 1998, p. 28).
\end{abstract}

Aliados a esses fatores, vários estudos discutem as condições estressantes da Residência Médica, tendo surgido muitas críticas, principalmente relacionadas à excessiva carga de trabalho, com sobrecarga assistencial e privação do sono. E, mesmo sendo definido como "treinamento em serviço, sob supervisão", alguns autores o comparam a "um ritual de passagem, um verdadeiro teste de resistência, pelo qual o médico recémformado deve passar para pertencer à ordem dos "verdadeiros médicos", sendo que essa situação tem repercussões diretas na qualidade do atendimento prestado à população (NOGUEIRA-MARTINS e JORGE, 2000).

No entanto, as queixas dos residentes não param por aí; incluemse ainda a falta de staff, o desrespeito aos direitos dos residentes, o atraso no pagamento de bolsas e o grande número de plantões (MESQUITA, 1999).

Mas, apesar de todos esses percalços, MESQUITA (1999) afirma que a Residência Médica ainda é considerada como a melhor forma de treinar o médico recém-formado. 
De igual modo, a certeza de que a Residência Médica faz parte do processo de educação profissional, é defendida por ROSENBERG (1992), que vê no planejamento - envolvendo professores, educadores e preceptores - o principal instrumento a ser observado no desenvolvimento dessa forma de capacitação.

Nesse aspecto, a adoção de propostas inovadoras de desenvolvimento curricular nos Programas de Residência Médica, comprometidas com o desenvolvimento de um conjunto de competências requeridas para que 0 profissional médico possa atender as demandas colocadas pelos serviços de saúde tem um papel fundamental no processo de formação por meio da Residência Médica.

No que se refere ao desenho curricular, SACRISTÁN (2000) explica que:

"Desde um enfoque processual ou prático, o currículo é um objeto que se constrói no processo de configuração, implantação, concretização e expressão de determinadas práticas pedagógicas e em sua própria avaliação, como resultado das diversas intervenções que nele se operam. Seu valor real para os alunos, que aprendem seus conteúdos, depende desses processos de transformação aos quais se vê submetido" (SACRISTÁN, 2000, p. 101).

Esse autor reconhece a complexidade no processo de construção curricular, pelo que afirma:

"Distinguiremos seis momentos, níveis ou fases no processo de desenvolvimento, que descobrem campos de pesquisa peculiares, que nos ajudam a compreender conexōes entre tais niveis e que tornam manifesto como, previamente e em paralelo ao que denominamos prática pedagógica, existem essas outras práticas. É preciso utilizar, nesses níveis, perspectivas e metodologias diversas, o que mostra que o campo do currículo é também de integração de conhecimentos 
especializados, paradigmas e modelos de pesquisas diversos" (SACRISTÁN, 2000, p. 104).

Assim, as fases ou níveis propostos por SACRISTÁN (2000) para interpretação do currículo compõem-se de: currículo prescrito, currículo apresentado aos professores, currículo moldado pelos professores, currículo em ação, currículo realizado e currículo avaliado.

LIMA e RIBEIRO (2002) apresentam uma variação ou adaptação desse modelo proposto e consideram cinco momentos na abordagem processual do currículo, a saber: currículo prescrito, currículo planejado, currículo organizado, currículo desenvolvido e currículo avaliado.

O currículo prescrito é representado pelos aspectos que atuam como referência na ordenação do sistema curricular, composto pelo conjunto das decisões político-administrativas e servem de base para a proposta pedagógica e elaboração de materiais (SACRISTÁN, 2000; LIMA e RIBEIRO, 2002). No caso dos Programas de Residência Médica é o conjunto da legislação vigente, representado pelas diretrizes curriculares, normas, regulamentações e orientações do Ministério da Educação, da Comissão Nacional de Residência Médica, do Ministério da Saúde, Conselho Federal de Medicina etc.

O currículo planejado significa a tradução que os docentes fazem das diretrizes curriculares para os manuais, guias e ementas (SACRISTÁN 2000; LIMA e RIBEIRO, 2002). Ainda para SACRISTÁN (2000, p. 105), nessa fase "os professores podem atuar em nível individual ou como grupo 
que organiza conjuntamente o ensino. A organização social do trabalho docente terá conseqüências importantes para a prática".

Nos Programas de Residência Médica consiste na construção do Projeto (Projeto Pedagógico, Planos ou Projetos de Curso) de cada Programa de Residência, que inclui a justificativa, as competências, os objetivos (gerais e específicos) de aprendizagem, o perfil da clientela (conhecimentos, habilidades e atitudes prévios), os princípios e premissas educacionais (definição das estratégias educacionais), a estrutura (módulos, unidades, blocos etc.), os conteúdos, os métodos e técnicas de ensino, o sistema de monitoramento e avaliação do aluno e do curso, e o sistema de organização e gerenciamento do curso e todo material didático produzido. Vale ressaltar que nessa construção é essencial a participação de todos os envolvidos nesse processo de formação, inclusive com representação dos próprios médicos residentes.

ROSENBERG (1992) assegura ainda que determinados aspectos devem ser considerados pelas instituições promotoras dos Programas de Residência Médica. Em primeiro lugar, a definição clara dos objetivos reais do programa, procurando "considerar uma visão da sociedade e do profissional a ser formado" em consonância com a função social da instituição, bem assim de acordo com as suas condições materiais e os recursos financeiros e humanos disponíveis. Observando isso, definir-se-ia o perfil do profissional que se pretende formar, passo fundamental na determinação dos conteúdos do programa, que teria, assim, um nível de aprofundamento adequado às necessidades desses profissionais. A 
metodologia adotada para transmitir os conhecimentos deverá ser diversificada, considerando que cada conteúdo adapta-se melhor a um determinado tipo de atividade. Um outro aspecto de extrema importância é o da avaliação, que teria seus critérios estabelecidos e repassados aos médicos residentes, antes do início das atividades (ROSENBERG, 1992).

O currículo organizado é representado pelas condições internas e de infraestrutura, bem como os recursos educacionais e apoio administrativo que permitem o desenvolvimento da prática educativa (SACRISTÁN 2000; LIMA e RIBEIRO, 2002). Nos Programas de Residência em Medicina de Família e Comunidade, as condições de infraestrutura dos espaços das práticas educativas, no caso Unidades de Saúde, Ambulatórios de especialidades, Hospitais etc. e dos locais utilizados para as atividades teóricas; assim como a formação dos docentes e preceptores têm um papel muito importante no processo de aprendizagem dos médicos residentes, conforme pode ser observado nas discussões desse estudo.

O currículo desenvolvido corresponde à própria prática educacional, caracterizado pelo que acontece na prática durante as atividades de ensino-aprendizagem (SACRISTÁN 2000; LIMA e RIBEIRO, 2002).

Nesse sentido SACRISTÁN (2000) pondera que:

"Como conseqüência da prática se produzem efeitos complexos dos mais diversos tipos: cognitivo, afetivo, social, moral, etc. São efeitos aos quais, algumas vezes, se presta atenção porque são considerados 'rendimentos' valiosos e proeminentes do sistema ou dos métodos pedagógicos. Mas, a seu lado, se dão muitos outros efeitos que por falta de sensibilidade para com os mesmos e por dificuldade para apreciá-los (pois muitos deles, além de complexos e 
indefinidos, são efeitos a médio e longo prazo), ficarão como efeitos ocultos do ensino" (SACRISTÁN, 2000, p. 106).

Nos Programas de Residência Médica também assume essa mesma perspectiva de desenvolvimento das atividades de ensinoaprendizagem, relatadas pelos médicos residentes participantes do estudo.

O currículo avaliado é constituído por determinados componentes e conteúdos e impõe critérios para o ensino e para a aprendizagem dos alunos, buscando situar a avaliação da aprendizagem do aluno e a avaliação do curso (SACRISTÁN 2000; LIMA e RIBEIRO, 2002).

De acordo com SACRISTÁN (2000):

"o currículo abarcado pelos procedimentos de avaliação é,
enfim, o currículo mais valorizado, a expressão da última
concretização de seu significado para professores, que,
assim, evidenciam uma ponderação, e para alunos, que,
dessa forma, percebem através de que critérios são
avaliados. Neste sentido. a ênfase dada pelos
procedimentos de avaliação sobre os componentes
curriculares é mais um aspecto da transformação do
currículo no curso de seu desenvolvimento dentro das
condições escolares" (SACRISTÁN 2000, p. 312).

Nos Programas de Residência Médica é representando pelos vários tipos de avaliação realizados durante o período do Programa, os quais se diferenciam de acordo com cada objetivo educacional, como relatado no estudo.

Tomando como base essa classificação, vale salientar que o presente estudo analisou os currículos prescritos e currículos planejados dos Programas de Residência em Medicina de Família e Comunidade existentes 
no Ceará mediante a análise de documentação dos órgãos oficiais que regem esse tema, bem como dos projetos pedagógicos de cada Programa. No que se refere aos currículos organizados, currículos desenvolvidos e currículos avaliados dos referidos Programas de Residência a análise foi inferida a partir dos relatos dos médicos residentes desses Programas sobre como se deu na prática. Ressalte-se ainda que, dada a abrangência do tema, optou-se por fazer esse recorte, buscando conhecer a percepção dos alunos acerca do processo educativo desses Programas. Ademais, como afirma SACRISTÁN (2000): "Pode-se comprovar que em cada um desses niveis se criam atuações, problemas para pesquisar, etc.".

Vale registrar ainda que, a polissemia do termo currículo suscita diversos entendimentos sobre a sua conceituação e seu papel no processo educacional, e, em virtude da sua complexidade, várias são as teorias (tradicionais, críticas e pós-críticas) que tentam explicá-lo, muito embora sejam enfoques parciais e fragmentários (SACRISTÁN, 2000; HORNBURG; SILVA, 2007; SAVIANI, 2008), sendo que o detalhamento desses conceitos não se constituiu objetivo desse estudo. 


\subsection{A ESTRATÉGIA SAÚdE DA FAMÍLIA E A QUALIFICAÇÃO DE SUAS EQUIPES}

A Estratégia Saúde da Família, criada em 1994, pelo Ministério da Saúde, teve suas origens no Brasil a partir do Programa de Agentes de Saúde, instituído pela Secretaria de Saúde do Estado do Ceará, sendo adotada como política pública de âmbito nacional de atenção primária em saúde, e se constitui, na opinião de MENDES (2002, p. 53), como a "mais importante mudança introduzida pelo SUS na política nacional de saúde".

Ressalte-se, porém que, muito embora se saiba que essa iniciativa tenha sido fundamental para ampliar a cobertura das ações básicas de saúde e para sistematizar certas práticas, notadamente no que se refere à vacinação, puericultura e pré-natal, além de ter inserido a figura dos Agentes Comunitários de Saúde (ACS), os quais promoveram mudanças no cenário das práticas sanitárias, o que sem dúvida deve ser valorizado; ainda está longe de se constituir em uma estratégia de organização do SUS, uma vez que até o presente, não ocorreram de modo significativo, as transformações propostas e esperadas.

Vários são os obstáculos à sua consolidação que precisam ser superados, para que se efetivem as proposições do Ministério da Saúde, pois segundo esse órgão govemamental, o PSF tem como objetivo "contribuir para a reorientação do modelo assistencial a partir da atenção básica, em conformidade com os princípios do SUS, imprimindo uma nova dinâmica de 
atuação nas unidades básicas de saúde, com definição de responsabilidades entre os serviços de saúde e a população” (BRASIL, 1998).

O documento do Ministério da Saúde que apresenta os princípios e as diretrizes operacionais da SF afirma ainda que esta tem como ponto central o estabelecimento de vínculos e a criação de laços de compromisso e de co-responsabilidade entre os profissionais de saúde e a população, visando à reversão do modelo assistencial hospitalocêntrico (BRASIL, 1998).

Declara também que, embora rotulado como programa, a SF contradiz a concepção usual dos demais programas criados pelo órgão, pois não é uma intervenção vertical e paralela às atividades dos serviços de saúde, e sim, uma estratégia que possibilita a integração e promove a organização das atividades em um território definido, com o propósito de enfrentar e resolver os problemas identificados (BRASIL, 1998).

Para tanto, busca prestar assistência integral, contínua, com responsabilidade e boa qualidade, voltada para atender às necessidades de saúde da população adscrita, tanto na Unidade de Saúde como no domicílio, intervindo sobre os fatores de risco aos quais a população está exposta (BRASIL, 1998).

Nessa perspectiva o PSF elege a família e o seu espaço social como núcleo básico de abordagem no atendimento à saúde e foca suas ações na humanização das práticas de saúde, mediante o estabelecimento de um vínculo entre os profissionais de saúde e a população, proporcionando a criação de parcerias no desenvolvimento de ações intersetoriais. 
O PSF busca ainda contribuir para a democratização do conhecimento do processo saúde-doença, da organização dos serviços e da produção social da doença, fazendo com que a saúde seja reconhecida como um direito de cidadania, e, como tal, uma expressão da qualidade de vida, além de servir de estímulo à organização da comunidade para o efetivo exercício do controle social.

Segundo o Ministério da Saúde as diretrizes para a implantação da estratégia de Saúde da Família nas unidades básicas são operacionalizadas de acordo com as realidades regionais, municipais e locais (BRASIL, 1998).

Entretanto, em linhas gerais, a SF está organizada a partir de diretrizes operacionais que estabelecem que a Unidade Básica de Saúde da Família (UBASF) deve realizar atenção contínua nas especialidades básicas, com uma equipe multiprofissional habilitada para desenvolver as atividades de promoção, proteção e recuperação, características do nível primário de atenção.

Desse modo, a UBASF representa o primeiro contato da população com o serviço de saúde, caracterizando-se como a porta de entrada ao sistema local de saúde, mas também, assegurando o atendimento nos diferentes níveis do sistema, através de um sistema de referência e contrareferência, desde que identificada a necessidade de maior complexidade tecnológica para a resolução dos problemas identificados.

Uma outra característica da SF é que a Unidade de Saúde da Família trabalha com a adscrição da clientela, que significa a definição de um território de abrangência, correspondendo à área sob sua responsabilidade; 
sendo que cada unidade pode atuar com uma ou mais equipes de profissionais, dependendo do número de famílias a ela vinculadas.

Nesse sentido, a recomendação do Ministério da Saúde é que cada equipe seja responsável por uma área onde residam de 600 a 1.000 familias, observando-se o máximo de 4.500 habitantes. Para tanto, cada equipe deve fazer o cadastramento das famílias através de visitas aos domicílios, dentro de sua área de abrangência (BRASIL, 1998).

Essa aproximação com a realidade das famílias permite identificar os componentes familiares, a morbidade referida, as condições de moradia, saneamento e condições ambientais das áreas onde estão inseridas. Permite também estabelecer o vínculo da unidade de saúde com a comunidade, a qual é informada sobre os senviços disponíveis e os locais de atendimento.

Ainda de acordo com as diretrizes do Ministério da Saúde, os profissionais das equipes de saúde são responsáveis por sua população adscrita, devendo residir no município onde atuam, trabalhando em regime de dedicação integral (BRASIL, 1998).

E, para que as atividades destes profissionais se desenvolvessem de forma harmônica, foram definidas as atribuições específicas de cada membro da equipe.

Quanto ao médico da equipe de saúde da família, objeto de estudo do presente trabalho, ficou estabelecido que este deveria ser, preferencialmente, um generalista, devendo, portanto, atender a todos os componentes das famílias, independentemente de sexo e idade. Determinou-se ainda que este profissional deveria comprometer-se com a pessoa, inserida em seu contexto 
biopsicossocial. Sua atuação não deveria estar restrita à assistência curativa, às doenças que demandem à Unidade de Saúde, sendo que seu compromisso envolveria o conhecimento e atuação sobre o processo saúde-doença da comunidade, incluindo ações de promoção e prevenção.

Ainda dentro dos requisitos estabelecidos para o profissional médico, definiu-se que este deveria procurar compreender a doença em seu contexto pessoal, familiar e social, inferindo-se que a convivência contínua Ihe propiciaria esse conhecimento e 0 aprofundamento do vínculo de responsabilidade para a resolução dos problemas e manutenção da saúde dos indivíduos adscritos à sua área de abrangência.

Nessa perspectiva, o documento editado pelo Ministério da Saúde em 1998, estabelece como atribuições básicas do médico:

- Prestar assistência integral aos indivíduos sob sua responsabilidade;

- Valorizar a relação médico-paciente e médico-família como parte de um processo terapêutico e de confiança;

- Oportunizar os contatos com indivíduos sadios ou doentes, visando abordar os aspectos preventivos e de educação sanitária;

- Empenhar-se em manter seus clientes saudáveis, quer venham às consultas ou não;

- Executar ações básicas de vigilância epidemiológica e sanitária em sua área de abrangência;

- Executar as ações de assistência nas áreas de atenção à criança, ao adolescente, à mulher, ao trabalhador, ao adulto e ao idoso, 
realizando também atendimentos de primeiros cuidados nas urgências e pequenas cirurgias ambulatoriais, entre outros;

- Promover a qualidade de vida e contribuir para que o meio ambiente seja mais saudável;

- Discutir de forma permanente, junto à equipe de trabalho e comunidade, o conceito de cidadania, enfatizando os direitos à saúde e as bases legais que as legitimam;

- Participar do processo de programação e planejamento das ações e da organização do processo de trabalho das unidades de Saúde da Família (BRASIL, 1998).

Assim, percebe-se que todas estas atribuições deixam claro que um dos requisitos essenciais para a consolidação do PSF é a adequação do trabalho das equipes às exigências e peculiaridades dos serviços orientados para a resolução dos problemas locais, o que pressupõe a ruptura com o conceito de sistema verticalizado e com as práticas tradicionais de saúde. Para tanto, faz-se necessário o estabelecimento de estratégias de formação dos profissionais de saúde, em especial, do médico de família, que irá exercer suas atividades neste campo de atuação.

Dessa forma, a preocupação com a formação, certificação e educação permanente destes profissionais passou a ser incorporada às discussões que já aconteciam em relação às demais categorias profissionais, nas várias instâncias do SUS (ROONEY e OSTENBERG, 1999).

Tanto assim que, dentre os princípios organizativos do PSF, está prevista a educação continuada para a equipe de saúde da família, ressaltando- 
se que para que esta produza resultados satisfatórios, necessita de um processo de capacitação e informação contínuo e eficaz, de modo a atender às necessidades trazidas pelo dinamismo dos problemas. Enfatiza ainda que a educação continuada, além de possibilitar o aperfeiçoamento profissional, tratase de um importante mecanismo no desenvolvimento da própria concepção de equipe e de vinculação dos profissionais com a população, característica que fundamenta todo o trabalho do PSF (BRASIL, 1998).

Todavia, estas orientações salientam que o planejamento das ações educativas deve estar adequado às peculiaridades locais e regionais, à utilização dos recursos técnicos disponíveis e à busca da integração com as universidades e instituições de ensino e de capacitação de recursos humanos, e que a formação em serviço deve ser priorizada, já que permite melhor adequação entre os requisitos da formação e as necessidades de saúde da população atendida (BRASIL, 1998).

MENDES (2002), ao propor um modelo analítico para o processo de implantação do PSF, considera que o grau de institucionalização dessa estratégia pode ser verificado em diversos espaços sociais: político, dos serviços de saúde, educacional, corporativo e da representação populacional.

E afirma que a institucionalização do PSF no espaço educacional envolve:

"reorientações significativas do sistema educacional para formar, reformar e/ou manter os profissionais de saúde em função da estratégia de saúde da família. Aqui se estabelece o grau de coerência dos sistemas educacionais formais e dos sistemas de educação permanente com os princípios, a ideologia e os recursos cognitivos e tecnológicos do PSF" (MENDES, 2002, p. 32). 
Entretanto, o mesmo autor reflete que as mudanças no sistema educacional ainda não são significativas, e que há uma "infiltração marginal no aparelho formador, financiada pelo Ministério da Saúde", mas sem muita força para se firmar como estratégia educacional hegemônica. Em conseqüência disso, poucos são os profissionais com especialização em saúde da família e insuficientes são as certificações das especialidades em saúde da família, além do mais, observa-se pouco reconhecimento dos profissionais das demais especialidades médicas àqueles que optam por trabalharem no PSF.

Isso certamente requer um consenso interinstitucional sobre os objetivos e estratégias de desenvolvimento, para a criação e acreditação de Programas de Residência Médica em Medicina de Família e Comunidade e a certificação do médico de família; a ser obtido pelas instituições representativas dos determinantes da educação médica no Brasil, dentes elas: Ministério da Saúde, CNRM, Conselho Federal de Medicina, Associação Médica Brasileira, secretarias estaduais e municipais de saúde, escolas médicas, escolas de saúde pública e pólos de educação permanente em saúde (BESSA e PENAFORTE, 2002). 


\subsection{O PROGRAMA DE RESIDÊNCIA EM MEDICINA DE FAMÍLIA E COMUNIDADE}

A Residência Médica, como modelo de ensino, é considerada padrão-ouro em especialização médica, sendo reconhecida como de excelência em todos os países que a praticam. Logo, ela tem se tornado fundamental para a qualificação de toda a prática médica, e, mais recentemente, para a formação dos médicos que irão atuar na Estratégia Saúde da Família.

Por isso, o Ministério da Saúde, visando consolidar a Estratégia Saúde da Família, enquanto eixo reordenador da atenção básica no SUS, tem proposto a Residência Médica em Medicina de Família e Comunidade, como a modalidade de pós-graduação para qualificação dos profissionais médicos em todo o Brasil.

A ênfase desta Residência está centrada no treinamento em serviço e tem como objetivo formar profissionais em saúde para desempenhar suas atividades em Unidades Básicas de Saúde, através de ações de saúde coletiva e de abordagem clínica individual. Implica trabalhar com a realidade local, associando competência técnica a uma prática humanizada e incorporando, sempre que possível, os conhecimentos populares sincronizados ao conhecimento científico.

No entanto, vale ressaltar que as primeiras experiências de formação do médico para atuar de modo a atender às necessidades de saúde 
da comunidade no Brasil tiveram início em 1976, em Porto Alegre, no Rio Grande do Sul, com uma iniciativa da Secretaria Estadual de Saúde, no Centro Médico-Social São José do Murialdo (atualmente denominado de Centro de Saúde-Escola Murialdo); no município de Vitória de Santo Antão, em Pemambuco, com Projeto Vitória, da Universidade Federal de Pemambuco e no Rio de Janeiro, no Serviço de Medicina Integral, da Universidade Estadual do Rio de Janeiro (UERJ), a partir da criação do Programa de Residência em Medicina Comunitária, antes mesmo da regulamentação dos Programas de Residência Médica e da criação da Comissão Nacional de Residência Médica, ambas ocorridas um ano depois, em 1977 (SILVA, 2002; FARIAS et al., 2004; ANDERSON e RODRIGUES, 2008, LOPES et al., 2009; SBMFC, 2010).

Entretanto, desde 1964, por força de um convênio assinado entre a Secretaria de Saúde e do Meio Ambiente (SSMA) e a Universidade Federal do Rio Grande do Sul (UFRGS), o Centro Médico-Social São José de Murialdo já servia como campo de estágio em medicina preventiva e saúde pública para alunos do curso de medicina. A proposta deste estágio era tão inovadora que, dentre as atividades destes estudantes, constava a visita domiciliar, que apesar de gerar resistências e conflitos, proporcionou a criação do Sistema de Saúde Comunitária de Murialdo, a qual estava fundamentada em um modelo de assistência personalizada, integral e continuada à saúde, associando ações preventivas, curativas e de reabilitação (SILVA, 2002; FARIAS et al., 2004).

Posteriormente, em 1981, a Comissão Nacional de Residência Médica, por meio da Resolução CNRM No 07/81, reconhece a Medicina 
Comunitária como especialidade médica, denominando-a de Medicina Geral Comunitária (MGC), e inclui o Programa de Residência Médica para formação deste especialista entre as especialidades médicas credenciáveis. Esta Resolução favoreceu a criação de Programas de Residência em Medicina Geral Comunitária em outros estados brasileiros a partir de então (CNRM, 1981a; SILVA, 2002; FARIAS et al. 2004).

Ainda em 1981 foi criada a Sociedade Brasileira de Medicina Geral Comunitária (SBMGC), uma entidade que congrega os profissionais médicos especialistas, como também outros profissionais interessados nesta área (SBMFC, 2010).

Em 1986, o Conselho Federal de Medicina reconhece a Medicina Geral Comunitária como especialidade médica para efeito de Registro de Qualificação de Especialistas nos Conselhos de Medicina, através da Resolução № 1.232/86 (CFM, 1986).

$\mathrm{Na}$ construção deste processo, iniciou-se na SBMGC um movimento de unificação dessa especialidade médica, resultando, em 2002, na mudança do nome de Medicina Geral Comunitária para Medicina de Familia e Comunidade (MFC), a partir da Resolução CFM n 1.634/2002, de 11 de abril de 2002, que dispõe sobre o convênio de reconhecimento de especialidades médicas firmado entre o Conselho Federal de Medicina, a Associação Médica Brasileira e a Comissão Nacional de Residência Médica (CFM, 2002; SILVA, 2002; FARIAS et al., 2004; SBMFC, 2010).

Em 2005, o Ministério da Saúde, através da Portaria $N^{\circ}$ 1.143/GM, de 7 de julho de 2005, vem apoiar os Programas de Residência 
Médica em Medicina de Família e Comunidade, por meio do Programa de Bolsas para a Educação pelo Trabalho, promovendo a expansão destes cursos e possibilitando a participação dos profissionais nos Estados em que trabalham. A referida Portaria estabelece que os "Programas deverão ter como campo central de práticas da especialidade os ambientes e os territórios de atuação das equipes de saúde da família que atuam nas áreas mais carentes dos municípios, complementado pelas demais unidades assistenciais da cidade e região, tendo em vista o conjunto das aprendizagens necessárias à especialidade"; e que haja uma cooperação entre instituições formadoras, secretarias municipais e estaduais de saúde, devendo ter uma definição do "itinerário de formação, considerando a situação de saúde e a realidade de trabalho existente na região, bem como a oferta das condições necessárias para a realização do processo de formação" (BRASIL, 2005; JANAUDIS et al. 2007).

1.6.1 O Programa de Residência em Medicina de Família e Comunidade no Ceará

No Ceará, os maiores programas de Residência Médica encontram-se na rede pública estadual do SUS-CE, sob a responsabilidade da Secretaria da Saúde do Estado do Ceará, e estão administrativamente vinculados à Escola de Saúde Pública do Ceará, sendo coordenados pelo 
Centro de Coordenação de Residência Médica (CERME) (MARIANO e SILVA, 2001; 2002; 2006).

Anualmente são ofertadas vagas nos seis hospitais da rede pública estadual: Hospital Geral de Fortaleza, Hospital Geral César Cals, Hospital Infantil Albert Sabin, Hospital de Cardiologia de Messejana, Hospital de Saúde Mental de Messejana e Hospital São José de Doenças Infecciosas (MARIANO e SILVA, 2001; 2002; 2006).

Quanto à capacitação dos profissionais para o PSF, a ESP-CE assumiu, em 2000, o Programa de Residência em Medicina Geral e Comunitária, este com o currículo adaptado para Medicina de Família e direcionado para o PSF.

E, em 2001, no ensejo de aprofundar o debate em tomo da capacitação deste profissional, a ESP-CE realizou o Seminário Intemacional sobre Saúde da Família, no qual foram discutidas a formação, certificação e educação permanente do médico de família. Este evento recebeu conferencistas de cinco países europeus e norte-americanos (Reino Unido, Canadá, Estados Unidos, Holanda e Espanha), experts em atenção primária e na formação de médicos de família, que contribuíram para a elaboração da "Carta de Fortaleza", documento com várias proposições acerca da graduação, pós-graduação, certificação e educação permanente deste profissional (BESSA e PENAFORTE, 2002).

Ao comemorar uma década de funcionamento do PSF, A ESPCE, em parceria com a Secretaria da Saúde do Estado do Ceará, realizou, em 2004, a I Mostra de Saúde da Família do Ceará e II Seminário 
Internacional sobre Saúde da Família, com o intuito de compartilhar os conhecimentos e as experiências adquiridas, tanto no Brasil como em alguns países da América Latina (Chile, Cuba e El Salvador).

Dando continuidade ao processo de desenvolvimento profissional do médico de família, em 2006 foram criados novos Programas de Residência em outras instituições, como na Secretaria de Saúde de Fortaleza, pelo Sistema Municipal de Saúde Escola (SMSE), em parceria com a Universidade Federal do Ceará (UFC) Ainda em 2006, foi criado o Programa de Residência no município de Sobral, mediante uma articulação entre a Secretaria de Saúde deste município, a Escola de Formação em Saúde da Família Visconde de Sabóia, a Universidade Federal do Ceará e a Universidade Estadual Vale do Acaraú (ambas com campus em Sobral).

Assim, mesmo diante das informações aqui apresentadas, persistem algumas indagações: Qual é o perfil do profissional formado na graduação que busca a Residência de Medicina de Família e Comunidade? Esta Residência Médica, como treinamento em serviço, atende às expectativas de cobrir as lacunas deixadas pela formação profissional? Qual a estrutura curricular dos cursos de Residência em Medicina de Família e Comunidade? No que se baseia a estruturação do currículo destes Programas?

Logo, a necessidade de responder a esses questionamentos envolve conhecer os Programas de Residência para formação do médico de familia no Estado do Ceará e se constituiu no principal motivo que impulsionou a realização desse trabalho, uma vez que a avaliação dos 
Programas de Residência em Medicina de Família e Comunidade no Estado do Ceará ainda é recente e necessita de maiores aprofundamentos.

No entanto, embora reconhecendo que a avaliação de um Programa envolve vários aspectos, por questões operacionais e por interesses profissionais, nesta pesquisa optou-se por analisar a estrutura curricular destes cursos, suas diferentes disciplinas e organização interna, como forma de avaliar a base cognitiva que apóia a prática destes profissionais e sua adequação ao perfil do profissional requerido para a atuação no PSF; bem como a coerência entre os conteúdos dos projetos pedagógicos destes Programas, no intuito de identificar a sua validade como instrumento de qualificação dos profissionais médicos oriundos da graduação.

Portanto, espera-se, com este estudo, contribuir para o aprimoramento dos programas de Residência em Medicina de Família e Comunidade, no Estado do Ceará, bem como proceder a uma discussão em torno das reais perspectivas destes programas, como agente formador de recursos humanos em saúde, no caso o profissional médico, a fim de atender às necessidades dos serviços aos quais serão inseridos. 


\section{OBJETIVOS}

\subsection{GERAL}

Caracterizar os Programas de Residência existentes no Estado do Ceará, para formação do médico de família.

\subsection{ESPECÍFICOS}

- Analisar os Programas de Residência em Medicina de Família e Comunidade no Estado do Ceará, no que se refere às suas propostas e execução;

- Verificar a percepção dos profissionais oriundos de Programas de Residência quanto à capacitação específica para médico de família;

- Identificar e analisar a adesão de profissionais médicos aos Programas de Residência Médica voltados para a formação do médico de família no Estado do Ceará. 


\title{
3 METODOLOGIA DO ESTUDO
}

\subsection{TIPO DE ESTUDO}

A escolha da abordagem metodológica a ser utilizada em uma pesquisa depende principalmente do objeto de estudo, devendo esta ser adequada para responder às indagações que norteiam a investigação e para alcançar os objetivos propostos. Assim, em consonância com esta afirmativa, desenvolveu-se uma pesquisa de cunho descritivo, com abordagem qualitativa, tendo por objetivo caracterizar os Programas de Residência existentes no Ceará para formação do médico de família.

Em outras palavras, POPE e MAYS (2005), afirmam que a escolha do método de pesquisa:

\begin{abstract}
"é tipicamente informada por uma estratégia de pesquisa, ou por um conjunto de decisões a respeito do design da pesquisa, e por crenças sobre como o mundo social pode ser estudado e como a validade do conhecimento social estabelecido por tal pesquisa poderia ser avaliada" (POPE e MAYS, 2005, p. 12).
\end{abstract}

Portanto, o delineamento de uma pesquisa requer conhecimento sobre qual a melhor forma de se descobrir, por meios científicos, a resposta para uma problemática estabelecida. Essa melhor forma pode surgir por causa de diversos fatores, como o interesse e a habilidade apresentados 
pelo pesquisador para conduzir a pesquisa; o tempo e os recursos disponíveis; o enquadramento do método ao objeto de pesquisa e principalmente pelos pressupostos ontológicos e epistemológicos adotados pelo pesquisador.

No caso da pesquisa com abordagem qualitativa o investigador vai à busca das significações que as pessoas dão ao objeto de estudo, ou seja, procura entender como este objeto de estudo acontece ou se manifesta.

Esta forma de abordagem investigativa tem no ambiente natural sua fonte direta de dados, em que o investigador é um instrumento essencial nesse processo; tem caráter descritivo; preocupa-se com o significado que as pessoas dão às coisas ou à sua vida, sendo por isso definida como subjetiva; tem enfoque indutivo na análise dos dados, sendo orientada pelo processo mais do que pelos resultados e produtos da investigação, que não são generalizáveis (GODOY, 1995).

Entretanto, como pondera MERCADO e BOSI (2006) não existe consenso generalizado quanto ao conceito de pesquisa qualitativa e suas características fundamentais, apesar de se observar que os estudos com abordagem quantitativa, em geral, se preocupam em observar rigorosamente um plano pré-estabelecido, no qual estão claramente formuladas as hipóteses e as variáveis a serem estudadas; enquanto que a pesquisa qualitativa vai se construindo ao longo do processo de investigação, sem a preocupação em enumerar ou medir eventos, nem ter como base o emprego de métodos estatísticos para a análise do material coletado. 
Ainda na abordagem qualitativa sobressai a obtenção de dados descritivos, os quais são conseguidos mediante o contato direto do pesquisador com a situação objeto do estudo, uma vez que o pesquisador procura entender os fenômenos a partir da perspectiva dos envolvidos na situação estudada, para então interpretar estes fenômenos.

Isso leva à compreensão de que a pesquisa qualitativa não expressa apenas um modelo de fazer ciência, estando envolvidos neste processo aspectos sociais, políticos, ideológicos e éticos.

POPE e MAYS (2005), fazendo uma reflexão acerca do debate sobre a aplicação da pesquisa qualitativa, ponderam que a escolha do método e de como ele é utilizado poderão ser informados, tanto pela questão da pesquisa, ou por considerações pragmáticas, como pela postura teórica do pesquisador, considerando que:

\footnotetext{
"esse pode particularmente ser o caso da pesquisa em serviços de saúde devido à sua natureza aplicada: aqui a pesquisa tende a ser confundida por problemas ou aspectos práticos específicos, e isso, em vez das tendências teóricas, pode determinar os métodos empregados". (POPE e MAYS, 2005, p. 13).
}

Esta pesquisa é também um estudo descritivo, por estar fundamentado na pesquisa qualitativa, que é por princípio, descritiva, tendo como objetivo descrever as características de uma realidade estudada. Por isso GIL (2006) enfatiza que "as pesquisas descritivas são as que habitualmente realizam os pesquisadores preocupados com a atuação prática". 
DESLAURIERS e KÉRISIT (2008) ao discorrerem sobre o delineamento da pesquisa qualitativa, afirmam que uma pesquisa de natureza descritiva poderá fornecer informações contextuais que servirão de base para pesquisas explicativas mais desenvolvidas, mas que quase sempre "ela é completa em si mesma", e não necessita de ser continuada por outros pesquisadores.

Baseado nesses conceitos e na natureza do estudo, o trabalho envolve não apenas a descrição, mas trata-se também de um processo analítico.

Desse modo, a consecução desta pesquisa ocorreu conforme os objetivos específicos propostos. Assim, como primeiro objetivo do estudo foram analisados os Programas de Residência em Medicina de Família e Comunidade do Estado do Ceará, no que se refere às suas propostas e execução, constando da análise de seus projetos pedagógicos, da identificação das semelhanças e diferenças existentes entre eles e da verificação de adequação destes Programas com as normas, diretrizes e orientações vigentes, emitidas pelo Ministério da Saúde e da Comissão Nacional de Residência Médica, que regulam essa formação, o que permitiu traçar o perfil de cada um deles. Como segundo objetivo verificou-se a percepção dos profissionais que cursaram a RMFC quanto a essa capacitação específica e, por fim, procurou-se identificar os fatores que influenciam a adesão e permanência dos profissionais nos Programas de Residência voltados para a formação do médico de familia no Estado do Ceará. 


\subsection{SUJEITOS DA PESQUISA}

A pesquisa foi desenvolvida com os coordenadores e residentes dos Programas de Residência em Medicina de Família e Comunidade do Estado do Ceará.

A população do estudo foi constituída por profissionais médicos que buscaram a Residência em Medicina de Família e Comunidade, dentre eles foram contemplados os residentes que estão atualmente cursando a RMFC, os que concluíram e aqueles que abandonaram o Programa de Residência e por algum motivo não concluíram sua capacitação; além dos Coordenadores dos Programas de Residência em Medicina de Família e Comunidade existentes no Estado do Ceará.

Para identificar os possíveis participantes, inicialmente foi solicitada às Coordenações dos Programas de Residência a relação, por turma, dos alunos destes Programas. De posse dos nomes destes profissionais iniciou-se a série de entrevistas por critério de conveniência, seguindo-se a técnica da bola de neve, ou seja, os primeiros entrevistados indicaram outros participantes para serem entrevistados, e assim sucessivamente, até que foi atingido o "ponto de saturação teórico". 0 "ponto de saturação" é atingido quando os novos entrevistados começam a repetir os conteúdos já obtidos em entrevistas anteriores, sem acrescentar novas informações relevantes (FONTANELLA et al., 2008). 
De acordo com TURATO (2003), no método de amostragem por saturação, o número de sujeitos da pesquisa é identificado quando “após as informações coletadas com certo número de pessoas, novas entrevistas passam a apresentar uma quantidade de repetições em seu conteúdo" (TURATO, 2003, p. 363).

Segundo SCHRAIBER (1995), o critério da exaustão ou saturação permite ao pesquisador verificar a formação de um todo e reconhecer a reconstituição do objeto no conjunto do material.

SCHRAIBER (1995) considera ainda que:

"A eleição de critérios que balizam a técnica de coleta dos depoimentos depende do objeto em estudo e do específico campo empírico de investigação. (...) a adoção de critérios implica perspectivas interpretativas do material pertinentes. Ademais, o rigor nos critérios de seleção dos entrevistados, como também seu número, liga-se a questões de controle sobre dados falsos ou comportamentos 'desviantes'. É a situação em que o pesquisador tenta assegurar-se de que colherá o dado pertinente e que conseguirá obter a prova que necessita frente a suas hipóteses (SCHRAIBER, 1995, p. 67)".

Alem disso, TURATO (2003; 2005) pondera que enquanto a pesquisa quantitativa procura observar "como o fenômeno se comportará matematicamente em uma população”, a pesquisa qualitativa, por sua vez, tenciona "interpretar o que as pessoas dizem sobre o tal fenômeno e o que fazem ou como lidam com isso". O mesmo autor complementa:

"No contexto da metodologia qualitativa aplicada à saúde, emprega-se a concepção trazida das Ciências Humanas, segundo as quais não se busca estudar o fenômeno em si, 
mas entender seu significado individual ou coletivo para a vida das pessoas. Torna-se indispensável assim saber o que os fenômenos da doença e da vida em geral representam para elas. $O$ significado tem função estruturante: em torno do que as coisas significam, as pessoas organizarão de certo modo suas vidas, incluindo seus próprios cuidados com a saúde" (TURATO, 2005, p. 509).

\subsection{TÉCNICAS E INSTRUMENTOS PARA A COLETA DOS DADOS}

$\mathrm{Na}$ coleta dos dados para esta pesquisa foram utilizadas técnicas e instrumentos coerentes com o tipo de informações necessárias ao alcance dos objetivos propostos. Logo, os procedimentos de coleta dos dados da pesquisa constaram da análise de fontes secundárias e documentais, por meio de revisão da literatura e do estudo da documentação existente acerca do tema da pesquisa; e da coleta de dados primários, mediante a realização de entrevistas em profundidade com informantes-chave.

\subsubsection{Estudo da Documentação Existente}

Em uma pesquisa qualitativa é de suma importância conhecer o contexto histórico do objeto de estudo mediante a análise de documentos, uma vez que todos os fatos e fenômenos são significativos e relevantes para elucidar o problema da pesquisa. 
Algumas pesquisas elaboradas com base em documentos são importantes, não porque respondem definitivamente a um problema, mas porque proporcionam melhor visão desse problema, ou então, produzem hipóteses que conduzem sua verificação por outros meios.

Assim, para a análise da documentação foram consultadas as propostas do Ministério da Saúde, da Associação Brasileira de Educação Médica e da Comissão Nacional de Residência Médica; os projetos dos Programas de Residência em Medicina de Família e Comunidade do Estado do Ceará, além de outros documentos sobre o tema, que se fizeram necessários durante o desenvolvimento do estudo.

Nesta perspectiva, procedeu-se primeiramente um aprofundamento sobre o assunto enfocado, com a realização de levantamento bibliográfico, a respeito da evolução da Educação Médica e da inserção da Residência Médica como componente do processo de formação do profissional médico, em especial das estratégias de capacitação do médico de família, a fim de estabelecer uma fundamentação teórica consistente que demarcasse, à luz dos conhecimentos já produzidos, a realidade do objeto estudado, garantindo que sua aproximação com o tema fosse moderada por parâmetros bem definidos quanto ao foco de observação do tema estudado.

Este procedimento está em consonância com a opinião de GÜNTHER (2006, p. 3), quando este afirma que como há na pesquisa qualitativa uma "aceitação explícita da influência de crenças e valores sobre a teoria, sobre a escolha de tópicos da pesquisa, sobre o método e sobre a 
interpretação de resultados" além de se aceitar "um envolvimento emocional do pesquisador com o seu tema de investigação", uma forma de lidar com essa influência requer um "maior detalhamento dos pressupostos teóricos subjacentes, bem como do contexto da pesquisa”.

Portanto, inicialmente foram mantidos contatos com os Coordenadores dos Programas de Residência Médica em Medicina de Família e Comunidade para explicar os objetivos do trabalho e solicitar a sua colaboração, tendo em vista o propósito de conhecer os Projetos Políticos Pedagógicos destes programas de capacitação, a fim de verificar a estrutura curricular destes cursos, suas diferentes disciplinas e organização interna, como forma de avaliar a base cognitiva que apóia a prática destes profissionais e sua adequação ao perfil profissional requerido para a atuação no PSF.

\subsubsection{Entrevista em Profundidade com Informantes-Chave}

A entrevista é antes mais nada uma conversação entre duas pessoas, mantida com um propósito definido. Segundo MARCONI e LAKATOS, (2005), trata-se de um "encontro entre duas pessoas, a fim de que uma delas obtenha informações a respeito de um determinado assunto". Logo, a entrevista é uma técnica muito eficiente para a obtenção de dados em profundidade acerca do que se está pesquisando. 
Além disso, é considerada uma técnica qualitativa que permite explorar um determinado assunto, mediante a busca de informações, percepções e experiências a partir de informantes-chave, procurando-se aprofundar o máximo possível nesta investigação, para depois analisar o produto desta indagação minuciosa e apresentá-lo de forma estruturada (RICHARDSON, 1999; MOREIRA, 2004).

Conforme orienta MOREIRA (2004), a entrevista é uma ferramenta que prioriza a experiência vivida, possibilitando aos sujeitos participantes do estudo descrever verbalmente suas experiências em relação ao fenômeno pesquisado.

A entrevista em profundidade apresenta como uma grande vantagem o fato de ser discursiva, permitindo que cada entrevistado demonstre sua linha de argumentação, de modo que o entrevistador possa inferir as associações que faz em seus pensamentos oferecendo, inclusive, oportunidades para extensivas sondagens de opiniões, atitudes e valores dos participantes.

Assim, optou-se por esta forma de coleta de dados pela sua flexibilidade, uma vez que permite aprofundar gradativamente o conteúdo das perguntas até se obter o máximo de informação possível para o tema em estudo, visto que se procurava intensidade nas respostas e não quantificação ou representação estatística.

Por isso, o instrumento utilizado foi um guia ou roteiro da entrevista, com perguntas abertas, as quais não obedeciam a uma ordem 
rígida quando da sua formulação aos entrevistados, obtendo-se assim relatos nas suas próprias palavras (Apêndice I e II).

Desse modo, para complementar as informações obtidas a partir da análise dos projetos políticos pedagógicos destes Programas de Residência foram realizadas entrevistas em profundidade com os Coordenadores dos referidos programas. Durante estas entrevistas buscouse conhecer aspectos relacionados à: tempo de criação dos Programas e de atuação do Coordenador; processo de desenho dos currículos dos cursos; participação do atual coordenador nesse processo de desenho do currículo, proposta pedagógica; objetivos do Programa; estrutura curricular; carga horária de atividades teóricas e práticas; local de desenvolvimento das atividades e sistema de avaliação do Programa.

De modo análogo, para a coleta de dados junto aos profissionais médicos utilizou-se também a entrevista em profundidade, abordando aspectos relacionados à percepção dos residentes acerca do Programa que eles cursaram; diferenças entre os conhecimentos adquiridos na graduação e no Programa de Residência; perspectiva de aplicabilidade desses conhecimentos em seus locais de trabalho; semelhanças entre as situações vivenciadas durante o curso e na prática diária; trabalho em equipe; organização do Programa em temos de: ordenação dos conteúdos, adequação dos conteúdos aos objetivos; definiçãc dos objetivos; carga horária do Programa para atividades teóricas e práticas; qualidade e organização do material didático; compatibilidade entre objetivos e necessidades de aprendizagem; qualidade das instalações; equipe docente (instrutores, preceptores etc.); avaliações 
realizadas durante o Programa; o que influenciou a escolha pela RMFC e causas de evasão dos residentes da RMFC.

O tempo de duração de cada entrevista foi de aproximadamente uma hora, as quais foram desenvolvidas utilizando-se um roteiro semiestruturado, sendo que no decorrer da entrevista, a pesquisadora pode formular outras perguntas que considerou relevantes para o assunto que estava sendo abordado, o que permitiu maior aprofundamento da temática e da experiência pessoal do entrevistado, possibilitando verificar a percepção dos profissionais oriundos de Programas de Residência quanto esta capacitação específica para médico de família, além de fomecer dados significativos acerca da adesão dos profissionais médicos aos Programas de Residência voltados para a formação do médico de família no Estado do Ceará.

As entrevistas foram gravadas na sua íntegra, mediante a autorização dos participantes, porque assim foi possível a reprodução exata dos depoimentos dos entrevistados e ainda permitiram à entrevistadora centrar sua atenção na fala do entrevistado, além de serem observados e anotados os acontecimentos-chave durante estes encontros.

Vale ressaltar que a pesquisadora participou de todas as etapas do trabalho de campo e fez a transcrição pessoalmente de todo material gravado, imediatamente após a sua obtenção, na forma íntegra do uso da palavra dos entrevistados, a fim de não perder informações relevantes à compreensão do fenômeno investigado. 


\subsection{PROCESSAMENTO E ANÁLISE DOS DADOS}

A pesquisa qualitativa é detentora de grande flexibilidade e adaptabilidade, o que a faz considerar cada problema como objeto de uma pesquisa específica, que requer a utilização de instrumentos e procedimentos específicos, prescindindo do uso de instrumentos e procedimentos padronizados. Portanto, existem muitas combinações entre os diferentes delineamentos, maneira de coletar, transcrever e analisar os dados (MERCADO e BOSI, 2006).

No que se referem aos dados qualitativos, estes, geralmente são apresentados como descrições narrativas, consistindo de palavras e textos, decorrentes de entrevistas e anotações no diário de campo. Entretanto, existe uma grande diversidade de técnicas de análise de dados em pesquisa qualitativa, cuja decisão de usar determinado método de análise, segundo MERCADO-MARTíNEZ (2004), não é produto de uma inspiração casual, mas sim de um conjunto de fatores; em um primeiro momento obedece ao objeto de estudo com suas próprias questões, aos atores envolvidos e a certos fatores do contexto acadêmico, social, cultural, técnico e ideológico. Em geral, dentre as estratégias utilizadas para a análise destes dados incluem-se a preparação e descrição do material bruto, a redução dos dados, a análise e interpretação.

Nesta pesquisa, para a análise dos dados coletados decidiu-se formular e organizar estes dados em categorias, por tratar-se de um 
procedimento útil em investigações qualitativas. E, para orientar a composição destas categorias utilizou-se a Análise do Conteúdo, preconizada por LAURENCE BARDIN (1977), a qual permite a padronização na organização do material coletado e o conseqüente rigor no processo de análise.

Segundo BARDIN (1977), a análise de conteúdo foi primeiramente utilizada nos Estados Unidos, como um instrumento de análise das comunicações, notadamente a análise de material jornalístico, principalmente no que se refere à contagem e à medida, caracterizando uma análise mais quantitativa dos dados.

Berelson (1948, apud BARDIN, 1977, p. 18) define a análise de conteúdo como:

"A análise de conteúdo é uma técnica de investigação que tem por finalidade a descrição objectiva, sistemática e quantitativa do conteúdo manifesto da comunicação".

Posteriormente, esta técnica foi empregada para o estudo de propaganda e desta para a investigação política; diversificando-se gradativamente o domínio de sua aplicação.

Portanto, de acordo com BARDIN (1977), no que se refere aos métodos de análise de conteúdo e ao domínio de sua aplicação, percebe-se que este campo é bastante vasto, e assegura que, qualquer comunicação, ou seja, "qualquer transporte de significações de um emissor para um receptor, controlado ou não por este, deveria poder ser escrito, decifrado pelas técnicas de análise de conteúdo". Por isso, a autora define a análise de conteúdo como: 
"um conjunto de técnicas de análise das comunicações, visando obter, por procedimentos, sistemáticos e objectivos de descrição do conteúdo das mensagens, indicadores (quantitativos ou não) que permitam a inferência de conhecimentos relativos às condições de produção I recepção (variáveis inferidas) destas mensagens" (BARDIN, 1977, p.42).

Conforme descrito por BARDIN (1977), o método de análise de conteúdo apresenta uma seqüência cronológica de três fases: pré-análise, exploração do material e tratamento dos resultados obtidos, a saber:

Pré-análise: consiste da fase de organização do material, objetivando operacionalizar e sistematizar as idéias iniciais, para facilitar o desenvolvimento das etapas subseqüentes. Inicialmente procedeu-se à "constituição do corpus", que de acordo com a autora "o corpus é conjunto dos documentos tidos em conta para serem submetidos aos procedimentos analíticos", sendo este formado pelos projetos dos Programas de Residência estudados e pelas entrevistas em profundidade, realizadas com os coordenadores do Programas e os com residentes. Assim, para operacionalizar esse procedimento, de início todas as entrevistas foram transcritas e impressas, a seguir realizou-se uma leitura detalhada, destacando-se os temas para análises posteriores, com base nos objetivos e conceitos centrais do estudo.

Exploração do material: esta fase representa a análise propriamente dita, e, após exaustivas leituras do material coletado, iniciou-se a exploração do material, compreendendo a categorização e composição de temáticas. As temáticas foram identificadas por palavras ou frases, e as subcategorias surgiram a partir da interpretação do material categorizado. 
Para a análise dos documentos os dados foram organizados nas seguintes categorias e subcategorias: I. Construção do PRMFC, II. Desenho do currículo: a) Competências a serem desenvolvidas; b) Estrutura curricular; c) Sistema de avaliação e III. Preceptoria.

Enquanto que para a análise da percepção dos entrevistados utilizaram-se as categorias e subcategorias que se seguem: I. Organização e Execução do Programa de Residência em Medicina de Família e Comunidade: a) Pontos Positivos, b) Dificuldades Percebidas; II. Contribuição da Residência em Medicina de Família e Comunidade para a Prática do Médico de Família e III. Captação e evasão da Residência em Medicina de Família e Comunidade: um dilema a ser enfrentado.

Tratamento dos resultados obtidos: Portanto, a categorização do material coletado subsidiou a análise temática, com base nas falas dos profissionais participantes, em conteúdos indicativos de significados, a partir da percepção dos profissionais que concluíram o Programa de Residência, daqueles que estão cursando e dos profissionais que iniciaram o Programa de Residência, mas que não o concluíram, tendo em vista a subjetividade do sujeito pesquisado, acerca de suas vivências e experiências durante sua participação no Programa de Residência em Medicina de Família e Comunidade. Assim, esses discursos foram analisados partindo-se dos conteúdos manifestos e dos argumentos apresentados pelos participantes, para desvelar significados e ressignificações de suas práticas e saberes. 


\subsection{ASPECTOS ÉTICOS DA PESQUISA}

A ética é um conjunto de princípios de conduta moral que determina um tipo de comportamento propriamente humano, sendo construída histórica e socialmente a partir das relações coletivas dos seres humanos nas sociedades onde nascem e vivem, devendo perpassar todas as atividades de ser humano.

Nesse sentido, o projeto desta pesquisa foi submetido à apreciação dos Comitês de Ética em Pesquisa da Faculdade de Saúde Pública (COEP/FSP), da Universidade de São Paulo (USP) e da Escola de Saúde Pública do Ceará (CEP/ESP-CE), em cumprimento às exigências legais dispostas na Resolução No 196/96, do Conselho Nacional de Saúde (CNS) / MS, que dispõe sobre as diretrizes e normas regulamentadoras de pesquisas envolvendo seres humanos. $O$ protocolo da pesquisa foi aprovado pelo COEP/FSP/USP de acordo com Protocolo No 1717/2007, em 07/12/2007 e pelo CEP/ESP-CE conforme Protocolo 110/2008, em 08/02/2008.

A Resolução Nº 196/96 visa assegurar os direitos e deveres que dizem respeito à comunidade científica, aos sujeitos da pesquisa e ao Estado, e para tanto incorpora, sob a ótica do indivíduo e das coletividades, os quatro referenciais básicos da bioética: autonomia, não maleficência, beneficência e justiça.

Para atender ao princípio da autonomia, que consiste no consentimento livre e esclarecido dos indivíduos-alvo e a proteção a grupos 
vulneráveis e aos legalmente incapazes, inicialmente, solicitou-se a autorização dos Secretánios da Saúde do Estado do Ceará, e do município de Fortaleza, para então realizar a pesquisa. Após essa etapa, foram mantidos contatos com os Coordenadores dos Programas de Residência Médica em Medicina de Familia e Comunidade para explicar os objetivos do trabalho e solicitar a sua colaboração, conforme referido anteriomente. Ademais, antes de cada entrevista, manteve-se contato telefônico com o entrevistado, para solicitar sua anuência e agendar a hora e o local da entrevista. Além disso, antes de iniciar as entrevistas em profundidade solicitou-se a assinatura do Termo de Consentimento Livre e Esclarecido (TCLE) a todos os participantes do estudo (Apêndice III e IV). $\mathrm{O}$ TCLE foi elaborado em duas vias, ficando uma com cada participante e outra com a pesquisadora; sendo também solicitada autorização para gravar as entrevistas, sendo permitida por todos os entrevistados.

Em consonância ao princípio da beneficência, esclareceu-se que os participantes não seriam submetidos a qualquer desconforto ou risco, e que os resultados da pesquisa poderiam apontar para a melhoria dos Programas de Residência em Medicina da Família e Comunidade do Ceará. Explicou-se ainda que a participação no estudo não acarretaria em custos para o entrevistado, como não seria oferecida qualquer compensação financeira.

Observando o princípio da não maleficência, assegurou-se aos participantes o esclarecimento sobre a pesquisa, em qualquer aspecto que desejassem. Para tanto, foram elaboradas perguntas claras e de fácil compreensão, sendo elucidadas todas as dúvidas apresentadas pelos entrevistados. 
Atendendo ao princípio da justiça foi esclarecido aos participantes, durante as entrevistas, que eles tinham total liberdade para recusar-se a participar, retirar seu consentimento ou interromper a participação a qualquer momento, caso julgassem necessário; e que uma possível recusa em participar não acarretaria qualquer penalidade ou perda de benefícios; sendo garantido também, o sigilo e a confidencialidade dos dados obtidos junto aos entrevistados.

Por isso, a fim de presenvar o anonimato e resguardar a identidade dos participantes deste estudo, utilizou-se como código as letras RM (residente médico) acompanhada pelo número de 1 a 6 , correspondente à ordem das entrevistas. 


\section{RESULTADOS E DISCUSSÃO}

Os resultados da pesquisa aqui apresentados foram obtidos a partir da análise textual dos documentos coletados e das entrevistas realizadas junto aos informantes. A apresentação dos resultados está de acordo com a seqüência dos objetivos específicos propostos para este estudo. Assim, primeiramente procurou-se analisar os Programas de Residência em Medicina de Família e Comunidade no Estado do Ceará, no que se refere às suas propostas e execução, traçando um perfil de cada um deles, a partir da construção de determinadas categorias de análise, que melhor pudessem evidenciar os vários aspectos envolvidos na elaboração e desenvolvimento dos Programas, enfocando a construção dos projetos destes Programas, o desenho do currículo, em que se buscou observar a definição das competências necessárias aos médicos de família para o desempenho de suas funções, a estrutura curricular e o sistema de avaliação; e também a organização da equipe de preceptoria da Residência.

O passo seguinte constou da análise destes Programas segundo a percepção dos profissionais que o cursaram e por fim, procurou-se apreender os fatores que influenciam a adesão de profissionais médicos aos Programas de Residência voltados para a formação do médico de família no Estado do Ceará. A seguir são apresentados estes resultados, seguidos da análise e compreensão do fenômeno estudado. 


\subsection{OS PROGRAMAS DE RESIDÊNCIA EM MEDICINA DE FAMÍLIA E COMUNIDADE NO ESTADO DO CEARÁ}

O Estado do Ceará conta atualmente com três Programas de Residência em Medicina de Família e Comunidade em funcionamento, ofertados por instituições públicas, sendo que um quarto Programa existiu por um curto período de tempo, havendo, no entanto, a possibilidade de voltar a ser ofertado no próximo ano. Este Programa apesar de extinto desde 2007, foi analisado por ter sido o pioneiro na formação do médico de família no Ceará, tendo, portanto importância histórica para a análise em evidência. Um dos Programas em funcionamento, apesar de ainda estar ativo, não constou dessa avaliação por apresentar dificuldades operacionais e técnicas na obtenção dos dados referentes a este Programa de Residência Médica.

Portanto, são objetos do estudo três Programas de Residência Médica (um extinto e dois ativos), os quais são bastante representativos da situação atual da Residência em Medicina de Família e Comunidade no Estado do Ceará. Estes Programas foram denominados de Programas A, B e C, como forma de manter o anonimato acerca de sua identificação, uma vez que sua exposição não se constitui objetivo desse estudo.

Para a análise documental dos projetos dos Programas de Residência em Medicina de Família e Comunidade foram utilizadas as seguintes categorias analíticas, conforme apresentadas no Quadro 1: 
Quadro 1 - Categorias e subcategorias para análise dos projetos dos Programas de Residência em Medicina de Família e Comunidade. Fortaleza, 2010.

\begin{tabular}{|l|l|}
\hline \multicolumn{1}{|c|}{ Categorias } & \multicolumn{1}{c|}{ Subcategorias } \\
\hline I. Construção do PRMFC & \\
\hline \multirow{3}{*}{ II. Desenho do currículo } & a) Competências a serem desenvolvidas \\
\cline { 2 - 2 } & b) Estrutura curricular \\
\cline { 2 - 2 } & c) Sistema de avaliação \\
\hline III. Preceptoria & \\
\hline
\end{tabular}

\subsubsection{O Perfil dos Programas}

\section{a) Programa A}

\section{Categoria l. Construção do PRMFC}

Este Programa foi criado em 2000, com a denominação de Programa de Residência em Medicina Geral Comunitária, propondo-se a formar médicos capazes de realizar uma atenção primária de alta qualidade, prestando cuidados integrais de saúde ao indivíduo no contexto da família e da comunidade, a partir de uma perspectiva bio-psico-social. O Programa de Residência tem duração de dois anos, sendo previsto para ser desenvolvido em regime de tempo integral. 
De acordo com informações obtidas nos documentos consultados, a estrutura para o desenvolvimento da aprendizagem do Programa A inclui:

* Os campos de treinamento, compreendendo:

- O espaço educacional da instituição promotora do Programa de Residência, com disponibilidade de auditórios, recursos áudio-visuais, biblioteca e computadores com acesso à Internet, conferências e seminários com convidados internacionais;

- A Unidade de Saúde, de atenção ambulatorial, funcionando com seis consultórios médicos e dois consultórios de enfermagem, responsável pela atenção integral à saúde de 7.000 famílias;

- Os domicílios de 7.000 famílias adscritas a essa Unidade de Saúde;

- Hospitais da rede pública de Fortaleza, compreendendo enfermarias de clínica médica, enfermarias de doenças infecciosas, enfermarias de emergência nas áreas de cardiologia, pneumologia, pediatria, obstetrícia e ginecologia.

- Centros ambulatoriais especializados nas áreas de dermatologia, reumatologia, hipertensão arterial, diabetes, pequena cirurgia e psiquiatria.

- Unidades de Medicina de Família de áreas rurais.

* Uma equipe de preceptores composta pelo Coordenador do Programa de Residência e os preceptores, realizando 
supervisão em tempo integral; e

* Intercâmbio para estágios em Programas de Residência em Universidades estrangeiras.

O Programa A ao iniciar suas atividades recebeu credenciamento provisório da CNRM através do Parecer N 110/2000. Em 2004, mediante uma avaliação realizada pela CNRM foram detectadas algumas irregularidades no funcionamento do Programa, sendo emitido o Parecer $\mathrm{N}^{\circ}$ 71/04, no qual descrevia a situação encontrada, e apresentava as recomendações para sua regularização. Em 2007, a CNRM apresentou o Termo de Aditivo $\mathrm{N}^{\circ}$ 01, ao Parecer anterior, de descredenciamento do então Programa de Residência em Medicina de Família e Comunidade, segundo dito Parecer, "por não estar de acordo com Resolução CNRM No 02/06".

\section{Categoria II. Desenho do Currículo}

De acordo com o documento analisado, foi criado um grupo de trabalho para construir o currículo deste Programa de Residência em Medicina Geral e Comunitária, sendo o desenho deste currículo orientado em função das necessidades da comunidade e, em termos educacionais, seguiu os princípios básicos da perspectiva cognitiva e foi direcionada para o uso da metodologia de Aprendizagem Baseada em Problemas (ProblemBased Learning - PBL). 
Ainda segundo verificação efetuada no projeto do Programa de Residência, para o desenho desse currículo o grupo de elaboração seguiu uma sistemática de trabalho organizada em uma seqüência de passos que envolveram: 1) identificação das necessidades dos potenciais usuários dos serviços a serem prestados pelo treinando; 2) identificação das necessidades em relação ao produto do curso/treinamento; 3) definição das tarefas a serem desenvolvidas pelo treinando; 4) elaboração dos objetivos gerais, intermediários e específicos de aprendizagem; 5) estabelecimento do conteúdo a ser incluído; 6) determinação da organização e seqüência do conteúdo; 7) escolha e adoção das estratégias educacionais; 8) escolha dos métodos e instrumentos de ensino-aprendizagem e 9) determinação do sistema de avaliação do aluno e do curso.

Conforme o projeto, para atender às necessidades técnicas quanto ao desenvolvimento destes passos foi utilizado um conjunto de fontes de informações, incluindo os boletins de perfil epidemiológico do estado do Ceará, o plano estadual de saúde, uma seleção de alguns planos municipais de saúde e referências bibliográficas internacionais na área de Medicina de Família. Além disso, três grupos de indicadores foram selecionados como preponderantes na determinação das necessidades de saúde da comunidade, as taxas de mortalidade (geral infantil e materna); as taxas de morbidade (prevalência e incidência) e os principais problemas percebidos pela comunidade. Esse trabalho de elaboração da proposta da Residência contou ainda com uma consultoria de experts do Reino Unido, da Holanda e do Brasil. 
Segundo a proposta do currículo, o grupo de trabalho procurou elaborar um Programa de Educação Médica Pós-Graduada orientado para a comunidade, em consonância com os padrões internacionais de qualificação profissional na área de medicina de Família, e estruturado com base em estratégias inovadoras de ensino-aprendizagem.

\section{II.a) Competências a serem desenvolvidas}

Ainda como etapa da construção do currículo os elaboradores buscaram definir o perfil profissional desejado do médico de família a ser formado, caracterizando-o como um profissional diferenciado dos demais especialistas médicos, o qual teria como campo fundamental de trabalho, a comunidade, sendo sua ação desenvolvida predominantemente no espaço do ambulatório e do domicílio familiar, com um olhar sobre a saúde e a doença, diferente daquele que é próprio ao ambiente hospitalar.

Nesta proposta, o perfil profissional deveria também:

1. ser facilmente acessivel às famílias sob sua responsabilidade, constituindo-se na instância imediata de recursos de cuidados de saúde para uma população definida;

2. ser comprometido com o ser humano em sua integralidade, independente de sexo, idade ou natureza do problema, ao invés de focar o interesse por uma área particular do 
conhecimento médico, grupo de doenças ou técnicas especiais;

3. ter compromisso de longo prazo com o paciente, transcendendo os períodos de doença, estendendo-se pelas fases em que a pessoa está saudável e antes mesmo que qualquer problema tenha surgido;

4. ter compreensão do contexto da doença, procurando entender a influência e a integração dos fatores físicos, psicológicos, sociais e ambientais na gênese das doenças e considerando 0 sofrimento da pessoa enferma como o centro de toda a ação terapêutica;

5. ter uma visão de população em risco, pensando não apenas em termos de pacientes individuais, mas no trabalho com grupos populacionais com riscos específicos de problemas de saúde, podendo assim intervir sobre os fatores de risco aos quais a população está exposta, e contribuindo para a redução da incidência de doenças e suas complicações;

6. ter uma percepção sistêmica da saúde, buscando a integração do seu trabalho com outras atividades públicas, articulando o uso dos recursos comunitários existentes para a erradicação das doenças e a promoção da saúde;

7. ter uma concepção de equipe de saúde, na qual compartilha responsabilidades e tarefas nos cuidados a pacientes individuais e nas ações comunitárias, trabalhando em cooperação com outros médicos, enfermeiras e outros 
profissionais de saúde;

8. saber referenciar seus pacientes dentro do sistema de saúde, orientando e conduzindo-os através dos vários níveis do sistema de saúde, guiando-os para profissionais e serviços adequados, quando necessário, e continuando responsável pela preservação da saúde deles, mesmo quando referenciados para especialistas ou para internação hospitalar, mantendo-se em constante comunicação e cooperação com os profissionais envolvidos;

9. saber gerenciar recursos humanos e materiais dentro de sua área de trabalho, procurando otimizar o uso destes recursos para maximizar os benefícios; e

10. ser comprometido com a qualidade nos cuidados de saúde, mantendo-se atualizado com os avanços científicos do conhecimento médico, com o aperfeiçoamento organizacional de sua prática e com o ensino de outros profissionais de medicina de família.

De acordo com esta proposta de formação, as funções a serem desenvolvidas pelo médico de família abrangeriam quatro grandes áreas: 1) atenção ao indivíduo; 2) prevenção de doenças / promoção da saúde; 3) gerenciamento de recursos e 4) desenvolvimento pessoal e profissional. E, para dar conta desses macro-conjuntos de tarefas, os responsáveis pela construção do currículo estabeleceram uma série de competências específicas que deveriam ser desenvolvidas, constituindo-se no referencial 
para a definição dos objetivos de aprendizagem em cada fase do treinamento do residente.

Assim, o desenho do currículo do Programa de Residência foi baseado nas competências que o profissional deveria desenvolver, sendo divididas nas quatro grandes áreas referidas já referidas:

$\mathrm{Na}$ área de atenção ao indivíduo, pressupondo que o médico de família, seja responsável por uma população definida, devendo ter a capacidade de resolver $90 \%$ dos problemas de saúde apresentados pelos membros da comunidade, independente de sexo, idade ou natureza da doença. Para sua formação o grupo propôs o desenvolvimento de competências que permitissem ao residente dominar o método clínico, e todo o conhecimento, habilidades e atitudes necessários para uma performance clínica resolutiva, incluindo-se:

a) Competência com relação a teorias e concepções sobre a doença e a saúde e seu uso na interpretação, análise e solução dos problemas, relacionadas:

- com o paciente individual (ciclos de vida, crescimento e desenvolvimento, epidemiologia, patologia, historia natural e tratamento das doenças);

- com a interação paciente-família (fases da família, interação familiar, epidemiologia das doenças na família, patologia familiar e sua abordagem pelo médico de família);

- com a interação paciente-comunidade (fatores econômicos, sociais e ambientais influenciando as doenças, significado 
social das doenças).

b) Competência com relação aos princípios de tomada de decisão:

- relatividade dos diagnósticos, valor e significado de testes e métodos de investigação, manuseio de árvores de decisão e protocolos.

c) Competência com trabalho sistemático e dirigido:

- obtenção de uma impressão inicial da natureza e localização dos sintomas, construção de uma história;

- realização do exame físico e solicitação de investigações complementares;

- escolha de uma estratégia, provisão de informação e conselhos, medicação, referenciamento para outros profissionais.

d) Competência na condução da relação médico-paciente:

- tranquilização do paciente, empatia, facilitação da comunicação;

- perguntas claras e específicas, sumarização, explicação e condução de conflitos;

- discussão com o paciente sobre a escolha da estratégia, promoção da aderência do paciente.

e) Competência na performance psicossocial:

- compreender o paciente, observar aspectos não-somáticos, perceber informação não-verbal; 
- elucidação psicossocial, abordagem holística;

- provisão de conselhos e informação, promoção de uma atitude ativa do paciente, referência para cuidados psicossociais.

f) Competência no cuidado com categorias específicas de pacientes e problemas:

- à saúde da mulher (controle de natalidade, prevenção de câncer de mama e colo de útero, diagnóstico e tratamento de problemas ginecológicos comuns);

- de gestantes (atenção ao pré-natal e puerpério);

- de neonatos, crianças e adolescentes (acompanhamento do crescimento e desenvolvimento, imunizações, diagnóstico e tratamento das doenças comuns);

- das doenças comuns de adultos (diabetes, hipertensão arterial, asma brônquica, cefaléia, problemas dermatológicos, gastrintestinais e outros);

- do idoso (mobilidade, dependência e aspectos psicossociais, reconhecimento de sintomas, curso e freqüência de problemas mais comuns e seu tratamento, estratégias de melhoria da qualidade de vida do idoso);

- problemas que requerem atenção urgente (trauma, condições médicas agudas e psiquiátricas);

- à saúde ocupacional (influência do trabalho na doença, doenças ocupacionais, incapacitação ocupacional); 
- pacientes terminais e seus familiares;

- problemas psicossociais comuns na prática de família (problemas sexuais, dependência a drogas, problemas relacionais e familiares, problemas educacionais, problemas da adolescência, problema de pessoas solitárias ou deprimidas, problemas de vítimas de violência);

- problemas menos comuns e com importantes implicações diagnósticas e terapêuticas (malignidade, certas doenças infecciosas).

$\mathrm{Na}$ área de prevenção de doenças / monitoração e promoção da saúde, o grupo de elaboração estabeleceu que o médico de família deve realizar também tarefas preventivas e ações direcionadas para a promoção da saúde, devendo adquirir conhecimento dos problemas de saúde da comunidade, assim como dos recursos que a mesma dispõe, tanto sanitários como de outra natureza, para poder priorizar as ações que dêem respostas aos problemas locais de maior importância. Assim, nos objetivos de aprendizagem do Programa de Residência, estão incluídos: o conhecimento necessário para a identificação de fatores de risco, atividades de prevenção clínica, e intervenções para reduzir as probabilidades de adoecer e morrer na comunidade. E definiram que as competências requeridas para o exercício dessa tarefa envolvem:

a) Competência na descrição do território da área de abrangência da equipe de medicina de família (identificação e localização de recursos existentes, identificação de barreiras geográficas); 
b) Competência em identificar microáreas de risco sóciosanitárias na comunidade;

c) Competência em equacionar soluções de problemas de saúde com dependência de ações intersetoriais;

d) Competência em estruturar sistema de informação sobre saúde na comunidade (seleção de indicadores, organização da coleta de dados, processamento de dados);

e) Competência na análise de dados epidemiológicos;

f) Competência em desenvolver o monitoramento de doenças transmissíveis e crônico-degenerativas em nível comunitário;

g) Competência em informação e educação em saúde (educação da comunidade em prevenção de acidentes, uso racional de medicamentos, higiene e prevenção de doenças, informação e aconselhamento de pacientes em questões de saúde e doença, estímulo ao autocuidado).

Quanto à área de gerenciamento de recursos o grupo entendeu que gerenciar recursos materiais e humanos, organizando-os de forma a otimizar a qualidade dos serviços de saúde prestados à população, é parte do aprendizado do residente em Medicina de Família, e que essa função requer o domínio de conhecimentos relativos ao planejamento e à avaliação de qualidade, e de habilidades de comunicação, liderança e trabalho em equipe e estabeleceu que o médico de família deveria possuir os conhecimentos e as habilidades necessários para o manejo adequado dos recursos disponíveis no sistema de saúde, visando a maximização dos 
benefícios e a redução dos custos. Para tanto, estabeleceu que um conhecimento básico em técnicas de gestão e administração sanitária deveria fazer parte de suas competências, incluindo:

a) Competência em planejar as ações da equipe na área de abrangência;

b) Competência na gerência de uma Unidade de Medicina de Família;

c) Competência em manter um sistema de registro de informações adequado;

d) Competência na organização de sistema de referência e contra-referência.

$\mathrm{Na}$ área de desenvolvimento pessoal e profissional o grupo identificou um conjunto de competências específicas consideradas de fundamental importância para que o médico de família desenvolva durante toda a vida profissional uma atitude crítica em relação a si próprio, ao conhecimento científico e à medicina que pratica, a aquisição do hábito da auto-aprendizagem permanente, a capacidade de estabelecer uma relação médico-paciente aberta, receptiva e plenamente comunicativa, e o domínio da estrutura do sistema de saúde e de seu papel dentro dele, mantendo permanentemente uma atitude de aprendizagem, colaboração e respeito ético, composto de:

a) Competência em se submeter a atividades de reciclagem profissional específicas com o propósito de preencher lacunas e corrigir procedimentos inadequados; 
b) Competência na coleta, seleção e análise de literatura profissional relevante;

c) Competência nos princípios de interpretação de resultados de pesquisa clínica e epidemiológica e integração destes resultados em sua própria educação e trabalho profissional;

d) Competência na cooperação com colegas médicos de famílias e especialistas;

e) Competência no trabalho em equipe com enfermeiras e outros profissionais de saúde;

f) Competência relativa ao conhecimento do funcionamento do sistema de saúde em sua região e sua inserção dentro dele;

g) Competência relativa à visão de suas tarefas e responsabilidade profissional, e à delimitação com as tarefas de outros profissionais de saúde;

h) Competência relativa às regulações legais de assistência à saúde (certificados de óbitos, notificação de doenças infecciosas, aspectos médicos legais importantes);

i) Competência no desenvolvimento de atitude crítica em relação à sua própria performance;

j) Competência no desenvolvimento de atitude crítica em relação à profissão. 


\section{II.b) Estrutura Curricular}

Conforme a proposta examinada, o grupo de elaboradores estruturou o Programa da Residência em Medicina Geral e Comunitária em quatro blocos, a partir das competências estabelecidas:

O Bloco I, Introdutório, com duração de 3 meses, contendo uma introdução geral ao conteúdo do Programa e à estratégia educacional adotada no Programa de Residência, o PBL; e treinamentos introdutórios em Medicina Baseada em Evidência, Vigilância Epidemiológica, Gerenciamento de Informações em Saúde, Educação e Promoção da Saúde e Mobilização Comunitária.

O Bloco II, voltado para o Treinamento Ambulatorial e Comunitário em Atenção Primária, com duração de 12 meses, a ser desenvolvido em uma Unidade de Saúde estruturada para receber os residentes. Este bloco prioriza as atividades de atenção a pacientes na comunidade, abrangendo atendimentos ambulatoriais e visitas domiciliares às famílias adscritas a esta Unidade. Além disso, as equipes de médicos e enfermeiros devem planejar e executar atividades de monitoramento, educação e promoção da saúde junto a núcleos estratégicos da comunidade, como escolas, creches e lares de idosos. Neste bloco ainda estão incluídas atividades teóricas sobre saúde mental, saúde da criança, da mulher, do adulto e do idoso, previstas para serem realizadas, sob a forma de seminários, estudos de caso, sessões clínicas e clubes de revista.

O Bloco III relativo ao Treinamento em Hospitais e Serviços 
Especializados da rede pública, com duração de 6 meses, devendo ser desenvolvido em rodízio por diversas unidades hospitalares. $O$ rodízio inclui também diversas Unidades ambulatoriais especializadas onde o residente irá adquirir familiaridade com o tratamento e acompanhamento de pacientes com problemas crônicos de maior complexidade.

No estágio hospitalar o residente deverá passar pelos serviços de doenças infecciosas; pediatria; ginecologia / obstetrícia e clínica médica. Além disso, o residente deve continuar inserido nas atividades da Unidade de Saúde durante dois períodos por semana, assegurando a continuidade da atenção aos pacientes e familiares de sua área de cobertura.

O rodízio em unidades ambulatoriais inclui: dermatologia, diabetes, hipertensão, DST/AIDS, além de um mês de estágio eletivo.

O Bloco IV relativo ao Treinamento em área rural, com duração de três meses, foi projetado pra possibilitar uma vivência de residente no contexto sócio-epidemiológico de uma área rural, participando do trabalho de equipes de saúde da família e desenvolvendo uma visão crítica do estágio atual de organização do PSF.

Ainda de acordo com a proposta, os residentes têm direito a dois meses de férias, sendo um a cada ano do programa. 


\section{II.c) Sistema de Avaliação}

O grupo de elaboração estruturou o sistema de avaliação do Programa de Residência Médica visando o alcance de dois principais objetivos: primeiro, dimensionar o progresso do residente, relacionado às atividades de avaliação do estudante, e segundo, colher informações para aperfeiçoar as atividades educativas, voltado para a avaliação do curso. Assim, o processo de avaliação do aluno é composto três modalidades: uma avaliação de situação, para verificar o nivel de conhecimentos do residente no momento do seu ingresso no Curso; uma avaliação formativa, a fim de observar se os objetivos de aprendizagem propostos estão sendo alcançados ao longo do curso, permitindo eventuais correções e uma avaliação certificativa, para conferir se a aprendizagem efetivamente ocorreu a contento.

Segundo o material coletado, a primeira modalidade proposta é a avaliação de situação, estando relacionada com a performance de entrada do estudante no Programa de Residência Médica, e tem, primariamente, o caráter de pré-teste, no intuito de revisar, quando possível, as atividades instrucionais e de desenvolver uma avaliação progressiva comparativa com testes subseqüentes. Esta forma de avaliação deveria ser aplicada no momento do Programa de Residência, de preferência antes do início das atividades dos módulos, buscando avaliar o aluno em três dimensões: conhecimento, habilidade e atitude:

a) avaliação do conhecimento, mediante a aplicação de uma 
prova de múltipla escolha, compreendendo todos os objetivos de aprendizagem do curso;

b) avaliação de habilidades, na qual os médicos residentes terão que realizar algumas tarefas específicas ou procedimentos em simulações da prática clínica ou ainda avaliar imagens, as quais deverão passar sequencialmente em estações cronometradas. $O$ instrumento para acompanhar esse tipo de avaliação poderá ser um check list ou uma lista de perguntas específicas sobre o tema; e

c) avaliação de atitudes, em que serão utilizados pacientes padronizados em consultas clínicas e os residentes serão instruídos a realizar uma tarefa específica, como realizar uma história clínica ou dar uma má notícia, por exemplo. Neste caso, a avaliação será feita também se utilizando um check list da consulta, que será filmada para possibilitar uma melhor interpretação pelos avaliadores, além de fornecer instrumento para o feedback do desempenho do residente.

A avaliação formativa é a segunda modalidade apresentada e visa acompanhar de forma contínua o processo de aprendizagem do residente, permitindo observar se os objetivos propostos estão sendo atingidos, além de identificar eventuais deficiências do ensino, possibilitando que sejam corrigidas, sendo realizada das seguintes formas:

a) autoavaliação, na qual o residente faria bimensalmente, uma avaliação sobre seu próprio desempenho, devendo englobar as dimensões relativas aos conhecimentos, habilidades e atitudes, de modo a ajudá-lo a reconhecer as suas dificuldades e assumir mais responsabilidade em cada 
etapa do processo de aprendizagem;

b) avaliação pelos pares, também com periodicidade bimensal, realizada pelos colegas do Programa de Residência Médica, acerca do desempenho de cada membro da equipe;

c) avaliação pelo facilitador, realizadas a cada dois meses, nos grupos tutoriais de PBL, quando o facilitador avalia o desempenho do grupo e de cada membro individualmente, mediante a utilização de um instrumento padronizado;

d) avaliação pelo preceptor, realizada enquanto o residente está desenvolvendo suas atividades nos serviços, seja no ambulatório, no hospital ou na comunidade. Esta avaliação também busca examinar nos três domínios do conhecimento (cognitivo, habilidades e atitudes).

E, completando as três modalidades previstas de avaliação do aluno tem-se a avaliação certificativa, que também procura abranger as três dimensões da competência (conhecimento, habilidades e atitudes) e visa identificar se a aprendizagem efetivamente ocorreu, sendo utilizados, alèm dos instrumentos da avaliação de situação, outras estratégias, como avaliação dos ensaios, trabalhos individuais e a monografia, que deverá ser entregue ao final do Programa de Residência Médica.

O grupo propôs ainda a avaliação dos facilitadores e preceptores, mediante a utilização de instrumentos específicos, construídos para esse fim e aplicados junto aos residentes; como também do próprio Programa de Residência, com a participação de todos os envolvidos com o processo de aprendizagem, como forma de buscar o constante aperfeiçoamento do Programa de Residência em questão. 


\section{Categoria III. Preceptoria}

Ainda segundo a documentação examinada, o preceptor teria por função básica a tarefa de ensino e supenvisão dos residentes em treinamento, conduzindo o processo educacional nas esferas técnica e ética, cuja descrição do seu trabalho inclui:

a) assistir ao treinando no atendimento ao paciente, assessorando-o no desenvolvimento de habilidades clínicas, de um processo correto de tomada de decisões, de atitudes éticas, e de uma ótima relação médico-paciente;

b) assistir ao treinando na análise dos problemas da comunidade, no desenvolvimento de projetos de intervenção e no monitoramento das ações desenvolvidas;

c) Acompanhar a evolução do treinando durante todo o período da Residência, avaliando o progresso de seus conhecimentos, habilidades e atitudes, e monitorando a sua performance com relação aos objetivos de aprendizagem estabelecidos no programa de treinamento.

O grupo estabeleceu que a função de preceptoria da Residência deveria ser exercida por profissionais que preenchessem alguns requisitos, tais como:

a) ter título de Residência Médica em uma das seguintes especialidades: clínica médica, pediatria, ginecologia e obstetrícia e saúde coletiva;

b) ter competência profissional reconhecida; 
c) ter experiência clínica adequada para garantir a expertise necessária para atender às necessidades do treinamento;

d) ter interesse pela atividade de educação médica;

e) ter dedicação de pelo menos 20 (vinte horas) semanais às atividades de treinamento;

f) ter conhecimento preciso do papel, natureza e funções do médico de família;

g) ter compromisso com a proposta do Programa de Residência;

h) ter comportamento profissional reconhecidamente ético.

Ficou estabelecido também no projeto do Programa de Residência que a instituição promotora realizaria a preparação adequada dos preceptores por meio de treinamento prévio, estabelecendo que os preceptores ao final desse processo de capacitação deveriam ser capazes de:

a) compreender os princípios da atenção primária à saúde;

b) ter visão correta do papel, das funções e das competências do médico de família;

c) perceber o processo saúde-doença a partir de uma perspectiva bio-psico-social;

d) dominar novos métodos e estratégias de ensino na área da educação médica; e

e) compreender as estratégias e os princípios organizacionais do Programa de Residência 


\section{b) Programa B}

\section{Categoria l. Construção do PRMFC}

Conforme registrado na documentação pesquisada, a concepção do Programa B originou-se a partir de uma série de oficinas organizadas em 2003, reunindo todas as instituições que ofereciam cursos de especialização em saúde da família; representantes das Secretarias Municipais e Estaduais de Saúde e a Sociedade Cearense de Medicina de Família e Comunidade, os quais chegaram à conclusão de que o desempenho dos profissionais que atuavam na estratégia saúde da família não estava satisfatório, e que seria necessária uma ação conjunta de todos aqueles parceiros, no sentido de formatar e oferecer um novo tipo de curso, que melhor preparasse o médico para o trabalho na saúde da família.

Logo, os participantes das referidas oficinas reconheceram que a Residência Médica seria o modelo ideal para a formação dos médicos de família, como acontece nas demais especialidades, e que deveria ser estimulado o seu desenvolvimento.

Perceberam também que o processo de formação através da Residência Médica é lento, pois só após dois anos de duração o profissional obtém o título de especialista, e, além disso, observaram que esta modalidade de ensino capacita poucos profissionais por vez, dado o número 
de vagas ofertadas a cada ano, e concluíram que seria necessária a busca de alternativas para atender, pelo menos parcialmente à qualificação do grande número de profissionais em atividade, visto que a descentralização do atendimento que tem ocorrido com a estratégia da saúde da família está provocando uma acentuada melhoria em alguns indicadores de saúde, apesar do grupo ainda identificar as deficiências na preparação do médico para o novo tipo de trabalho.

As discussões que se seguiram em 2004 com as Universidades facilitaram o trabalho de construção e organização do Programa de Residência. Na perspectiva de formar uma quantidade maior de profissionais, pleitearam inicialmente, 200 vagas, e, após avaliação pela Comissão Estadual de Residência Médica do Ceará e Comissão Nacional de Residência Médica em dezembro de 2005, receberam credenciamento provisório, com autorização para oferta de 76 vagas no primeiro ano de funcionamento.

Assim, conforme os documentos analisados, o Programa B, com a denominação de Programa de Residência em Medicina de Família e Comunidade foi implantado em março de 2006, com o objetivo formar médicos com conhecimentos, habilidades e atitudes, necessários para a atuação na especialidade da Medicina de Familia e Comunidade dentro da rede do SUS.

De acordo com seus idealizadores, este PRMFC apresenta como diferencial a proposta da "tenda invertida", segundo os quais, ao invés de o processo educativo estar centrado no cenário hospitalar, característico do modelo de saúde baseado na atenção individual e nas ações curativas, em que os alunos vão aos hospitais para a sua capacitação com os "mestres"; 
explicam que nesta proposta o processo de ensino está centrado na idéia de que o "mestre" é quem deve ir até o local de atuação do aprendiz (tenda), ajudando-o a refletir sobre suas práticas, participando diretamente do processo de construção e reconstrução do conhecimento do médico residente, e afirmam que o preceptor vai à Unidade de Saúde da Família e ao território de abrangência desta, convivendo, juntamente com os residentes, com a realidade local, buscando soluções para os problemas apresentados, capacitando-o a desenvolver sua prática profissional de modo a responder a questões contextualizadas.

\section{Categoria II. Desenho do Currículo}

Muito embora os documentos relatem a realização de uma série de oficinas para a construção do Programa B, não há um detalhamento dos passos seguidos para a construção do currículo do referido Programa. Conforme está registrado no projeto, o colegiado de coordenação, o corpo de preceptores e as instituições parceiras seguiram as normas da Comissão Nacional de Residência Médica e as diretrizes da Sociedade Brasileira de Medicina de Família e Comunidade, as quais ressaltam o fortalecimento dessa especialidade em todo o Brasil e alertam para a necessidade de maior integração entre as estratégias de formação dos profissionais de saúde e o perfil de recursos humanos requeridos pelas políticas públicas desse setor. 


\section{II.a) Competências a serem desenvolvidas}

Segundo as fontes consultadas o grupo de elaboração do Programa B estabeleceu competências para atenção integral à saúde da família a serem desenvolvidas pelos residentes até a conclusão da RMFC, quais sejam:

a) Competência para exercer com compromisso, de forma crítica e criativa, a função de médico de família em equipe multiprofissional no contexto do Sistema Único de Saúde, incluindo:

- Exercício profissional no SUS;

- Promoção da saúde e abordagem comunitária;

- Abordagem sistêmica da família e saúde mental;

- Atenção à saúde do trabalhador.

b) Competência para atenção integral a saúde no contexto da atenção primária por ciclos de vida e gênero, incluindo:

- Atenção integral à saúde da criança e do adolescente;

- Atenção integral à saúde da mulher;

- Atenção integral à saúde da gestante;

- Atenção integral à saúde do homem;

- Atenção integral à saúde do adulto;

- Atenção integral à saúde do idoso.

c) Competências clínicas para o atendimento a situações de 
emergência, urgência e internamento hospitalar na atenção primária; e

d) Competências para produção científica e tecnológica.

\section{II.b) Estrutura Curricular}

Conforme apurado na pesquisa, o Programa B conta com uma carga horária total de 5.760 horas, distribuídas em 60 horas semanais, ao longo dos dois anos de duração do Programa (R1 e R2), tendo $85 \%$ desta carga horária preenchida com atividades práticas, sob a forma de treinamento em serviço, sendo o restante (15\%) destinado para atividades teórico-complementares.

As atividades práticas e teóricas do Programa B são desenvolvidas semanalmente, dentro de uma seqüência de atividades que caracteriza uma semana padrão de trabalho, perfazendo uma carga horária de 60 (sessenta) horas semanais. Existe uma diferenciação entre a semana padrão do primeiro ano de Residência (R1) e aquela do segundo ano (R2).

No primeiro ano do Programa a carga horária está assim distribuída:

- Atividades na Unidade de Saúde da Família (34 horas), em que o residente realiza atendimento ambulatorial a crianças, mulheres, adultos e idosos; participa de atividades de planejamento, administração e 
gerenciamento; com grupos terapêuticos; de reuniões com a equipe de saúde da família e preceptores de território; de discussão de casos; realiza visita domiciliar ou alguma outra atividade na comunidade;

- Estágio em ambulatórios ou serviços especializados (4 horas), cujo objetivo é aumentar a resolutividade dos profissionais no conjunto de práticas e saberes biomédicos, possibilitando o reconhecimento dos casos clínicos que podem ser tratados no nível primário de saúde e os que devem ser encaminhados para os outros niveis de atenção. Os residentes passam pelos serviços especializados de hipertensão e diabetes; hanseníase e tuberculose; geriatria; DST/AIDS; saúde mental e acompanhamento de crianças com distúrbio nutricional;

- Atividades teórico-complementares (10 horas), sendo 4 horas no turno da noite e 6 horas para discussão de casos na Unidade de Saúde e para seminários. Segundo as informações obtidas, estas atividades teóricocomplementares do Programa em estudo são divididas em aulas teóricas; seminários e sessões clínicas com discussão de casos, abordando aspectos médicos, sociais, econômicos, comportamentais, ambientais, históricos e culturais, em uma perspectiva holística do indivíduo. Também consta a discussão de documentos técnicos do Ministério da Saúde, artigos científicos nacionais e internacionais, sendo estimuladas a produção científica e a participação em congressos, cursos e palestras, nas quais devem constar obrigatoriamente temas relacionados com Bioética, Ética Médica, Metodologia Científica, Epidemiologia e Bioestatística. Recomendando ainda a participação do médico residente em atividades relacionadas ao controle das 
infecções hospitalares, conforme os dados pesquisados. Para a realização das aulas teóricas reúnem-se todos os médicos residentes, ao passo que as discussões dos casos clínicos são descentralizadas por regional de saúde sob a responsabilidade dos coordenadores regionais da Residência, enquanto que os seminários são realizados nas Unidades de Saúde com a coordenação dos preceptores de especialidades.

Nas aulas teóricas são abordados temas que compõem um total de onze módulos temáticos em Saúde Coletiva: Módulo 1: O Sistema Único de Saúde, o Sistema Municipal de Saúde e a Estratégia Saúde da Família; Módulo 2: Avaliação da Situação de Saúde e Planejamento de Intervenções na Comunidade; Módulo 3: Abordagem à Família; Módulo 4: Educação Popular, Promoção da Saúde e Participação Social; Módulo 5: Epidemiologia e Bioestatística; Módulo 6: Metodologia do Trabalho Científico; Módulo 7: Vigilância à Saúde e Sistemas de Informação em Saúde; Módulo 8: Planejamento Estratégico; Módulo 9: Organização e Gerenciamento Local; Módulo 10: Acompanhamento do Processo de Elaboração da Monografia e Módulo 11: Terapias Alternativas / Complementares, perfazendo um total de 296 horas / aulas.

Os temas tratados nas sessões clínicas correspondem aos módulos temáticos por Ciclos de Vida e Clínicos, correspondendo a Atenção Integral à Saúde da Mulher; Atenção Integral à Saúde da Criança; Condutas Clínicas (ressuscitação cardio pulmonar e cerebral e manejo de reações alérgicas com ênfase em anafilaxia, endocrinologia, psiquiatria, reumatologia, cardiologia, gastroenterologia, hematologia, dermatologia, pneumologia, neurologia, 
doenças infecciosas e parasitárias e nefrologia); Proteção à Saúde do Adulto e Proteção à Saúde do Idoso, num total de 354 horas / aulas.

- Plantão em hospitais secundários e terciários (12 horas), tendo como objetivo proporcionar experiências em atendimentos de urgência e emergência em clínica médica, pediatria e ginecologia e obstetrícia, além do atendimento a traumas e a realização de pequenas cirurgias ambulatoriais de urgência.

O segundo ano da Residência é destinado ao aprofundamento das atividades que o residente já desenvolve desde o primeiro ano, atuando, a partir de então, com mais autonomia e capacidade de reflexão. Além disso, outras atividades são acrescentadas, como a docência do R1, em que o residente R2 começa a orientar, de forma preliminar, os residentes do primeiro ano em algumas atividades, contando com o apoio dos preceptores; o rodízio dos plantões passa a ser em enfermaria e a realização do estágio opcional, no horário correspondente ao estágio em ambulatório de especialidades, podendo ser em um serviço conveniado com o Programa.

$\mathrm{Na}$ proposta desse Programa cada residente terá dedicação exclusiva e será responsável por 500 a 800 famílias. 


\section{II.c) Sistema de Avaliação}

O sistema de avaliação, segundo proposto no documento, deve contemplar tanto o desempenho dos residentes, como de todo o processo de ensino-aprendizagem, referindo-se a uma avaliação de estrutura, processo e resultados, incluindo nesse processo avaliativo a avaliação do impacto do PRMFC na atenção à população e na mudança dos indicadores de saúde. Estabelece também que a avaliação dos residentes será formativa e certificativa.

$\mathrm{Na}$ avaliação certificativa os residentes são analisados quanto à aquisição de conhecimentos, mediante a aplicação de duas provas escritas por ano (semestralmente); à assiduidade, por meio de verificação da freqüência com que participa das atividades; ao desempenho nas sessões de prática e na apresentação dos estudos de casos, sendo pelo menos um caso clinico por semestre, pelo preceptor.

$\mathrm{Na}$ avaliação formativa, utiliza-se um instrumento de avaliação, especifico para avaliar as habilidades dos residentes, sendo que o preceptor a cada três meses realiza uma avaliação das habilidades dos residentes e envia para a coordenação geral. Essa avaliação é discutida a nível regional, e dependo do caso, os residentes são chamados, para um feedback, ocasião em que são discutidas as deficiências encontradas e apresentados caminhos de superação.

O sistema conta também com a proposta de um processo de autoavaliação do residente, mediante a elaboração de um portfólio, utilizado como ferramenta de monitoramento e avaliação, pois, de acordo com a 
descrição dada, trata-se de um instrumento que se destina à sistematização das informações sobre crenças, intenções e práticas, com o objetivo de documentar o percurso do aluno, de sistematizar processos de reflexão para desenvolver competências, ou seja, analisar e tomar decisões apropriadas em situações reais da prática profissional.

Já para a avaliação do Programa em si são realizados três fóruns anuais, em que se reúnem residentes, preceptores e coordenadores, os quais escolhem uma temática e vão discuti-la, trabalhando em grupos separados ou em grupos mistos. Trata-se também do momento dos residentes avaliarem os preceptores, utilizando um instrumento elaborado com essa finalidade.

\section{Categoria III. Preceptoria}

De acordo com os seus autores, o Programa de Residência ora apresentado tem um sistema de acompanhamento do médico residente composto por duas modalidades de preceptoria: a preceptoria de território e a preceptoria clínica. Isto porque, segundo eles, a proposta pedagógica enfatiza a necessidade de uma formação clínica e não apenas uma formação técnica do profissional para trabalhar na atenção primária.

O projeto do Programa B esclarece que o preceptor de território tem como propósito o ensino dos princípios e diretrizes do SUS, das questões relativas à saúde pública e das ações coletivas de saúde, a partir de situações 
reais vivenciadas na prática cotidiana e da realidade local do território de abrangência da Unidade de Saúde, sendo suas atividades voltadas para o acompanhamento dos residentes, da equipe de saúde da família e da coordenação das equipes, e contribuindo para definir coletivamente a política local de saúde, incluindo o reconhecimento do território, seus aparelhos sociais (comunitários e institucionais); a análise da situação de saúde; vigilância à saúde; identificação das práticas de medicina popular e articulação com os atores locais da medicina popular; planejamento local participativo, organização dos serviços, promoção da saúde; co-gestão do coletivo e participação no conselho local de saúde. Segundo o projeto, para cumprir com essa programação, cada Unidade de Saúde tem no mínimo oito horas semanais de acompanhamento com o preceptor de território.

O documento segue explicando que o preceptor clínico tem como objetivo principal promover, junto com os preceptores de território discussões mais amplas sobre os assuntos relacionados à saúde em cada ciclo de vida, envolvendo as demais categorias profissionais envolvidas no atendimento do indivíduo ou da família. E que a preceptoria clínica é exercida por equipes matriciais de preceptores médicos, formadas por um médico especialista em medicina de família e comunidade, um pediatra, um ginecologista-obstetra e um clínico. Estes preceptores foram identificados dentro do próprio sistema de saúde, e, a partir de um curso de capacitação para preceptores clínicos, passaram a exercer essa função, aliada ao trabalho assistencial que já realizavam dentro da Unidade de Saúde.

Assim, em conformidade com a proposta do Programa B cada 
residente pode contar com a presença de pelo menos um dos membros da equipe matricial de preceptores clínicos trabalhando na mesma Unidade de Saúde, como também com visitas periódicas dos preceptores clínicos das outras especialidades.

\section{c) Programa C}

\section{Categoria I. Construção do PRMFC}

De acordo com a documentação examinada, as primeiras iniciativas para criação do Programa C datam de 1998, quando, em dezembro deste ano foi realizada uma oficina que contou com a participação de todas as instituições pertencentes ao Pólo de Capacitação do Programa Saúde da Família do Estado do Ceará; sendo que as discussões giraram em torno da necessidade de capacitação dos profissionais para atuarem na estratégia Saúde da Família, culminando com a criação, em 1999, de um Programa de Residência em Saúde da Família, de caráter multiprofissional, do qual faziam parte várias categorias profissionais, realizando, de maneira sistemática, ações preventivas, curativas e reabilitadoras, e em especial, ações de promoção da saúde em atenção primária. No entanto, por determinação do Conselho Regional de Medicina do Ceará, este subsidiado 
por Resolução do CFM, foi retirada, em 2003, a categoria médica dessa Residência, uma vez que os médicos formados não receberiam 0 reconhecimento desta especialização.

Conforme a documentação analisada, a partir desta data foram iniciadas as discussões para a criação de uma Residência Médica exclusiva à categoria médica, mas no mesmo ambiente. $\mathrm{E}$, em 2005, numa parceria interinstitucional, envolvendo três instituições públicas, foi criado o Programa de Residência em Medicina de Família e Comunidade, após ser reconhecido pela Comissão Estadual de Residência Médica, tendo como objetivo formar um especialista cuja característica básica é atuar, prioritariamente, em Atenção Primária à Saúde, a partir de uma abordagem biopsicossocial do processo saúde adoecimento, integrando ações de promoção, proteção, recuperação e de educação em saúde no nível individual e coletivo.

O Parecer conclusivo da CNRM de $\mathrm{N}^{\circ}$ 04/06, aprovado em 12/12/2005 regulamentou este Programa de Residência, sendo que 0 primeiro ano de Residência em Medicina de Família e Comunidade iniciou em 2006. Ainda, segundo as informações colhidas, a Residência continua com a idéia da interdisciplinaridade, no qual o trabalho em conjunto com a Residência Multiprofissional em Saúde da Família tende à sincronia, sendo a atenção primária o locus de atuação onde acontece o aprendizado e o fazer do médico, tendo, no entanto, também atividades referentes aos cuidados secundários e terciários. 


\section{Categoria II. Desenho do Currículo}

O projeto para criação do Programa C está bastante detalhado, com uma extensa descrição de todos os seus componentes, no entanto, não descreve o processo de construção do currículo do Programa. $O$ documento refere que o Programa foi elaborado respeitando a Resolução da Comissão Nacional de Residência Médica, CNRM Nº5/2002.

\section{II.a) Competências a serem desenvolvidas}

No projeto de formatação do Programa de Residência está referido que na elaboração do currículo as competências a serem desenvolvidas pelos residentes foram divididas em dois grupos: no primeiro, as competências dos médicos de família comuns às de outros profissionais inseridos na estratégia Saúde da Família e, no segundo, aquelas específicas dos médicos de família e da comunidade:

No primeiro grupo encontram-se as competências que, segundo 0 documento, seriam comuns a todos os profissionais da Saúde da Família:

- Fornecer atenção integral, de qualidade, à população adscrita, no âmbito da atenção básica compreendendo a atenção ambulatorial e domiciliar. 
- Conhecer os princípios e diretrizes do SUS e suas implicações na prática da atenção básica.

- Conhecer as políticas de governo na área da saúde, suas principais normas e estratégias de operacionalização.

- Realizar análise da situação de saúde, entendendo os fatores que interferem no processo saúde/doença,visando a elaboração de propostas de intervenção.

- Estabelecer mecanismos de integração e articulação entre os serviços de saúde nos diferentes níveis de complexidade, definindo mecanismos de referência e contra-referência.

- Realizar ações de vigilância à saúde, envolvendo os indivíduos, as famílias, a comunidade (área de abrangência) e a sociedade.

- Entender as características do trabalho em equipe e desenvolver a capacidade de trabalhar em conjunto com todos os profissionais que integram a Saúde da Família, a partir da noção de complementariedade das ações e tendo como objeto as necessidades dos indivíduos, das famílias e da comunidade.

- Dominar o conceito de território e as técnicas de trabalho que se aplicam à noção de território.

- Compreender as características sócio-culturais da população, respeitando seus valores, crenças, costumes, práticas e formas de organização.

- Desenvolver a capacidade de comunicação com a população 
da sua área de abrangência visando entender suas necessidades de saúde e os modos como se organizam para resolver os diferentes problemas vivenciados.

- Estabelecer vínculos com a população criando compromisso e responsabilidade com a saúde da população adscrita.

- Assumir uma postura de respeito e solidariedade para com a população, na relação do atendimento às suas demandas.

- Entender a natureza da resistência da população às propostas de atendimento e tratamento, procurando encontrar alternativas mais eficazes.

- Entender os sistemas de informação disponíveis e proceder à análise dessas informações para a produção de ações dirigidas à população.

- Organizar e gerenciar ações e serviços de saúde no nível local.

- Realizar o diagnóstico dos problemas de saúde da população adscrita e da comunidade em que se insere essa população, tendo como base os instrumentos da epidemiologia.

- Realizar diagnóstico da situação sócio-sanitária do território a partir dos indicadores disponíveis e da utilização do instrumental epidemiológico, tendo como referência as características da comunidade e da sociedade.

- Elaborar o planejamento e a programação em saúde para o território de abrangência, considerando as características sócio-culturais da comunidade e da sociedade. 
- Desenvolver estratégias que facilitem a participação social nas decisões sobre as práticas dos serviços de saúde.

- Desenvolver sistemas de acompanhamento e avaliação das ações desenvolvidas junto à população.

- Criar mecanismos para divulgação das propostas de ação, das atividades realizadas e dos resultados e impactos dessas ações para discussão com a população.

- Identificar o trabalho desenvolvido pelos setores organizados da sociedade civil e estabelecer parcerias, visando potencializar a ação dos serviços de saúde e o trabalho dessas entidades.

- Estabelecer parcerias com outros setores da administração pública visando o desenvolvimento de políticas intersetoriais.

Enquanto que no segundo grupo estão as competências inerentes às funções do médico de família:

- Fornecer atenção integral, de qualidade, à população adstrita no âmbito da atenção básica compreendendo a atenção ambulatorial e domiciliar.

- Ser capaz de atender os principais problemas de saúde da competência da atenção básica apresentados por crianças, adolescentes, adultos e idosos, além dos problemas de saúde próprios do ciclo reprodutivo e aqueles decorrentes das condições de trabalho.

- Diagnosticar e tratar os principais problemas de saúde que 
demandam as unidades de saúde.

- Identificar e tratar os principais problemas de saúde não percebidos pela população.

- Solicitar os exames laboratoriais compatíveis com o atendimento realizado na atenção básica.

- Propor planos terapêuticos adequados aos problemas apresentados e envolver na proposta terapêutica os recursos da comunidade.

- Desenvolver ações de promoção da saúde e prevenção das doenças, entendendo o território como base para essas ações.

- Entender os limites da atenção básica e estabelecer mecanismos de articulação e integração com os demais serviços, nos diferentes níveis de complexidade, visando atender as necessidades apresentadas pela população.

- Responsabilizar-se pelo tratamento dos seus pacientes, contando para isso com os outros profissionais da equipe de saúde.

- Acompanhar a trajetória do paciente encaminhado para outros serviços, identificando as possibilidades de intervenção para que o paciente seja acolhido nesses serviços.

- Estabelecer mecanismos de articulação com os profissionais dos demais senviços de saúde para discussão dos casos clínicos e encaminhamento de pacientes.

- Atuar de acordo com os princípios éticos inerentes ao exercício 
profissional.

Ainda de acordo com a proposta do Programa da Residência, para as atividades de atenção integral à saúde deverão ser desenvolvidas no médico residente as seguintes habilidades:

- Em nível individual:

a) Implementar ações de promoção e proteção à saúde da criança, da mulher, do adolescente, do adulto, do trabalhador e do idoso;

b) Identificar as fases evolutivas e assistir aos transtomos adaptativos da infância, da adolescência, da idade adulta e da velhice;

c) Prestar assistência à gestação normal, identificando os diferentes tipos de risco;

d) Assistir ao parto e ao puerpério normais;

e) Diagnosticar e tratar as afecções mais freqüentes do ciclo gravídico-puerperal;

f) Proporcionar cuidados ao recém-nascido normal e realizar puericultura;

g) Diagnosticar e tratar as afeç̧ões mais freqüentes na infância, na adolescência, na idade adulta e na velhice;

h) Reconhecer e proporcionar os primeiros cuidados às afecções graves e urgentes;

i) Examinar e constatar anormalidades em exames complementares e de apoio ao diagnóstico relacionado com a 
complexidade de sua atividade clínica;

j) Diagnosticar e tratar distúrbios psicológicos mais comuns, encaminhando para assistência psicológica ou psiquiátrica os pacientes que dela necessitarem;

k) Diagnosticar patologia cirúrgica freqüente e encaminhar à sua resolução;

I) Executar cirurgia ambulatorial de pequeno porte;

m) Encaminhar para serviços adequados pacientes que necessitem de procedimentos diagnósticos e / ou terapêuticos especializados;

n) Orientar o pré e pós-operatórios das intervenções mais simples;

o) Diagnosticar e tratar os problemas mais freqüentes de saúde do trabalhador, encaminhando para a assistência especializada sempre que se fizer necessário.

- Em nível familiar e coletivo:

a) Conhecer o ciclo vital, a estrutura e a dinâmica familiar;

b) Reconhecer e assistir, quando necessário, às crises familiares, evolutivas e não evolutivas;

c) Reconhecer e assistir às disfunções familiares, encaminhando corretamente para assistência psicológica ou psiquiátrica as famílias que dela necessitarem;

d) Conhecer e utilizar as técnicas de dinâmica de grupo;

e) Conhecer e promover ações de educação em saúde, bem 
como participar de ações em parceria com a comunidade, buscando desenvolvimento simultâneo e mútuo;

f) Identificar os problemas e necessidades de saúde da comunidade, particularizando grupos mais vulneráveis, e implementar ações de promoção, proteção e recuperação da saúde de caráter coletivo e no âmbito da atenção primária;

g) Desenvolver ações de caráter multiprofissional e interdisciplinar;

h) Realizar cadastro familiar e estabelecer o perfil de saúde de grupos familiares.

- Nas atividades de administração e planejamento:

a) Chefiar ou apoiar à chefia da unidade em questão de gerência;

b) Realizar programação quantificada das atividades da unidade $e$ criação de parâmetros para medir o alcance das metas propostas;

c) Montagem e operação do sistema de informação para acompanhamento da prestação de atividades finais e de produtividade, visando à avaliação da unidade quanto a eficácia, a eficiência e a efetividade;

d) Orientação da organização e funcionamento de um arquivo médico da unidade;

e) Montagem, orientação e avaliação do sistema de referência e contra-referência dentro e fora da unidade, visando promover a complementaridade da atenção médica sanitária; 
f) Atuação intersetorial, acionando secretarias municipais, entidades, instituições e outras organizações sempre que se fizer necessário.

- Nas atividades na área do ensino e pesquisa:

a) Promover estudos de incidência e prevalência de morbimortalidade e de indicadores de saúde na população sob sua responsabilidade;

b) Participar da realização de investigações operacionais como estudos de demanda e estudos de setores específicos da unidade, visando à melhoria no funcionamento da mesma e sua adequação às necessidades de saúde da população a que serve;

c) Desenvolver e implementar novas tecnologias na assistência e atenção no âmbito da medicina geral, de família e da comunidade, baseadas no paradigma biopsicossocial;

d) Participar da implementação, controle e avaliação do programa de imunização da unidade, de acordo com a norma vigente na Instituição e de acordo com o Programa Nacional de Imunizações;

e) Participar das atividades de vigilância epidemiológica na área de referência da unidade, acionando o sistema de vigilância epidemiológica sempre que necessário; desenvolver e participar da orientação e implementação de atividades de treinamento de pessoal de vários níveis e de educação 
continuada para a equipe de saúde;

f) Promover o auto-aprendizado e a atualização de conhecimentos na área da medicina geral, familiar e comunitária.

\section{II.b) Estrutura Curricular}

Conforme descrito no projeto, o Programa de Residência tem a duração de dois anos, com carga horária de cerca de 2.800 horas anuais. Neste Programa está previsto um $3 .^{\circ}$ ano, complementar e opcional, que poderá ser efetivado de acordo com a conveniência e possibilidade da Instituição, objetivando o aprofundamento de conhecimentos e habilidades técnicas dos residentes.

No projeto do Programa de Residência está estabelecido que de 85 a $90 \%$ da carga horária total destina-se a atividades de treinamento em serviço. Estas atividades são desenvolvidas obedecendo à seguinte proporção, em termos de espaço de formação referente à atenção individual e coletiva:

a) atividades desenvolvidas na comunidade: domicílios, escolas, igrejas, centros comunitários, locais de trabalho e lazer aproximadamente $10 \%$ da carga horária total;

b) atividades em unidades de atenção primária à saúde: unidades básicas de saúde da família e centros de saúde ou unidades mistas de 
saúde situadas em centros de referência aproximadamente $70 \%$ da carga horária total;

c) atividades em unidades de cuidados secundários e terciários: hospitais gerais, hospitais de especialidades ou especializados aproximadamente $10 \%$ da carga horária total.

Complementando as atividades do Programa de Residência, de 10 a $15 \%$ da carga horária total referem-se às atividades teóricocomplementares, constituídas por aulas, seminários e sessões clínicas com discussão de casos, tendo periodicidade semanal, tanto no horário reservado para preceptoria de território na semana padrão, quanto em horários específicos que ocorrerão na primeira, segunda e terceira quartas-feiras de cada mês, no período noturno, quando são abordados temas clínicos. $\mathrm{Na}$ última quarta-feira de cada mês são abordados temas de saúde coletiva em conjunto com os residentes da Residência Multiprofissional em Saúde da Família. Estes temas compõem um total de onze módulos temáticos em Saúde Coletiva: Módulo 1: Políticas de Saúde: história do SUS, a estratégia saúde da família e o sistema municipal de saúde; Módulo 2: Avaliação da Situação de Saúde e Planejamento de Intervenções na Comunidade; Módulo 3: Abordagem à Família; Módulo 4: Educação Popular, Promoção da Saúde e Participação Social; Módulo 5: Epidemiologia e Bioestatística; Módulo 6: Metodologia do Trabalho Científico; Módulo 7: Vigilância à Saúde e Sistemas de Informação em Saúde; Módulo 8: Planejamento Estratégico; Módulo 9: Organização e Gerenciamento Local; Módulo 10: Acompanhamento do Processo de Elaboração da Monografia e Módulo 11: Terapias Altemativas / 
Complementares, perfazendo um total de 296 horas / aulas.

Os temas tratados nas sessões clínicas correspondem aos módulos temáticos por Ciclos de Vida e Clínicos, correspondendo a Atenção Integral à Saúde da Mulher; Atenção Integral à Saúde da Criança; Condutas Clínicas (ressuscitação cardio pulmonar e cerebral e manejo de reações alérgicas com ênfase em anafilaxia, endocrinologia, psiquiatria, reumatologia, cardiologia, gastroenterologia, hematologia, dermatologia, pneumologia, neurologia, doenças infecciosas e parasitárias e nefrologia); Proteção à Saúde do Adulto e Proteção à Saúde do Idoso, num total de 286 horas / aulas.

Estas atividades são organizadas por regional de saúde sob a responsabilidade de cada uma das Instituições de Ensino parceiras.em uma perspectiva que englobe os aspectos médicos, sociais, econômicos, comportamentais, ambientais, históricos e culturais em que está envolvido o indivíduo; discussão de documentos técnicos do Ministério da Saúde e de artigos científicos nacionais e internacionais; congressos; cursos e palestras.

Além disso, o Programa de Residência conta com uma sala de teleconferência e um laboratório de informática, possibilitando a formação continuada por meio de atividades à distância.

Em todas as atividades teórico-complementares que compõem os módulos do programa de residência serão inseridos temas relacionados com a Bioética e a Ética Médica em uma perspectiva de transversalidade.

Os módulos contam com atividades de concentração e dispersão. A metodologia de ensino/aprendizagem está fundamentada na concepção Freireana, utilizando técnicas de problematização. 
Segundo a proposta de estruturação do Programa, o cronograma de atividades consta de 60 (sessenta) horas semanais, plantão de 12 horas; um dia de folga semanal; e 28 (vinte e oito) dias de repouso por ano.

Logo na primeira semana do Programa de Residência, as instituições parceiras no Projeto promovem um encontro para acolhimento inicial dos residentes e entrega do Programa da Residência, e também para detalharem a estruturação do Programa, apresentando os seus objetivos (gerais e de aprendizagem); a programação e o formato organizacional da RMFC; a Especialização em Medicina de Família e Comunidade; a Preceptoria de Território e a Preceptoria de Especialidades Básicas, destacando suas funções e atividades a serem exercidas com os residentes. Ainda nesse mesmo período acontece o primeiro módulo temático em saúde coletiva.

Um outro procedimento adotado pelo Programa de Residência consiste de um levantamento do perfil dos residentes, abordando os aspectos demográfico, social, profissional, de patologias prévias e de imunização, mediante a aplicação de um instrumento de coleta de dados, realizado antes do início das atividades da Residência. $O$ objetivo principal desse levantamento inicial é acompanhar o desenvolvimento de cada residente e oferecer o suporte necessário às suas necessidades.

A programação da RMFC nas segunda e terceira semanas acontece em cada uma das Unidades de Saúde da Família, constando de apresentação da equipe de saúde da família, reconhecimento e mapeamento da área da abrangência da Unidade de Saúde, levantamento dos recursos comunitários e institucionais, análise da situação de saúde, dos 
sistemas locais de informação em saúde e planejamento local participativo. Estas semanas são coordenadas pelos gerentes de cada unidade e acompanhadas pelos preceptores de território e equipe de Coordenação. Acontecem ainda discussões específicas com a participação dos preceptores das especialidades básicas. São organizadas atividades de leitura e discussão de textos e aulas expositivas para orientar e provocar reflexões sobre as atividades práticas desenvolvidas concomitantemente.

A partir da quarta semana da Residência é estabelecida uma rotina que se repete até o final do primeiro ano. A semana padrão tem uma carga horária de 60 horas distribuídas em 30 horas atividades na Unidade de Saúde da Familia (consultório em MFC, planejamento, administração e gerenciamento, grupos terapêuticos, reunião com equipe e preceptor de território), 4 horas de visita domiciliar ou outra atividade na comunidade, 4 horas de estágio em ambulatórios especializados, 4 horas para reunião da equipe de saúde da família e/ou preceptoria de território, 3 horas noturnas de atividade teórico-prática; e 12 horas de plantão em hospitais secundários e terciários de referência. 0 objetivo destes plantões seria proporcionar experiências em atendimentos de urgência e emergência em clínica médica, pediatria e gineco-obstetrícia, além do atendimento a traumas e a realização de pequenas cirurgias ambulatoriais de urgência.

Os residentes contam também com um estágio de 4 horas semanais em ambulatórios ou serviços especializados durante a Residência, que iniciam a partir do segundo mês do programa. Os profissionais que trabalham nestes serviços atuarão como preceptores de especialidade no que 
diz respeito ao levantamento de necessidades de capacitação do residente, proposição de protocolos e condutas, disponibilidade para assistir a pacientes referidos pelos residentes e apoio por telefone. O objetivo geral deste estágio em ambulatórios e senviços especializados é aumentar a resolutividade dos profissionais no conjunto de práticas e saberes biomédicos. Os objetivos específicos a serem alcançados são: reconhecer os casos clínicos que podem ser tratados no nível primário e os que devem ser encaminhados para os outros níveis de atenção; ampliar os conhecimentos e habilidades em áreas clínicas especializadas importantes do ponto de vista da Saúde Pública e estimular a discussão de casos clínicos.

No segundo ano do Programa de Residência, os residentes passam a realizar as atividades que desenvolviam durante o primeiro ano, com maior autonomia e capacidade de reflexão, além do acréscimo de outras, compatíveis com o nível de maturidade alcançado:

- Preceptoria do R1: o residente do segundo ano passa a orientar, de forma preliminar, os residentes do primeiro ano em algumas atividades, contando com o apoio dos preceptores de território e de especialidades médicas básicas.

- Estágio Opcional: durante um mês do segundo ano, em tempo integral, o residente poderá optar por estágio em um serviço determinado.

- Estágio Obrigatório: durante um mês do segundo ano, em tempo integral, o residente realizará estágio em uma Unidade Hospitalar.

A proposta deste Programa de Residência prevê ainda um terceiro ano opcional para aprofundamento dos conhecimentos e habilidades 
técnicas do médico residente, a partir de ações de preceptoria mais direta (tanto para novos médicos residentes quanto para alunos de graduação) e de desenvolvimento de pesquisas dentro da perspectiva de mestrado na área (acadêmico ou profissionalizante).

\section{II.c) Sistema de Avaliação}

De acordo com os dados recolhidos, o sistema de avaliação do Programa C é composto da avaliação do aluno e da avaliação do Programa de Residência. O processo de avaliação do aluno, por sua vez, correspondendo a uma avaliação formativa e uma avaliação certificativa.

$\mathrm{Na}$ avaliação formativa o residente é acompanhado de forma contínua, sendo observado o seu processo de aprendizagem, mediante a verificação do alcance dos objetivos propostos pelo Programa, possibilitando identificar eventuais deficiências no aprendizado do residente e desenvolver estratégias para superá-las. Esta avaliação é realizada a cada dois meses, na qual são avaliados os conhecimentos relativos aos temas tratados no período, sendo executada pelos coordenadores de serviço/área (saúde da mulher, saúde da criança e do adolescente, saúde do adulto e do idoso, educação e saúde etc.).

Verificou-se que nessa modalidade de avaliação, o residente realiza uma autoavaliação, registrando em uma ficha de avaliação, o seu 
progresso no período e a sua análise sobre a atuação da preceptoria que está recebendo. A partir de cada avaliação, é elaborado um plano de trabalho para os próximos dois meses, para corrigir as eventuais deficiências detectadas. Este plano deve ser apresentado em reunião de preceptoria.

A avaliação certificativa é empregada para verificar se o residente está apto a desempenhar com destreza as atividades de sua competência (cognitivas, habilidades, atitudes). Este tipo de avaliação é realizado a cada três meses, mediante a utilização de prova escrita, oral, prática ou de desempenho por escala de atitudes, que incluam atributos tais como: comportamento ético, relacionamento com a equipe de saúde e com o paciente, interesse pelas atividades dentre outros.

A proposta do Programa é que sejam utilizadas tanto a avaliação formativa como a certificativa para mensurar os conhecimentos adquiridos pelos residentes ao longo da Residência.

A avaliação dos módulos teóricos tem por objetivo verificar se os residentes apreenderam as informações técnicas e processaram essas informações no sentido de construir uma nova visão da clínica, entendendo os limites da atenção básica e os princípios da Saúde da Família. Essa avaliação consta dos seguintes itens:

- Freqüência total em cada módulo teórico mensal de 20 horas, considerada um item fundamental, sendo reprovado o residente que obtiver menos de $85 \%$ da freqüência total. A mensuração da freqüência é dada pela atribuição de conceitos: A, B e C, de acordo com o percentual atingido pelo aluno, em três intervalos: 
$\checkmark$ A - freqüência ótima - com 95 a 100\% de assiduidade;

$\checkmark$ B - freqũência regular - $85 \%$ a $94 \%$ de comparecimento nas atividades; $e$

$\checkmark$ C - freqüência insuficiente - menos de $85 \%$ participação.

- Participação nas discussões, também é um item em que são atribuídos conceitos: $A, B, C$ e D, distribuídos em quatro intervalos:

$\checkmark$ A - 90 a 100\% - ótima participação;

$\checkmark$ B - 80 a $89 \%$ - boa participação;

$\checkmark$ C - 70 a $79 \%$ - participação regular;

$\checkmark$ D - abaixo de $75 \%$ - participação insuficiente.

- Na avaliação da realização de tarefas é observado o cumprimento de algumas atividades referentes ao trabalho a ser realizado, a saber:

$\checkmark$ Entrega no prazo estipulado:

0 - não entregue;

1 - entregue com atraso;

3 - entregue no prazo.

$\checkmark$ Apresentação da tarefa de forma clara, bem escrita, coerente:

0 - não cumpre os requisitos;

1 - regular;

2 - boa;

3-ótima.

Adequação das intervenções propostas:

0 - inadequada; 
1 - regular;

2 - boa;

3 - ótima.

$\checkmark$ Criatividade:

0 - sem inovações;

1 - regular;

2 - boa;

3-ótima.

- A avaliação escrita tem por finalidade verificar se o residente apreendeu os conteúdos técnicos discutidos nos módulos, assim como as leituras e pesquisa bibliográfica realizadas e é realizada por ocasião do fechamento do módulo. Nessa avaliação o percentual mínimo de aproveitamento é de $70 \%$ do total de questões, atribuindo-se os seguintes conceitos:

$\checkmark 100 \%$ - ótima

$\checkmark 80$ a $99 \%$ - boa

$\checkmark 70$ a $79 \%$ - regular

$\checkmark$ menos de $70 \%$ - insuficiente.

A avaliação final do módulo será obtida mediante a soma dos resultados das avaliações de todos esses itens, sendo atribuídos os seguintes conceitos:

\footnotetext{
$\checkmark$ ótima (100\%) -10 a 12 pontos

$\checkmark$ boa $(80$ e $90 \%)-8$ e 9 pontos

$\checkmark$ regular $(70 \%)-7$ pontos
} 
$\checkmark$ insuficiente $(<70 \%)$ - abaixo de 7 pontos.

A aprovação do residente está condicionada à obtenção de, no mínimo, $70 \%$ de aproveitamento, considerando todos os itens propostos para a avaliação dos módulos. Caso o residente apresente aproveitamento regular em algum item, o preceptor de território junto com o coordenador do módulo devem procurar esclarecer as razões para esse desempenho e propor formas de superação para que o residente possa melhorar sua aprendizagem. Os médicos residentes que não obtiverem resultados suficientes para serem aprovados em um determinado módulo deverão repeti-lo no ano seguinte. $\mathrm{O}$ preceptor de território e o coordenador da residência deverão procurar o médico residente para entender as dificuldades no seu processo de aprendizagem e ajudá-lo a melhorar o seu rendimento.

Como alguns desses critérios são subjetivos, o conceito final de avaliação do residente deve ser a média final das avaliações de todos os módulos, o que permite reduzir o grau de subjetividade presente nos avaliadores.

A avaliação das atividades teórico-práticas será realizada compreendendo os seguintes itens:

- habilidades de atitudes no atendimento ao paciente -1 a 10

- participação nas reuniões de equipe -1 a 5

- desempenho nas visitas domiciliares - 1 a 10

- participação nas reuniões da UBS - 1 a 5

- apresentação de caso nas reuniões de discussão de caso - 1 a 10

- grau de responsabilidade na atenção às famílias - 1 a 15 
- relação profissional-indíviduo-família - 1 a 15

- envolvimento no trabalho com a comunidade - 1 a 10

- crescimento em relação aos conhecimentos técnicos - 1 a 10

A nota final dessa avaliação será dada pela soma das notas obtidas em cada item, sendo atribuídos os seguintes conceitos:

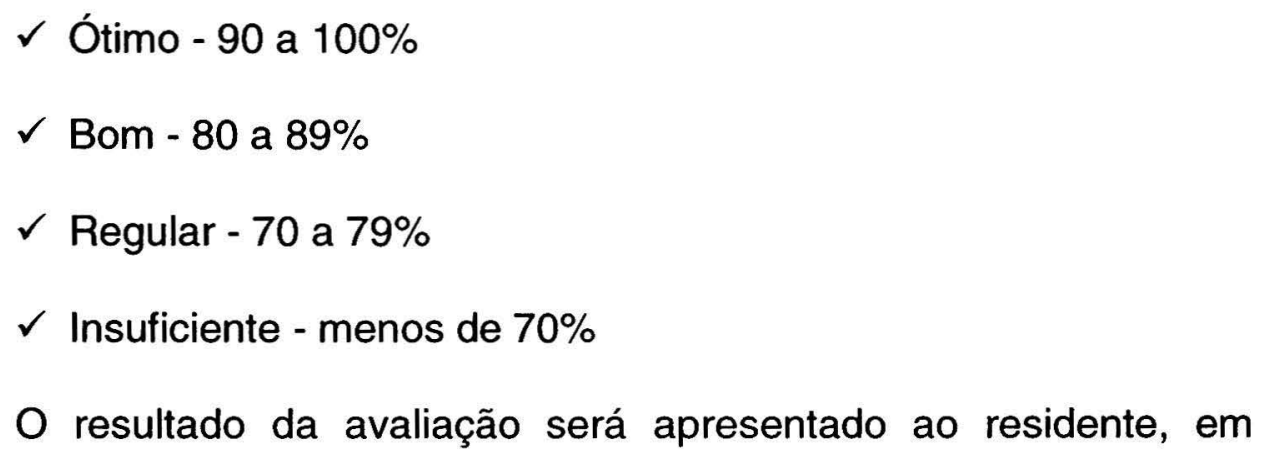
reunião do conjunto de preceptores de território, de especialidades e de áreas específicas.

De acordo com o projeto, para a avaliação do Programa de Residência está prevista a realização de quatro fóruns para ouvir os residentes, e, caso haja solicitação específica nesse sentido, poderão ser realizadas reuniões extraordinárias com o intuito de também avaliar o Programa.

Para subsidiar os debates nos fóruns, os residentes elaboram previamente um questionário de avaliação e aplicam junto a todos os residentes. Os dados coletados devem ser tabulados e levados aos fóruns para serem discutidos. Além disso, ao final de cada módulo teórico os residentes fazem uma avaliação do módulo, mediante o preenchimento de um instrumento para avaliação fornecido pela coordenação do Programa de Residência, contendo os seguintes itens:

- Relevância do tema 
- Organização do módulo

- Didática da exposição

- Atualização do tema

Para cada item e para cada módulo será dado um conceito:
A - ótimo;
B - bom;
C - regular;
D - insuficiente.

Uma outra forma de avaliação do Programa é por meio das visitas de acompanhamento realizadas pelas Comissão Estadual e Nacional de Residência Médica e a Sociedade Brasileira de Medicina de Família e Comunidade.

Estão previstas também a autoavaliação do Programa realizada por todos os envolvidos no Programa de Residência e a avaliação e monitoramento efetuada pela Comissão de Residência Médica (COREME) local, mediante a realização de reuniões semanais para verificar o funcionamento do Programa.

Ainda outras formas de avaliação do Programa de Residência consistem da avaliação dos indicadores de saúde do município através de pesquisa de dados secundários comparando-os com os mesmos indicadores em momentos anteriores à Residência; avaliação da percepção da comunidade, dos profissionais de saúde e dos gestores sobre mudanças da qualidade da atenção, por meio de pesquisa qualitativa com entrevistas e grupos focais e ainda a avaliação do impacto do Programa de Residência na atenção à população e na mudança dos indicadores de saúde. 


\section{Categoria III. Preceptoria}

A análise do Programa $\mathbf{C}$ revelou que este conta com dois tipos de preceptores: o preceptor clínico e o preceptor de território.

O preceptor clínico é responsável pelo apoio às atividades clínicas dos residentes, sendo este, especializado em Medicina de Família ou de outras especialidades médicas básicas. Este preceptor também monitora, em conjunto com o residente e a equipe de saúde, a situação epidemiológica do grupo populacional relativo à sua especialidade. Nesse caso, por exemplo, o preceptor especialista em ginecologia e obstetrícia acompanha junto a equipe a situação de saúde das gestantes e mulheres do território. A proposta é de envolver os profissionais que já trabalham na rede e tem experiência em atenção primária à saúde na formação dos residentes de Medicina de Família e Comunidade, que passarão a exercer a função de preceptor dos residentes médicos, além do papel estritamente assistencial que exercem no momento. Para tanto, esses profissionais passarão por uma capacitação e após essa capacitação serão formadas ainda equipes matriciais compostas por pediatra, ginecologista-obstetra, psiquiatra e clínico, além do especialista em medicina de família e comunidade, cada equipe matricial responsável pelo acompanhamento de cerca de seis residentes.

Cada Unidade conta com um preceptor clínico fixo com carga horária mínima de vinte horas semanais, com residência ou título de especialista em Medicina de Família e Comunidade, Pediatria, Clínica 
Médica ou Ginecologia e Obstetrícia, responsável pelos residentes de uma maneira geral. Os residentes têm ainda uma visita semanal de 4 horas de preceptoria em Pediatria, Clínica Médica e Ginecologia-Obstetrícia e uma visita mensal de preceptoria em Psiquiatria. O especialista em Medicina de Família e Comunidade realiza visita mensal às unidades e coordena uma reunião periódica com os preceptores de especialidade.

Para exercer a função de preceptor clínico, o profissional deverá apresentar o seguinte perfil:

- Médico especialista em Saúde da Família ou com experiência de mais de dois anos como médico de família;

- Professor da Faculdade de Medicina com interesse na área de MFC;

- Médico das emergências hospitalares e das especialidades ambulatoriais que já têm compromisso com o ensino;

- Professor convidado para discussão de temas específicos;

- Outros profissionais de saúde qualificados e que tenham domínio de temas de interesse para MFC (enfermeiro, cirurgião-dentista, fisioterapeuta, nutricionista, terapeuta ocupacional, trabalhador social, pedagogo etc.).

O preceptor de território é o profissional com nível superior na área de saúde, pertencente ou não ao quadro da secretaria de saúde do município, com Especialização em Saúde da Família ou Saúde Pública, preferencialmente com dedicação de 40 horas semanais. Este preceptor passa por uma capacitação prévia no início dos Programas de Residência 
no formato de um curso de aperfeiçoamento.

Durante o desenvolvimento da RMFC o preceptor de território participa de uma reunião semanal com membros da coordenação da Residência para apoio institucional e pedagógico ao seu trabalho.

O preceptor de território é um profissional que desenvolve um trabalho de natureza pedagógica na gestão em saúde da família (de território), mas também com os residentes de saúde da família, além de atividades de supenisão e avaliação do trabalho realizado pelas equipes de saúde da família.

Atua junto aos residentes, a equipe de saúde da família e a gerência das equipes na definição coletiva da política local de saúde, que inclui o reconhecimento do território e seus recursos comunitários e institucionais, análise da situação de saúde, vigilância à saúde, identificação das práticas de medicina popular e articulação com os atores locais da medicina popular, planejamento local participativo, organização do serviço, promoção da saúde, co-gestão do coletivo e participação no Conselho Local de Saúde. Cada Unidade de Saúde recebe no mínimo oito horas semanais de acompanhamento pelo preceptor do território e tem como objetivo principal de ensino o enfoque dos princípios e diretrizes do SUS, as questões de Saúde Pública, as ações coletivas de saúde e a formação de uma nova atitude diante da prática. 


\subsubsection{A Análise dos Programas de Residência}

Os sistemas de saúde solidamente estruturados em diversos países do mundo adotam a Atenção Primária à Saúde como seu pilar básico. Neles, as unidades do primeiro nível têm a atribuição de assegurar a todos os cidadãos a elas vinculados uma atenção contínua, integral e resolutiva, proporcionando-lhes o primeiro contato com o sistema de saúde e conduzindoos, quando assim indicado, na utilização de outros serviços (OPAS, 2005). No Brasil, a estratégia Saúde da Família propõe-se a abrir caminhos para a estruturação da Atenção Primária de Saúde e milhares de equipes vêm sendo instaladas nos diversos estados (CAMPOS e AGUIAR, 2006).

Nesse cenário, o médico de família desempenha um importante papel ao assumir funções complexas que envolvem a oferta de cuidados integrais de saúde, de âmbito individual e coletivo, a todos os grupos populacionais. São tarefas que exigem deste profissional competências que vão além do domínio dos conhecimentos, já extremamente vastos, requeridos para lidar adequadamente com os processos diagnósticos e terapêuticos. Assim, do médico de família espera-se que possua a capacidade de analisar e compreender o processo saúde-doença de indivíduos e comunidades, planejando e pondo em prática intervenções apropriadas. Isso exige articular conhecimentos de diversas disciplinas, integrar a dimensão da saúde pública à prática clínica e apoiar-se em uma relação médico-paciente renovada (BLASCO, 2009). 
Por isso, a educação do médico de família vem ocupando a atenção de diversos setores em muitos países, inclusive no Brasil. Dentre os tipos de pós-graduação lato sensu que existem, a Residência Médica vem se consolidando como a modalidade mais apropriada para a formação do médico de família, por ser caracterizada como treinamento em serviços, verificando-se um movimento em busca de modelos e estratégias educacionais que possam torná-la mais efetiva (BLASCO et al. 2008).

Ressalte-se, no entanto, que essa modalidade de formação médica não atende à toda demanda do sistema de saúde por médicos de família, tendo em vista a grande carência de profissionais especialistas nessa área, sendo essencial identificar outras formas de capacitação que dêem conta de suprir de forma mais rápida essa necessidade do SUS.

Assim sendo, a análise dos Programas de Residência em Medicina de Família e Comunidade no Estado do Ceará permitiu o conhecimento da realidade em torno da formação dos médicos de família e a discussão dos resultados que ora se segue procura trazer para 0 debate as questões relacionadas com a formatação e execução desses Programas no Estado.

Para esta análise fez-se uso das mesmas categorias analíticas empregadas quando da apresentação dos Programas de Residência, na qual foram enfatizados aspectos referentes à construção do PRMFC; ao desenho do currículo, utilizando subcategorias que tratavam das competências a serem desenvolvidas, da estrutura curricular e do sistema de avaliação; além da constituição da equipe de preceptoria. 


\section{Categoria l. Construção do PRMFC}

De início, ao buscar conhecer os Programas de Residência em Medicina de Família e Comunidade existentes no Estado do Ceará, verificou-se que a sua criação é relativamente recente, com exceção de um Programa que iniciou em 2000, mas que permaneceu somente até 2007, época do seu descredenciamento; os demais datam de 2005 e 2006, o que evidencia a pouca experiência acumulada pelo Estado na capacitação médica nessa especialidade, visto que os Programas ora em funcionamento têm apenas cerca de cinco anos de existência. Além disso, a quantidade de Programas também é reduzida, uma vez que o Estado conta atualmente com apenas três Programas de Residência em Medicina de Família e Comunidade em funcionamento.

Essa realidade, inserida na insuficiência ou mesmo ausência de políticas para transformar a formação profissional, por si só, reforça a idéia fundamentada no Postulado de Coerência de MÁRIO TESTA (1992), segundo o qual, deve existir uma necessária relação de coerência entre os propósitos de governo (ou de um programa), os métodos utilizados para implementá-los e as organizações onde deverão ser operacionalizados; e que MENDES (1996) reitera afirmando que "a um objeto institucional devem corresponder métodos e estruturas organizacionais com ele coerentes". De fato, a necessidade de pessoal qualificado para atuar nos sistemas e serviços de saúde já se fazia sentir, principalmente, desde a instituição do SUS, quando 
emergiu uma proposta comprometida com uma mudança radical e estrutural do sistema de saúde vigente, caracterizado pelo modelo médico-assistencial privatista, e sua substituição por um sistema público, universal e participativo, pautado pelos princípios da Atenção Primária à Saúde, e que tem na Saúde da Família a estratégia de eleição para organizar a atenção básica.

Nesse caso, uma das grandes incoerências na implantação do SUS consistia na inadequação na formação dos recursos humanos, caracterizada pela hegemonia do modelo flexneriano de formação médica adotado pelas Universidades brasileiras, como afirma CUTOLO (2001), hospitalocêntrico, biologicista, fragmentado e que utiliza metodologia de ensino verticalizada e não problematizadora, ou, como referido por FREIRE (2005, p. 83), uma "educação bancária", sendo esta legitimada como processo, e que assume uma posição antagônica ao SUS; uma vez que esse novo sistema requeria um perfil de profissionais preparados para uma atuação na perspectiva da atenção integral à saúde e de práticas que contemplem ações de promoção, proteção, prevenção, atenção precoce, cura e reabilitação.

SOUZA e RANGEL (2003) relatam que a inadequação na formação destes profissionais suscitou a criação da Comissão Interinstitucional do Ensino Médico (CINAEM), e no desenvolvimento de um projeto com o objetivo de transformar as escolas médicas para que formem médicos capazes de dar atendimento resolutivo às necessidades de saúde da população brasileira.

De acordo com os estudos realizados por este projeto, observouse, na prática, que o modelo pedagógico ainda apresenta uma fragmentação 
entre teoria e prática, há falta de integração entre os conteúdos do curso, coexistência de disciplina de maneira isolada e hierárquica e o predomínio das atividades centradas no professor. Além disso, verificou-se que no sistema de avaliação do educando prevalecem as avaliações centradas na memória, sem incluir as habilidades e atitudes na aplicação do conhecimento (SOUZA e RANGEL, 2003).

Desse modo, percebeu-se que o ensino não demonstrava buscar o desenvolvimento das competências (conhecimento, habilidades e atitudes) necessárias às exigências dos serviços de saúde aos quais os profissionais serão inseridos. Tanto assim, que nos fóruns promovidos pela Associação Brasileira de Educação Médica (ABEM) defende-se que esta avaliação se estenda para além do domínio cognitivo e inclua também a avaliação de habilidades e atitudes.

Por isso, a educação dos profissionais de saúde tem passado por intensos questionamentos quanto à sua relevância, à adequação de seus enfoques e perspectivas, à efetividade de suas abordagens e métodos, o que se reflete em uma exigência cada vez maior das instituições de ensino a fim de que elas demonstrem sua capacidade de responder às necessidades das comunidades onde se inserem e justifiquem os investimentos nelas realizados pela sociedade contribuindo com seus produtos e serviços para 0 bem-estar de sua população.

Esta tem sido também a preocupação da Organização Mundial de Saúde (OMS) e da Organização Panamericana da Saúde (OPAS), que têm avaliado uma grande quantidade de informações teóricas e empíricas sobre o 
alcance, o funcionamento e a eficácia da APS, diante da falta de pessoal capacitado para implementá-la, e como afirmam NEBOT ADELL et al. (2009):

"En efecto, la renovación de la APS exige una transformación profunda en los programas de formación de los profesionales de la salud, así como la expansión y diseminación del conocimiento sobre este nivel de atención. Tal propósito supone resolver problemas difíciles, entre los que cabe destacar la insuficiencia de personal calificado para proveer la cobertura universal, el desequilibrio de recursos en favor de la concentración en ciudades y hospitales, la falta de políticas de incentivos, los elevados costos del personal, la escasez de supervisión apropiada, la formación con enfoque predominantemente curativo y orientada a las especialidades, así como el débil desarrollo del trabajo en equipo, todos considerados como los problemas más frecuentes que afrontan actualmente los servicios de salud" (NEBOT ADELL et al., 2009, p. 176)

Nessa mesma linha de análise, verificam-se incoerências semelhantes na estrutura de implantação da estratégia Saúde da Família no Ceará, pois, muito embora seja o Estado pioneiro nessa iniciativa em todo o país e já tenha a Saúde da Família presente nos 184 municípios cearenses, ainda não desenvolveu estratégias eficazes de formação dos profissionais para atuar nas 2.154 equipes de saúde da família implantadas em todo o Estado até março de 2010, de acordo com dados do Departamento de Atenção Básica (DAB), da Secretaria de Atenção à Saúde (SAS), do Ministério da Saúde (MS).

Logo, há uma insuficiência no número de instituições cearenses voltadas para capacitação desse grande contingente de profissionais de saúde, de modo a adequar o perfil dos profissionais já inseridos no sistema, e minimizar os efeitos da formação inadequada dos profissionais, levando-os 
para ambientes de ensino/aprendizagem diferentes do hospital, nos quais classicamente são formados, para ambientes mais próximos da comunidade, buscando assim, meios de garantir que suas práticas atendam as necessidades dessas comunidades, e, desse modo, respondam aos desafios que estão sendo colocados para a implementação do sistema, em especial no âmbito dos municípios.

Fato este comprovado pelos dados colhidos por ocasião da pesquisa realizada. Durante o período de vigência do Programa A foram formados treze (13) especialistas, conforme Tabela 1. O primeiro processo seletivo para este Programa aconteceu em dezembro de 1999, sendo ofertadas 10 (dez) vagas, para as quais concorreram 16 (dezesseis) candidatos, sendo que apenas quatro candidatos concluíram essa Residência.

Tabela 1 - Distribuição das turmas do Programa de Residência em Medicina Geral e Comunitária do Programa A. Fortaleza, 2010.

\begin{tabular}{cccc}
\hline $\begin{array}{c}\text { Turma / } \\
\text { Período }\end{array}$ & $\begin{array}{c}\mathbf{N}^{\circ} \text { de } \\
\text { vagas }\end{array}$ & $\begin{array}{c}\mathbf{N}^{\circ} \text { de } \\
\text { matriculados }\end{array}$ & $\begin{array}{c}\mathbf{N}^{\circ} \text { de } \\
\text { concludentes }\end{array}$ \\
\hline $2000 / 2002$ & 10 & 4 & 4 \\
$2001 / 2003$ & 10 & 4 & 2 \\
$2002 / 2004$ & 10 & 6 & 6 \\
$2003 / 2005$ & 10 & 3 & 1 \\
\hline TOTAL & & 15 & 13 \\
\hline
\end{tabular}

Fonte: dados da pesquisa 
Além disso, os residentes das turmas 2000-2002 e 2001-2003, num total de 6 (seis) profissionais não receberam certificado da Comissão Nacional de Residência Médica, pois a mesma não estava possuía o credenciamento definitivo, sendo que os profissionais receberam uma declaração de conclusão da Residência emitida pela própria instituição promotora. Os demais, das turmas 2002-2004 e 2003-2005 foram certificados pela CNRM, num total de 7 (sete) concludentes.

Já o Programa B está na sua quarta edição, sendo que para a primeira turma foram ofertadas 76 (setenta e seis) vagas, para as quais concorreram 106 (cento e seis) candidatos; destes foram selecionados 71 (setenta e um) candidatos, pois 35 (trinta e cinco) não atingiram o perfil. Do total de candidatos (71) que iniciaram a Residência, 20 (vinte) desistiram na primeira semana, permanecendo 51 (cinqüenta e um) até agosto do primeiro ano de Residência, quando saíram alguns residentes, ficando então 36 (trinta e seis) profissionais, dos quais 28 (vinte e oito) concluíram a Residência. Para a segunda turma foram ofertadas 45 (quarenta e cinco) vagas, candidatandose 55 (cinquenta e cinco) profissionais, sendo preenchida a totalidade das vagas ofertadas. Destes, 31 (trinta e um) residentes concluíram o curso. $\mathrm{Na}$ terceira turma foram matriculados 33 (trinta e três) alunos, e destes 6 (seis) concluíram a Residência. A quarta turma que se encerra em 2010, iniciou com 33 (trinta e três) matriculados, estando prevista a formação de 11 (onze) profissionais, de acordo com a Tabela 2. 
Tabela 2 - Distribuição das turmas do Programa de Residência em Medicina de Família e Comunidade do Programa B. Fortaleza, 2010.

\begin{tabular}{cccc}
\hline $\begin{array}{c}\text { Turma / } \\
\text { Período }\end{array}$ & $\begin{array}{c}\mathbf{N}^{\circ} \text { de } \\
\text { vagas }\end{array}$ & $\begin{array}{c}\mathbf{N}^{\circ} \text { de } \\
\text { matriculados }\end{array}$ & $\begin{array}{c}\mathbf{N}^{\circ} \text { de } \\
\text { concludentes }\end{array}$ \\
\hline $2006-2008$ & 76 & 71 & 28 \\
$2007-2009$ & 45 & 45 & 31 \\
$2008-2010$ & 40 & 40 & 6 \\
$2009-2011$ & 40 & 33 & 11 \\
\hline TOTAL & 201 & 189 & $\mathbf{7 6}$ \\
\hline
\end{tabular}

Fonte: dados da pesquisa

Quanto ao Programa C, este oferta anualmente 12 vagas, no entanto, estas vagas nunca são preenchidas, iniciando sua primeira turma em 2006, com seis residentes médicos. Nas três turmas que já aconteceram foram formados seis profissionais, sendo 4,1 , e 1 , nas $1^{a}, 2^{a}$ e $3^{a}$ turmas, respectivamente, enquanto que para a $4^{a}$ turma, com término também em 2010, espera-se a formação de três médicos de família, conforme Tabela 3.

Tabela 3 - Distribuição das turmas do Programa de Residência em Medicina de Família e Comunidade do Programa C. Fortaleza, 2010.

\begin{tabular}{cccc}
\hline $\begin{array}{c}\text { Turma I } \\
\text { Período }\end{array}$ & $\begin{array}{c}\mathbf{N}^{\circ} \text { de } \\
\text { vagas }\end{array}$ & $\begin{array}{c}\mathbf{N}^{\circ} \text { de } \\
\text { matriculados }\end{array}$ & $\begin{array}{c}\mathbf{N}^{\circ} \text { de } \\
\text { concludentes }\end{array}$ \\
\hline $2006-2008$ & 12 & 06 & 04 \\
$2007-2009$ & 12 & 02 & 01 \\
$2008-2010$ & 12 & 02 & 01 \\
$2009-2011$ & 12 & 06 & 03 \\
\hline TOTAL & $\mathbf{4 8}$ & $\mathbf{1 6}$ & $\mathbf{0 9}$ \\
\hline
\end{tabular}




\section{Categoria II. Desenho do Currículo}

Os Programas de Residência existentes no Ceará, muito embora sejam poucos, verifica-se, no entanto, que têm projetos bem fundamentados, e principalmente, o desenho do currículo destes Programas mostra-se coerente com a preocupação das instituições de ensino em acompanhar as profundas mudanças ocorridas nas últimas décadas na concepção de saúde e na compreensão de seus fatores determinantes; nos modelos de organização dos sistemas de saúde e na natureza e exercício da prática profissional no campo da saúde.

De fato, na elaboração de qualquer programa educacional o desenho do currículo se configura como um elemento fundamental para a sua consecução, e como afirma SACRISTÁN (2000):

"o currículo deve ser entendido como um processo que envolve uma multiplicidade de relações, abertas ou tácitas, em diversos âmbitos, que vão da prescrição à ação, das decisões administrativas às práticas pedagógicas, na escola como instituição e nas unidades escolares especificamente".

SILVA (2005) afirma que na construção de um currículo a questão central é a de saber qual conhecimento deve ser ensinado, para tanto devese procurar responder a uma pergunta básica: "qual conhecimento ou saber é considerado importante ou válido ou essencial para merecer ser considerado parte do currículo" (SILVA, 2005, p. 14-15).

E o autor continua ponderando que "o currículo é sempre o 
resultado de uma seleção: de um universo mais amplo de conhecimentos e saberes seleciona-se aquela parte que vai constituir, precisamente, o currículo" (SILVA, 2005, p. 15).

No caso específico da construção desses Programas de Residência em Medicina de Família e Comunidade no Ceará, isto se reveste de especial importância, em virtude da imperiosa necessidade de formar médicos de família com o perfil profissional adequado às práticas de atenção integral à saúde da família e dos indivíduos, e dotado de compromisso ético e responsabilidade social.

Por isso, Tyler (1974, p.1 apud SILVA, 2005, p. 25) considera o currículo tão necessário e o qualifica como um eficiente instrumento de educação. Esse renomado educador identifica quatro questões fundamentais que devem ser respondidas para a organização e desenvolvimento de qualquer currículo: "1. que objetivos educacionais a escola deve procurar atingir; 2. que experiências educacionais podem ser oferecidas e que tenham probabilidade de alcançar esses propósitos; 3. como organizar eficientemente essas experiências educacionais; e 4. como ter certeza de que esses objetivos estão sendo alcançados".

O mesmo autor identifica ainda três fontes fundamentais das quais é possivel derivar os objetivos da educação, assegurando que cada uma delas seja igualmente considerada: "1. estudos sobre os próprios aprendizes; 2. estudos sobre a vida contemporânea fora da educação e 3. sugestões dos especialistas das diferentes disciplinas".

Nessa perspectiva, observou-se, a partir da leitura dos 
documentos, que o processo de construção do currículo do Programa A seguiu uma sistemática de utilização de dez passos, iniciados a partir da identificação das necessidades dos potenciais usuários dos serviços a serem prestados pelo médico de família, seguindo-se da descrição do perfil desejado para esse profissional, sendo então listadas as suas tarefas quando em serviço e definidas as respectivas competências necessárias para desempenhar o macro-conjunto de tarefas concernentes ao trabalho do médico de família. A partir da definição destas competências foram estabelecidos os objetivos gerais de aprendizagem requeridos em cada fase do treinamento do médico residente, os quais foram agrupados nas quatro grandes categorias de tarefas do médico de família, referidas quando da apresentação do Programa, quais sejam: atenção ao indivíduo; prevenção de doenças / monitoração e promoção da saúde; gerenciamento de recursos e desenvolvimento pessoal e profissional.

O projeto relata ainda que, baseado nestes objetivos gerais, foram definidos os objetivos específicos de aprendizagem, os quais são apresentados em uma matriz para cada grupo de tarefas, contendo os temas a serem estudados, representados pelos principais problemas de saúde da comunidade; os objetivos gerais e específicos de aprendizagem acerca daqueles problemas; os domínios dos objetivos educacionais, se cognitivos, afetivos ou psicomotores; as estratégias educacionais a serem utilizadas para o alcance de cada objetivo, a carga horária prevista para o cumprimento do objetivo e o local a ser realizada a atividade educativa. Demonstrando, assim, o nível de detalhamento referido no projeto do 
Programa A para a construção do seu currículo.

Esse modelo de construção de currículo foi posteriormente relatado na literatura por WIERS et al. (2002), descrevendo em detalhes cada um dos passos, enfatizando que não se trata, no entanto, de um processo linear, pois muitos passos estão inter-relacionados, sendo essencialmente interativo, de freqüentes idas e voltas, tornando-se necessária a elaboração de vários esboços antes da versão final do currículo.

Quanto aos Programas B e C, não foi possível identificar como se deu o processo de desenho dos seus currículos. Os projetos destes Programas de Residência analisados, embora tenham apresentado todos os componentes próprios de um programa educacional, inclusive com bastantes informações, detalhando como será desenvolvido o Programa, faltou o registro de como ocorreu esse processo de criação, definição e execução das várias etapas de construção dos currículos. Sabe-se, porém que os seus organizadores seguiram as normas estabelecidas pela Comissão Nacional de Residência Médica.

\section{II.a) Competências a serem desenvolvidas}

$\mathrm{Na}$ análise dos documentos, pelo que se pôde constatar, o Programa A foi elaborado na compreensão de que esse contexto tem requerido o desenvolvimento de novas competências tanto no âmbito 
gerencial como assistencial, e na busca de formar profissionais capazes de conviver com essas transformações e influenciá-las, o que certamente contribui para o processo de reforma no campo educacional.

Fato é que, de acordo com DELUIZ (2001), o enfoque das competências começou a ser difundido na área da educação, a partir dos questionamentos feitos ao sistema educacional para corresponder às exigências de competitividade, produtividade e de inovação do sistema produtivo.

Ainda segundo a autora, o modelo das competências surgiu na América Latina, quando das reformas educacionais, as quais eram parte de um conjunto de reformas estruturais ocorridas no aparelho do Estado, em decorrência do ajuste macroeconômico imposto aos países latino-americanos, ao longo dos anos 90 , na tentativa de superar a inflação e a estagnação e retomar o crescimento econômico interrompido nos anos 80 (DELUIZ, 2001).

Consequentemente, a reforma educacional implementada no Brasil a partir da Lei № 9394/96, Lei de Diretrizes e Bases da Educação Nacional (LDB) e, a seguir, nos dispositivos de regulamentação no que se refere à educação superior, como o Decreto-Lei $N^{\circ}$ 2.306/97, que a regulamenta, a Lei $\mathrm{N}^{\circ} 10.172$, de 9/1/2001, que estabeleceu o Plano Nacional de Educação (PNE) e as Diretrizes Curriculares Nacionais para os Cursos de Graduação Superior, assumem como concepção orientadora o modelo das competências (FRANKLIN, 2000; DELUIZ, 2001).

Observa-se, assim, que ao desenhar um currículo diferente da proposta do modelo flexneriano de ensino médico, o Programa A mostrouse coerente com a preocupação que BOELEN (1992) já manifestava, 
alertando para a necessidade de uma reforma na educação médica que atendesse aos novos desafios em saúde demandados tanto pelos prestadores de cuidados de saúde como pelos usuários, os quais forçavam questões fundamentais como a igualdade de acesso, cobertura total, qualidade de atendimento individual, atendimento integral, a satisfação do usuário, ética, perspectiva da população na prestação de cuidados de saúde, a promoção de estilos de vida saudáveis, a proteção do meio ambiente, avaliação de tecnologias e a contenção de custos.

Nesse aspecto, PIERANTONI et al. (2006) reconhecem que:

\begin{abstract}
"Vêm sendo desencadeados alguns movimentos no campo da formação médica relacionados com as formatações curriculares como forma de agregar qualidade $e$ desenvolvimento de competências para o exercício profissional. Os currículos até então aplicados, salvos experiências pontuais, têm demonstrado inadequações de conteúdo e de práticas pedagógicas para o exercício de atividades que envolvam a pluralidade das necessidades do sistema de saúde" (PIERANTONI et al., 2006, p. 94).
\end{abstract}

Realmente, não apenas as instituições promotoras dos Programas de Residência estudados, mas diversas instituições de ensino do país vêm implementando processos de reforma mais ou menos abrangentes em seus programas educacionais, na perspectiva de fazer face às crescentes demandas por adequação do ensino às necessidades dos serviços de saúde. Entretanto, os aspectos enfatizados, as estratégias adotadas e o ritmo de implementação desses processos de reforma variam entre as instituições, ocorrendo ainda uma diversidade de situações nos vários estados do país. 
Esse processo de reformas na educação médica intensificou-se, principalmente, após a aprovação da Resolução CNE/CES $N^{\circ} 4$, de 7 de novembro de 2001, que instituiu as Diretrizes Curriculares Nacionais (DCN) para o Curso de Graduação em Medicina, que apresentam como proposta uma abordagem ampliada e integrada dos currículos, norteando a formação por competência e estimulando a utilização de metodologias ativas de aprendizagem, como também destacam o compromisso das Universidades com as necessidades da sociedade, em especial no que se refere a implementação das diretrizes constitucionais do SUS de defesa da saúde como um direito e na garantia da universalização e da integralidade do cuidado à saúde (CNE, 2001).

E como ponderam VANNUCHI e CAMPOS (2007)

\begin{abstract}
"Apesar das DCN serem formuladas para a graduação de profissionais da área da saúde, entendemos também que seus pressupostos devem ser aplicados aos cursos de pós graduação, principalmente em cursos de especialização como no caso das residências, em que a grande maioria dos estudantes são recém-formados e que por conseqüência das mudanças curriculares no país, vivenciaram as metodologias ativas em sua graduação" (VANNUCHI e CAMPOS, 2007, p. 359).
\end{abstract}

Lembrando ainda que estas diretrizes curriculares trazem uma série de pressupostos que orientam a construção do currículo dos cursos de graduação e propõe uma inversão na lógica dos currículos tradicionais, tornando o ensino mais centrado no estudante, colocando-o como sujeito do seu aprendizado, em que o professor leva-o a identificar as lacunas do seu conhecimento e a buscar ativamente informações para a resolução de 
problemas; enfatizando a utilização da aprendizagem significativa (que promove e produz sentidos) e não a excessiva aquisição e memorização de informações e salientando a articulação teoria-prática para a construção das competências, além de estimular professor e estudante a buscar novos conhecimentos em resposta às questões oriundas da prática (CNE, 2001).

Desse modo, enfoques coerentes com os modelos explicativos da aprendizagem gerados pela pesquisa na área de educação têm sido adotados em busca de assegurar os fins mais amplos e mais complexos da formação e educação permanente do profissional de saúde. Procura-se ainda renovar as estratégias para a aquisição de conhecimentos, integrandoos ao desenvolvimento de habilidades no campo afetivo e perceptual-motor, procurando-se articular teoria e prática e promover a integração entre diversas dimensões da formação.

Certamente que, na perspectiva de estar em consonância com todo esse cenário, o desenho do currículo do Programa A tem como características marcantes estar baseado nas competências a serem desenvolvidas pelos residentes para atuarem como médicos de família e ser orientado em função das necessidades da comunidade. Ressalte-se que a proposta de desenho do currículo deste Programa adota o conceito de competência como a capacidade de realizar determinada ação ou atividade que depende de um conjunto de conhecimentos, habilidades e atitudes a serem desenvolvidas pelo residente durante o programa educacional. Dito isto para esclarecer o sentido que é dado ao termo competência, em razão da polissemia deste termo, fez-se necessário explicitar-se a concepção aqui 
empregada, essencialmente imbricada nas questões referentes tanto a educação profissional quanto a qualificação e, consequentemente, às políticas educacionais e de trabalho.

Nesse mesmo raciocínio, DELUIZ (2001) observa que a noção de competências proposta nos Referenciais Curriculares Nacionais compreende as competências:

“...enquanto ações e operações mentais, (que) articulam os conhecimentos (o "saber", as informações articuladas operatoriamente), as habilidades (psicomotoras, ou seja, o "saber fazer" elaborado cognitivamente e socioafetivamente) e os valores, as atitudes (o "saber ser", as predisposições para decisões e ações, construídas a partir de referenciais estéticos, políticos e éticos) constituídos de forma articulada e mobilizados em realizações profissionais com padrões de qualidade requeridos, normal ou distintivamente, das produções de uma área profissional" (DELUIZ, 2001, p. )

Portanto, é possível concordar com DELUIZ (2001) quando esta ressalta a confusão conceitual existente entre competências e habilidades, nas regulamentações que tratam desse tema. E corretamente observa a autora:

\begin{abstract}
"Se, por definição, as competências são operações mentais que articulam e mobilizam os conhecimentos, as habilidades e os valores, as habilidades seriam, então, elementos constitutivos das competências. A identificação das competências, das habilidades e das bases tecnológicas, feita de forma separada, fragmentada, nas matrizes de referência das áreas profissionais, converte-se, portanto, em uma incoerência teórico-metodológica" (DELUIZ, 2001, p. 1).
\end{abstract}

Ainda, no propósito de ser um programa de educação médica orientada para a comunidade, observou-se que o documento analisado do Programa A cita a utilização de um conjunto de fontes de informações 
pertinentes, a fim de aproximar os objetivos do programa e as estratégias educacionais da realidade local, como os boletins do perfil epidemiológico do Estado do Ceará, dentre outras.

Os Programas B e C também referem o uso de documentação relevante e da apropriação de dados importantes para o conhecimento das necessidades de saúde da comunidade, principalmente as resoluções dos órgãos que regulamentam a Residência Medica, inclusive a Resolução CNRM Nº 05/2002 estabelece que as atividades de prática integral à saúde incluem uma série de habilidades, em nível individual e em nível familiar e coletivo; além das atividades de administração e planejamento e na área do ensino e pesquisa, as quais são listadas no referido documento.

No que concerne às bases teóricas e metodológicas que fundamentam o currículo, todos os Programas utilizam metodologias ativas de aprendizagem, sendo que o Programa A teve seu currículo desenhado na perspectiva da abordagem metodológica de Aprendizagem Baseada em Problemas ou Problem-Based Learning (PBL), enquanto que os Programas B e C utilizam a metodologia da Problematização.

Isto se configura também como uma tendência atual dos modelos de ensino, os quais têm procurado adotar estratégias de ensinoaprendizagem com enfoque na dimensão problematizadora, sendo que uma dessas abordagens educacionais utilizada é a Aprendizagem Baseada em Problemas, no caso, empregada no Programa A. Esta abordagem nasceu na Universidade McMaster, no Canadá e hoje é amplamente adotada em diversos países, sendo considerada como uma das mais importantes 
inovações no campo da educação dos profissionais de saúde nas últimas décadas e guarda estreita coerência com os princípios da aprendizagem consolidados pela investigação no campo da psicologia cognitiva. O PBL permite, por suas características essenciais, superar muitas das limitações centrais da educação convencional e vem, conseqüentemente, sendo adotado como eixo central em diversas escolas que atuam na formação e educação permanente de profissionais de saúde em diversas instituições em diversos paises, incluindo o Brasil (MAMEDE, 2001).

De acordo com as considerações de SOBRAL (2000):

"O desenvolvimento de enfoque profundo de estudo e de habilidades de aprendizagem autodirigida correlatas pode ser encorajado no método da Aprendizagem Baseada em Problemas quando os estudantes se confrontam com problemas relevantes numa seqüência de aprendizagem contextualizada" (SOBRAL, 200, p. 49).

A outra concepção pedagógica, utilizada pelos Programas B e C, refere-se à Metodologia da Problematização, defendida por Paulo Freire, como sendo a forma pedagógica que serviria para libertar os homens dos seus opressores e seria emancipadora do homem, tendo, portanto, um caráter fortemente político. Esta metodologia enfatiza que os problemas a serem estudados precisam valer-se de um cenário real, e que estes, ao serem obtidos pela observação da realidade, manifestam-se para alunos e professores com todas as suas contradições, partindo assim, de uma crítica do ensino tradicional e propondo um ensino diferenciado, cuja problematização da realidade e a busca de soluções, possibilitam o desenvolvimento do raciocínio crítico do 
aluno, sendo a problematização voltada para a transformação e conscientização dos direitos e deveres do cidadão, sendo os conhecimento elaborados a partir de um movimento de ação-reflexão-ação (BERBEL, 1998; CYRINO e TORALLES-PEREIRA, 2004; BATISTA et al., 2005).

Quanto à adequação dos Programas de Residência às normas que regulam esse tipo de formação médica, verificou-se que o Programa $\mathbf{A}$ foi elaborado seguindo as orientações da Resolução CNRM No 07/81, publicada no Diário Oficial da União de 17 de junho de 1981. Esta Resolução reconheceu e incluiu o Programa de Residência Médica em Medicina Geral Comunitária entre as especialidades médicas já existentes até então. Dentre estas figurava o Programa de Residência Médica em Medicina Preventiva e Social (RMPS), criado por ocasião do Decreto $N^{\circ} 80.281$ de 5 de setembro de 1977, que regulamentou a Residência Médica e criou a CNRM.

Por outro lado, os Programas B e C foram orientados pela Resolução CNRM Nº5/2002, republicada no Diário Oficial da União de 23 de dezembro de 2003, seção 1, por ter saído com incorreção, do original. Esta Resolução dispõe sobre as especialidades com acesso direto e com prérequisito e muda o nome do Programa de Residência Médica em Medicina Geral Comunitária para Programa de Residência Médica em Medicina de Família e Comunidade, a partir de um convênio celebrado entre o Conselho Federal de Medicina (CFM), a Associação Médica Brasileira (AMB) e a Comissão Nacional de Residência Médica (CNRM), para estabelecer critérios para o reconhecimento e denominação de especialidades e áreas de atuação na Medicina, e forma de concessão e registro de títulos. 
Percebe-se ainda que as construções dos Projetos dos Programas B e C orientaram-se também pela Resolução CNRM No 04/2003, de 23 de dezembro de 2003, que dispõe sobre a organização de Programas de Residência de Medicina de Família e Comunidade, entre outros programas de Residência Médica e oferece os requisitos mínimos para credenciamento desses Programas.

\section{II.b) Estrutura Curricular}

No que se refere aos aspectos gerais da estrutura curricular dos Programas de Residência em estudo, verificou-se que os Programas A, B e C seguem as orientações da Comissão Nacional de Residência Médica, com relação ao tempo de dois anos de duração do Programa, carga horária de 2.800 horas anuais, carga horária semanal de 60 horas, distribuição da carga horária com $80 \%$ a $90 \%$ para atividades de treinamento em serviços e de $10 \%$ a $20 \%$ para atividades teórico-complementares, dentre outras determinações.

Todavia, observou-se que estrutura geral do Programa A está dividida em quatro blocos, ao longo dos dois anos de duração da Residência, sendo o primeiro bloco introdutório; o segundo engloba as atividades de treinamento ambulatorial e comunitário em Atenção Primária; o terceiro reúne as atividades de treinamento em hospitais e serviços especializados; além de um quarto bloco relativo ao treinamento em área rural. 
Já o Programa B apresenta uma estrutura em que as atividades são distribuídas dentro de uma semana padrão de 60 horas, constando de 50 horas de atividades de treinamento em serviços: sendo 34 horas na Unidade de Saúde da Família, 4 horas de estágio em ambulatórios especializados e 12 horas de plantão em hospitais secundários e terciários; além de 10 horas de atividades teórico-complementares.

Ao passo que o Programa $\mathbf{C}$ também distribuiu suas atividades dentro de uma semana padrão de 60 horas, porém, apresentou uma outra organização de horários no decorrer da semana, sendo 30 horas de atividades na Unidade de Saúde da Família, 4 horas de visita domiciliar ou outra atividade na comunidade, 4 horas de estágio em ambulatórios especializados; 4 horas para reunião da equipe de saúde da família e/ou preceptoria de território, 3 horas no período da noite de atividade teóricocomplementares e 12 horas de plantão em hospitais secundários e terciários de referência. Tanto o Programa B como o Programa C referiram que a semana padrão do segundo ano de Residência seria acrescida de algumas atividades compativeis com o grau de aprofundamento requerido para esta etapa da formação do médico de família, incluindo preceptoria do R1, estágio em enfermaria e estágio opcional.

Quanto aos conteúdos teóricos a serem desenvolvidos durante o período da Residência, observou-se que no Programa A estes foram organizados em quatro blocos: atenção ao indivíduo; prevenção de doenças/monitorização e promoção da saúde; gerenciamento de recursos e desenvolvimento pessoal e profissional. Em cada um destes blocos constavam 
as competências, os objetivos gerais e os objetivos específicos de aprendizagem, sendo apresentados como anexos as matrizes, contendo ainda os domínios de aprendizagem de cada objetivo específico, a metodologia utilizada, a carga horária e o local de realização de cada atividade educativa.

Por outro lado, os Programas B e C organizaram os conteúdos teóricos em estruturas modulares semelhantes, ambas compostas de onze módulos temáticos de saúde coletiva, ministrados sob a forma de aulas e seminários; quatro módulos temáticos referentes aos ciclos de vida e um módulo de condutas clínicas, discutidos em sessões clínicas. Estes Programas apresentaram também as ementas de cada módulo, constado da carga horária, objetivos, conteúdos e competências.

Logo, percebe-se pelo detalhamento dos projetos dos Programas estudados que, na organização da estrutura curricular houve não apenas a preocupação com a seleção dos conteúdos teóricos, como também em estabelecer a seqüência com que estes seriam ministrados. Constata-se assim, que os conteúdos foram agrupados em módulos, o que favorece a integração dos conteúdos e consequentemente promove-se a visão holística do individuo, uma vez que organização do currículo por disciplina reproduz o modelo de fragmentação entre a teoria e a prática.

Lembrando ainda que a forma como o conteúdo é organizado em um processo de construção do currículo indica se a ênfase está sendo dada ao processo de ensino-aprendizagem ou somente à exposição dos conteúdos, como é o caso do currículo por disciplinas. Já quando se constrói um currículo salientando o processo de ensino-aprendizagem a seqüência 
na ordenação dos conteúdos segue outra lógica, partindo, por exemplo, de experiências de aprendizagem para dominar uma determinada conduta.

Vale ressaltar que, para que o currículo se configure como um plano de aprendizagem torna-se necessário que tanto o seu conteúdo como os processos de ensino sejam organizados de modo a permitirem que os objetivos educacionais sejam alcançados. E que além do conteúdo, o currículo deve conter também os métodos e técnicas de ensino a serem utilizados, devendo ainda estar bem claro para os alunos a seqüência de conteúdos a serem ministrados e qual o objetivo de cada um deles.

Por isso, SACRISTÁN (2000) adverte que:

"Sem perder de vista a importância do currículo como projeto cultural, se sugere que sua funcionalidade está em sua sintaxe, como algo elaborado, que não é mero puzzle onde se justapõem conteúdos diversos; sua utilidade reside em ser um instrumento de comunicação entre a teoria e a prática. Jogo no qual professores e alunos têm que desempenhar um papel ativo muito importante" (SACRISTÁN, 2000, p. 51)

Nota-se ainda que a configuração da estrutura curricular ao permitir a alternância entre momentos de concentração em sala de aula e momentos de dispersão no trabalho, favorece a aproximação da teoria com a prática.

Além disso, essa forma de organização do conteúdo curricular encontra-se em consonância com as abordagens metodológicas referidas pelos Programas de Residência analisados, uma vez que as metodologias ativas de aprendizagem, as quais são centradas no aluno, são contrárias à pedagogia da transmissão do conhecimento. 


\section{II. c) Sistema de Avaliação}

Quanto ao sistema de avaliação descrito nos projetos dos Programas de Residência estudados observa-se a estruturação de um abrangente conjunto de tipos de avaliação, destinados a avaliar tanto os residentes como o próprio Programa em si.

Para a avaliação dos residentes, o Programa A refere a utilização de uma avaliação da situação, a fim de verificar a performance do aluno ao ingressar no Programa, englobando aspectos relacionados aos domínios do conhecimento (cognitivos, habilidades e atitudes). Além disso, o Programa conta ainda com avaliações formativas, nas quais se encontram autoavaliação, avaliação pelos pares e pelos preceptores e facilitadores; e avaliações certificativas, ao longo dos dois anos de duração do Programa. Relata ainda momentos de avaliação dos preceptores e facilitadores e do Programa.

Os Programas B e C também apresentam um complexo sistema de avaliação que incluem avaliações formativas bimensais e certificativas trimestrais, sendo descritos todo esquema de pontuação para cada grupo de atividades realizadas durante os dois anos do Programa. Estes Programas mencionam ainda um processo de autoavaliação do residente, mediante a construção de um portfólio. Para a avaliação dos preceptores e do Programa são realizados três fóruns por ano.

Para todos estes tipos de avaliações realizadas ao longo dos Programas foram elaborados instrumentos de avaliação específicos. 
Nesse sentido, a Resolução CNRM No 04/2003 discorre sobre o processo de avaliação do médico residente, estabelecendo que esta deve ser realizada no mínimo uma vez por trimestre, podendo ser utilizadas as modalidades de prova escrita, oral, prática ou de desempenho por escala de atitudes, que incluam atributos tais como: comportamento ético, relacionamento com a equipe de saúde e com o paciente, interesse pelas atividades e outros a critério da Comissão de Residência Médica (COREME) da Instituição; deixando a critério da instituição promotora a exigência de monografia e/ou apresentação ou publicação de artigo científico ao final do treinamento.

Ainda de acordo com a mesma Resolução, como se trata de um treinamento com dois anos de duração, a promoção do médico residente do primeiro para o segundo ano será condicionada ao cumprimento integral da carga horária do Programa e da aprovação obtida por meio do valor médio dos resultados das avaliações realizadas durante o ano, com nota mínima estabelecida no Regimento da COREME da instituição, sendo desligado do Programa o residente que não cumprir estas exigências.

Observando-se o esforço dos Programas A, B e C para mensurar adequadamente o desempenho dos residentes, percebe-se que a avaliação é difícil, em qualquer situação, mas se reveste de especial cuidado no que diz respeito aos recursos humanos, face aos aspectos subjetivos que envolvem o processo de atribuir valor. E mais crítica ainda se apresenta a tarefa de avaliar recursos humanos na área da saúde, em razão das peculiaridades inerentes ao setor.

No caso específico da formação dos profissionais de saúde, a 
avaliação se configura como um "componente crítico da instrução", e desde que seja convenientemente elaborada e utilizada adequadamente, pode ser útil para obtenção de um diagnóstico preciso do sistema educacional, além de contribuir para o alcance dos objetivos curriculares propostos, tornando mais efetiva a instrução e aumentando a aprendizagem dos estudantes (AMES et al., 1995; CASE e SWANSON, 1996; GRONLUND, 1998).

O sistema de avaliação posposto pelos Programas A, B e C está em consonância com a opinião de alguns autores, quando afirmam que se pode julgar os ganhos de conhecimento do estudante, através de comparações ao longo de um período de tempo, o que subtende a dinâmica na aquisição de conhecimento e a necessidade de um processo contínuo de avaliação (BATTEN e TRAFFORD, 1985; DIETEL et al., 1991; MADAUS e KELLAGNAN, 1992).

No entanto, é preciso esclarecer que dentro de um processo de avaliação, um único método não é suficiente para abranger todos os aspectos que se deseja avaliar; portanto, quanto mais ampla for a avaliação, maior quantidade e diversidade de tipos e instrumentos de avaliação são necessários. Assim, a avaliação deve contemplar desde a categorização das habilidades cognitivas, começando com as habilidades mais simples e ir aumentando, gradualmente, a sua complexidade (conhecimento, compreensão, aplicação, análise, síntese e avaliação) até a avaliação da performance do profissional, na qual se requer a realização de determinadas tarefas, que também pode ir desde uma tarefa limitada, mas bem estruturada, e o grau de elaboração está relacionado à aplicação do 
conhecimento, até uma atividade mais abrangente e menos estruturada e está mais relacionada à analise de uma situação, pois além de aplicar o conhecimento, o estudante ainda elabora esse conhecimento (LINN e GRONLUND, 1995; ROWNTREE, 1997).

No caso em questão, que se refere à avaliação dos Programas de Residência Médica, em especial da Residência em Medicina de Família e Comunidade, e do desenvolvimento das competências requeridas dos profissionais capacitados, alguns aspectos fundamentais devem ser considerados. Como se trata de uma modalidade de ensino de pósgraduação, caracterizada por treinamento em serviço, faz-se necessária a adoção de instrumentos e procedimentos específicos que consigam apreender os processos e produtos deste treinamento.

\section{Categoria III. Preceptoria}

$\mathrm{Na}$ análise dos documentos ficou clara a preocupação dos Programas de Residência em foco com a questão da preceptoria. Todos os Programas evidenciaram a importância do papel do preceptor nesse processo de aprendizagem, fato comprovado inclusive pela definição do perfil destes profissionais, quando são apresentados os requisitos necessários para ocupar esta função.

Percebe-se que a organização do processo de preceptoria destes 
Programas atende às orientações da Resolução CNRM N ${ }^{\circ}$ 04/2003, segundo a qual durante o período de treinamento o médico residente deve ter supenvisão permanente, realizada por docentes, por médicos com titulação de Residência Médica na área ou na especialidade, ou título superior, ou que sejam possuidores de qualificação equivalente, de acordo com critérios da CNRM; como também à Resolução CNRM Nº 005/2004, de 08 de junho de 2004, que dispõe sobre os serviços de preceptor/tutor dos programas de Residência Médica e estabelece que:

"Art. $2^{\circ}$. O preceptor/tutor terá a atribuição de orientar diretamente os médicos residentes do programa de treinamento. $\S 1^{\circ}$. Haverá um preceptor/tutor para cada programa de Residência Médica. $\S 2^{\circ} \mathrm{A}$ carga horária do preceptor/tutor será de $\mathbf{4 0}$ (quarenta) horas semanais, em tempo integral, com folga de um dia, preferencialmente aos domingos" (CNRM, 2004a, p.1).

Os Programas B e C apresentam uma inovação acerca do processo de preceptoria, e criam duas modalidades de preceptores: o preceptor de território e o preceptor de especialidades ou de ciclos de vida, neste caso denominado de preceptor clínico. Isto porque, segundo os organizadores dos Programas, existe um desafio fundamental na proposta pedagógica para a Residência em Medicina de Família e Comunidade, que se trata da formação clínica dos residentes, sob a perspectiva do Programa de Saúde da Família. E fazem uma clara distinção entre as características de uma formação técnica de profissionais para trabalhar na atenção primária e a atenção à saúde almejada para o Programa Saúde da Família, segundo os quais, requer mais do que uma formação clínica. 
Neste caso propõe-se a utilização da lógica da "tenda invertida", que de acordo com ANDRADE et al. (2004), busca "a superação do conceito tradicional da especialidade médica, que é oriundo do conceito medieval do mestre e do aprendiz de ofício, em que um aprendiz que quer aprender um ofício vai para a tenda do mestre, para depois montar sua própria tenda. No Saúde da Família, em vez de o aprendiz ir para a tenda do mestre, é o mestre que vai para a tenda do aprendiz".

Quanto à capacitação destes profissionais, o Programa A desenvolveu o seu processo de treinamento prévio, a partir da definição de algumas competências consideradas essenciais para a prática da preceptoria. Já os Programas B e C semelhantemente passaram por um processo de capacitação de seus preceptores, conduzido pelas instituições formadoras envolvidas nos Programas; e também baseado em um conjunto de competências necessárias ao desempenho de suas atividades.

Estes Programas contaram ainda com material didático fornecido pela Sociedade Brasileira de Medicina de Família e Comunidade, sob a forma de um manual para subsidiar a realização de oficinas de capacitação dos preceptores em Medicina de Família e Comunidade (LOPES et al., 2009). Trata-se certamente de uma iniciativa oportuna, tendo em vista que a grande carência de profissionais com titulação nesta especialidade compromete sobremaneira o processo de formação encetado mediante os Programas de Residência. 


\subsection{A PERCEPÇÃO DOS RESIDENTES DOS PROGRAMAS DE RESIDÊNCIA EM MEDICINA DE FAMÍLIA E COMUNIDADE}

Conforme delineamento anterior, a análise dos dados coletados a partir das entrevistas realizadas se deu através de análise do conteúdo dos participantes, na qual os assuntos coincidentes existentes nos relatos de todos os sujeitos entrevistados foram agrupados em categorias de análise sempre relacionadas com o objetivo da pesquisa, observando-se os consensos e as diferenças a respeito de cada tema.

Participaram desse estudo seis profissionais, que estão na seguinte condição: três já concluíram a Residência; dois ainda estão em processo de formação e um que não concluiu o Programa de Residência, e, portanto não recebeu o certificado de especialista. Dos seis entrevistados, dois estão trabalhando como professores de Universidades cearenses; dois estão na Estratégia Saúde da Família, sendo que um deles não concluiu o Programa de Residência e o outro trabalhou por um ano e meio como preceptor, depois que recebeu o titulo de especialista em Medicina de Família e Comunidade; um ainda está na Residência como R2 e o último, apesar de estar no Programa de Residência, é chamado de especializando, pois concluiu o curso de graduação no exterior, em Cuba, e está em processo de validação do diploma no Brasil. Vale ressaltar que não se constituiu objetivo desta pesquisa quantificar os fatores analisados em ordem de freqüência, e sim, compreender as percepções sobre os aspectos pesquisados. Dessa 
forma, optou-se então por não apresentar as categorias de análise a partir da ordem de freqüência com que emergiram, mas sim, analisar cada uma delas isoladamente, à luz do referencial teórico, objetivando com isso atingir as percepções dos entrevistados quanto à proposta de formação para médico de família mediante um Programa de Residência.

As falas desses profissionais que passaram pelos Programas de Residência em Medicina de Família e Comunidade no Estado do Ceará, as quais tratam das suas vivências acerca desse processo de formação na especialidade de médico de família e comunidade, possibilitaram a construção das categorias e subcategorias descritas no Quadro 2, a seguir:

Quadro 2 - Categorias e subcategorias construídas a partir dos discursos dos entrevistados. Fortaleza, 2010.

\begin{tabular}{|l|l|}
\hline \multicolumn{1}{|c|}{ Categorias } & Subcategorias \\
\hline I. Organização e Execução do Programa de Residência & a) Pontos Positivos \\
\cline { 2 - 3 } em Medicina de Família e Comunidade & b) Dificuldades Percebidas \\
\hline II. Contribuição da Residência em Medicina de Família & \\
e Comunidade para a Prática do Médico de Familia & \\
\hline III. Captação e evasão da Residência em Medicina de & \\
Família e Comunidade: um dilema a ser enfrentado. & \\
\hline
\end{tabular}




\section{Categoria L. Organização e Execução do Programa de Residência em} Medicina de Familia e Comunidade

No discurso dos entrevistados foi detectada sua percepção sobre a organização e execução do Programa de Residência em Medicina de Família e Comunidade que eles freqüentaram. Foi evidenciado que a qualidade na organização do Programa é percebida como um elemento fundamental para o alcance dos objetivos deste processo de formação. Nos depoimentos dos entrevistados foi possível detectar pontos positivos, mas também dificuldades na organização e execução do Programa. Figuram como pontos positivos a inserção do residente na comunidade desde o início do Programa; a presença do preceptor acompanhando o processo de formação; os estágios nos ambulatórios de especialidades. Já as dificuldades na organização do Programa são atribuídas, principalmente, ao pouco tempo de existência do Programa; carência de recursos humanos qualificados, no caso específico de preceptores especialistas em Medicina de Família e Comunidade; falta de recursos materiais e financeiros; problemas estruturais das Unidades de Saúde.

Desse modo, nas falas dos participantes do estudo foi possível evidenciar alguns elementos, que possibilitaram uma análise de um processo em franca efetivação, demonstrando seus avanços, mas, principalmente, elementos que ainda impedem a sua efetivação. 


\title{
I.a) Pontos Positivos na Organização e Execução do Programa
}

A possibilidade de participar ativamente do processo de conhecimento da comunidade e de suas demandas de saúde, podendo planejar suas ações a partir das necessidades percebidas e referidas por essa comunidade se configura como um diferencial do Programa conforme relato a seguir.

\begin{abstract}
"(...) estar inserido na comunidade desde o primeiro momento da Residência, porque diferente de outros Programas de Residência de Medicina de Família que a gente vê por aí, conversando com o pessoal, geralmente o primeiro ano em algumas Residências é totalmente hospitalar, depois, no segundo ano é que eles entram realmente na comunidade (...) desde o primeiro ano a gente está dentro da comunidade, a gente já tem um jeito melhor de fazer um vínculo com aquela comunidade e conhecer realmente o que é a medicina de família" (RM1)
\end{abstract}

Essa forma de desenvolver programas de ensino médico voltados para a comunidade é corroborada por MAGZOUB e SCHMIDT (2000), ao enfatizarem que a educação orientada e baseada na comunidade possibilita que os assuntos estudados pelos alunos tenham relevância direta no que diz respeito aos problemas prioritários de saúde da comunidade na qual os alunos serão treinados; sendo constituída por atividades de aprendizagem que utilizam extensivamente a comunidade como um ambiente de aprendizagem, no qual, não só os alunos, mas também os docentes, membros da comunidade e representantes de outros setores estão ativamente envolvidos em toda experiência educacional. 
Isto tem se configurado não apenas como uma tendência do ensino nas Universidades e escolas médicas, mas como uma prioridade absoluta da educação médica, uma vez que esta, sendo entendida como, a ciência e a arte de preparar os futuros médicos para atuarem adequadamente na sociedade, implica que tem a responsabilidade de influenciar as circunstâncias e condições em que eles exercem sua prática médica, sendo cada vez maior a necessidade de investir esforços no sentido de dotar estes profissionais de saúde de conhecimentos oriundos do campo da Educação Orientada para a Comunidade que venha a fundamentar e possibilitar o aprimoramento de sua prática profissional.

Essas considerações são ratificadas por NEBOT ADELL et al. (2009) quando afirmam que:

"Más aún, en los últimos años se han constatado las ventajas de desplazar la formación desde las aulas al seno de la comunidad, precisamente donde los trabajadores de la salud deberán aplicar sus habilidades y conocimientos. (...) Este tipo de iniciativas son consideradas fundamentales para adquirir las competencias necesarias en APS, pues permite el contacto de los profesionales con los individuos y sus familias, familiarizándolos con sus características sociales y culturales" (NEBOT ADELL et al., 2009, p. 182)

Um outro ponto positivo relatado nas falas dos entrevistados, quanto ao processo de desenvolvimento do Programa de Residência referese à preceptoria. Sabe-se que, ao preceptor cabe acompanhar, avaliar e apoiar os residentes, atuando como mediador no processo de ensinoaprendizagem, por intermédio da realização das reuniões de preceptoria, 
incentivando-os na prática das atividades complementares, visando o cumprimento do cronograma de execução do currículo. A importância do papel do preceptor na organização e execução do Programa é manifestada nas falas que se seguem.

“(...) a gente teve preceptor em todos os momentos, alguns preceptores de medicina de família, outros, preceptores de especialidades" (RM1)

"Eu acho que um ponto forte é a parte de você poder estar com o preceptor ao seu lado durante o atendimento, então você está tirando aquelas dúvidas, a parte das discussões dos casos clínicos, conhecimento mesmo, assim, você aprender a parte da ginecologia da saúde da família ao lado de um ginecologista, Ihe dá muito mais segurança para quando você estiver atendendo sozinha, então o ponto forte mesmo foi o conhecimento na prática, porque a gente atendia com um preceptor ao nosso lado, (...)" (RM3)

" (...) ele [preceptor] fica com a gente, quando a gente é R1, eles ficam com a gente nos atendimentos, direto, fica ali colado, nos atendimentos ambulatoriais; quando a gente está desenvolvendo as atividades educativas, eles acompanham, eles ajudam a desenvolver a atividade, eles dão idéias." (RM4)

De fato, é imprescindível a presença do preceptor durante o processo de formação do residente, no entanto, é essencial que este profissional possua as competências necessárias para exercer as complexas funções que Ihe são atribuídas. A preceptoria na Residência de Medicina de Família e Comunidade se reveste de especial importância, uma vez que, dada a atuação e o compromisso desse profissional com a proposta da Saúde da Família, pode fazer grande diferença para aqueles que estão 
ingressando nessa especialidade ainda tão pouco reconhecida. Isto porque, os médicos ao saírem da graduação trazem como bagagem de conhecimento um modelo de atenção médica muito diferente do que é proposto pela Estratégia Saúde da Família, e, mesmo participando de um Programa de Residência em Medicina de Família e Comunidade, eles continuam buscando dar continuidade à formação da Universidade e esperam ser treinados nas práticas de saúde peculiares ao modelo de atenção ensinado na Faculdade, como se fosse uma extensão da graduação. Tanto assim que, como foi relatado nas entrevistas, quando as atividades do Programa de Residência eram relacionadas às áreas clínicas, uma discussão sobre hipertensão, por exemplo, havia a concorrência de todos os residentes; no entanto, quando se tratava de atividades correspondentes aos temas de saúde coletiva, vigilância em saúde, por exemplo, havia um nítido desinteresse por parte dos residentes, como se aquele assunto não lhes dissesse respeito.

Desse modo, cabe, principalmente, ao preceptor levá-los a uma reflexão crítica acerca dessas práticas, motivando a quebra desses paradigmas, visto que dito preceptor estará diretamente envolvido no processo de formação do médico de família.

Outro aspecto destacado nas falas dos entrevistados como algo importante no Programa de Residência refere-se aos estágios nos ambulatórios especializados, conforme denota as falas a seguir. 
de especialidades, porque mesmo você sendo médico de família, mas você tem que ter noção do terciário também, até porque você encaminha seus pacientes para os níveis secundários e terciários, então tem que ter noção também sobre o que é, como é que faz, o que é que o paciente quando chega lá procura, por quem ele é acompanhado é até uma maneira de você criar vínculo com aquele profissional, de você poder trocar experiência com aquele profissional sobre aquele paciente que você está encaminhando" (RM1)

"a gente ia para algum serviço especializado, durante dois meses ficava nesse serviço acompanhando, isso era muito bom, isso foi uma parte muito boa da Residência porque, eu vou dar um exemplo, uma vez por semana, um turno por semana eu ia para o ambulatório de hanseníase, então lá pegava os casos mais específicos, mais complicados, então isso fez com que eu desse um melhor encaminhamento aos nossos pacientes na Unidade, porque eu fui para um serviço especializado mesmo, então eu via o que chegava lá, o que deveria encaminhar, o que não deveria, o que dava para resolver na atenção primária, o que poderia resolver até mesmo pelo fato de ter passado pelo serviço mais especializado" (RM3)

A inclusão dos estágios em ambulatórios de especialidades ou especializados no currículo dos Programas de Residência segue orientações da Resolução CNRM No 05/2002 que, quando trata do Programa de Residência Médica em Medicina de Família e Comunidade estabelece que:

"As atividades de treinamento em serviço devem ser programadas por meio dos seguintes meios e formas:

- atividades na comunidade: domicílios, escolas, locais de trabalho e lazer - um mínimo de $10 \%$ da carga horária total; - atividades em unidades de cuidados primários de saúde: postos de saúde em áreas rurais e/ou urbanas; centros de saúde ou unidades mistas de saúde e unidades básicas situadas em centros de referência - um mínimo de $50 \%$ da carga horária total;

- atividades em unidades de cuidados secundários e terciários: hospitais gerais, de especialidades ou especializados - um mínimo de $10 \%$ da carga horária total. 
Vale salientar que estudos internacionais recomendam essa prática, tanto assim que, HAQ et al. (1996) ao identificarem os desafios para a formação do médico de família e listarem doze estratégias relevantes para o desenvolvimento bem-sucedido da medicina de família afirmam que uma das ações nesse sentido seria envolver os sub-especialistas no treinamento e trabalho com o médico de família. Para tanto, os autores explicam que:

"Subspecialists can play a critical role in providing family physicians with a disciplined approach to clinical decision making, recognition of patients with problems that need referral, and stabilization of critically ill patients for transfer. Subspecialists' skills can be most effectively utilized when they work in a co-ordinated fashion with primary care providers who care for common problems and refer patients to them with more complex diseases" (HAQ et al., 1996, p. 355).

Trata-se, portanto, de uma atividade necessária à formação do médico de família uma vez que oferece a oportunidade de o profissional acompanhar, no ambiente hospitalar, pacientes portadores de patologias de maior gravidade e/ou complexidade, desenvolvendo a aprendizagem com ênfase especial no manejo de condições agudas e nos procedimentos diagnósticos e terapêuticos realizáveis em níveis ambulatorial e domiciliar. Ao passo que nas Unidades ambulatoriais especializadas o residente irá adquirir familiaridade com o tratamento e acompanhamento de pacientes com problemas crônicos de maior complexidade. 


\section{I.b) Dificuldades Percebidas na Organização e Execução do Programa}

Quanto às dificuldades percebidas na organização e execução do Programa, é possível verificar através dos discursos dos entrevistados, a percepção de problemas na organização, atribuídos ao pouco tempo de criação do Programa para algum tanto deles, observado nas declarações de que enfrentaram algumas dificuldades, pelo fato de terem frequentado os Programas de Residência enquanto estes ainda estava sendo implementados.

“(...) no meu ponto de vista, teve algumas desvantagens por eu ter sido da segunda turma da Residência, que ainda não estava muito bem estruturada" (RM1)

"Bem, eu fui da primeira turma dessa proposta (...) então a proposta ainda muito incipiente (...) eu acredito que hoje deve estar melhor (...)" (RM2)

“(...) era um Programa novo de Residência, muitas vezes a gente tinha que ter um pouco de paciência e tinha que entender as situações porque estava apenas no segundo ano, era um Programa que ainda estava se estruturando, por mais boa vontade que eles tivessem algumas coisas não saíam como era para sair, pelo fato de ser um Programa novo" (RM3)

De fato, a percepção desses residentes de que se tratava de um processo em construção é corroborada pela coordenação de um dos Programas quando enfatiza que ao longo desse processo foram feitas adequações para poder melhor atender às necessidades dos residentes e do próprio Programa. Para tanto, contam com a realização de momentos de avaliação, nos quais a coordenação do Programa, os preceptores e os 
residentes se reúnem para avaliar as atividades realizadas e identificar os entraves ao bom andamento do Programa, e, de posse dos resultados dessas avaliações são implementadas as mudanças necessárias.

É bem verdade que, se o Programa de Residência mais antigo e que está em atividade atualmente conta com apenas cinco anos de existência, sem dúvida pode-se inferir que se trata de programas que ainda estão se estruturando, sendo que estas dificuldades iniciais enfrentadas pelos residentes, são esperadas em qualquer projeto no seu início, e que, a conjunção de forças entre os atores envolvidos nesse processo poderá transpor estes obstáculos, que na grande maioria das vezes, são problemas de natureza organizacional, passiveis de serem corrigidos com adequada orientação e a implementação dos ajustes que se fizerem necessários em cada situação específica.

Por outro lado, a fala dos entrevistados denota a percepção de dificuldades ligadas à capacidade estrutural dos serviços de saúde em que as atividades de treinamento em serviço são realizadas, conforme retratado nas falas seguintes.

“(...) No começo a gente não tinha sala suficiente, ainda hoje é assim (...) então a gente já chegou a atender em sala sem ar condicionado, sem janela, às vezes não tinha sala para atender e a gente tinha que esperar outro profissional ir embora. Computador, ele é muito devagar (...). Impressora, eu que trouxe a minha, porque a Unidade não oferece. Falta muita coisa, até mesmo material para fazer prevenção, muitas vezes a gente não fazia porque não tinha material. Desde coisa simples, como glicosímetro, a maioria das vezes não tem fita; como papel para enxugar a mão; e às vezes eram coisas que a gente trazia de casa ou dava um jeito, mas às vezes a gente se prejudicava, tipo, material 
para prevenção, a gente tinha ali um tempo para aprender com o preceptor, toda vez que não tinha, a gente perdia aquela oportunidade" (RM3)

“Falta estrutura, falta um ar-condicionado para você atender, falta o sistema de computação, infelizmente no nosso posto a gente está com praticamente um computador disponivel para os médicos, a gente tem necessidade de marcação de exames, de colocar no sistema (...), e quando eu preciso passar um exame para o sistema, eu tenho que tirar um horário da minha carga horária, aproveitar quando falta um paciente, para tentar, ver se o computador está liberado para eu poder passar todos os exames para o sistema, e isso dificulta muito (...) às vezes o paciente está ali lhe cobrando, com a necessidade daquele exame (...) o nosso posto é pequeno e a gente não tem estrutura para fazer atividades de grupo" (RM4)

\begin{abstract}
"A proposta é linda. A teoria é maravilhosa, mas em relação aos recursos tem uma deficiência muito grande, que acaba meio que, não desanimando, mas deixando a gente sem muita coisa que fazer, mas trabalhando com os poucos recursos que tem, acreditando que um dia isso possa melhorar, porque o trabalho mais ou menos é esse, e a gente não pode desanimar, a gente tem que tentar fazer o melhor trabalho possivel, independentemente das circunstâncias" (RM5)
\end{abstract}

"A questão estrutural, as próprias estruturas das Unidades de Saúde elas não são boas, eu digo porque até hoje elas continuam ruins, até hoje eu trabalho como médica, são horriveis, não é um trabalho bom, que dá prazer estar trabalhando" (RM6)

Nestas falas dos entrevistados percebe-se uma concordância com os achados de CASTRO e NÓBREGA-THERRIEN (2009), que, no propósito de avaliar um dos Programas de Residência do Estado, realizaram uma pesquisa junto aos residentes desse Programa, cujos resultados demonstraram que, dentre os aspectos mais citados como lacunas na formação, "as más condições de infra-estrutura das Unidades de Saúde" 
lideram a opinião dos residentes, juntamente com a "necessidade de mais conhecimentos clínicos especializados”, ambos apontados por $25 \%$ de seus entrevistados.

É sabido que os problemas relacionados à infra-estrutura física têm sido considerados como um dos grandes entraves para a implantação de Programas de Residência em todo país. Estudos realizados no Brasil alertam que as Unidades de Saúde, em sua maioria, não apresentam infra-estrutura adequada para atividades de ensino e que há a necessidade de uma melhor infra-estrutura para que os residentes busquem um comportamento pró-ativo, além de se sentirem estimulados com esta especialidade (ALMEIDA e FERREIRA FILHO, 2008; MISSAKA e RIBEIRO, 2010).

Vale ressaltar ainda que o Ministério da Saúde, reconhecendo os entraves que impedem a expansão da Estratégia Saúde da Família, vem empreendendo esforços no sentido de transpor esses obstáculos. Para tanto, em 2003, celebrou um Acordo de Empréstimo com o Banco Intemacional para a Reconstrução e o Desenvolvimento (BIRD), a fim de viabilizar o Projeto de Expansão e Consolidação da Saúde da Família (PROESF), cujo objetivo é apoiar, por meio da transferência de recursos financeiros fundo-a-fundo, a expansão da cobertura, consolidação e qualificação da estratégia Saúde da Família, nos municípios brasileiros com população acima de 100 mil habitantes. Composto de três fases, o PROESF encerrou a Fase I em junho de 2007 e agora inicia sua Fase II, prevista para acontecer no periodo de 2010 a 2013. O componente I desta Fase trata justamente da expansão e qualificação da saúde da familia nos municípios com população acima de 100 mil habitantes, 
que concentram cerca de $55 \%$ da população brasileira, financiando a melhoria da infra-estrutura das unidades de saúde da família e de serviços públicos de média complexidade ambulatorial, assim como o fortalecimento da capacidade de gestão municipal, a capacitação dos recursos humanos e a avaliação do PSF como um requisito obrigatório (BRASIL, 2010b).

Logo, espera-se que com esse aporte de recursos seja possivel estruturar melhor as Unidades de Saúde a fim de torná-las adequadas ao desenvolvimento de atividades de ensino em todo Estado.

Ainda nesta análise da organização dos Programas verificou-se também a percepção de um aparente distanciamento entre a proposta teórica e a atividade prática, em que o residente muitas vezes não se sentia participante de um processo educativo.

\begin{abstract}
"Teve alguns pontos negativos, principalmente em termos de organização, (...) parecendo às vezes que a gente estava até meio que levando mais um serviço do que necessariamente aprendendo. (...) Muitas vezes a gente era cobrado para atender a demanda e não para fazer a Residência, e quem está fazendo um estágio em serviço tem que fazer algo bem feito, é qualidade e não quantidade e, às vezes a gente era cobrado quantidade e não qualidade, e isso terminava interferindo também na formação" (RM1)
\end{abstract}

“(...) alguns dos plantões nos hospitais não eram focalizados na nossa realidade, eu cheguei a dar um plantão em clínica médica, com um médico para atender uma população gigantesca, não tinha a menor condição de ele estar parando para me explicar nada, eu ficava até constrangida de estar lá, porque eu sabia que isso fazia com que ele tivesse que me ensinar alguma coisa, tivesse que me dar atenção, sendo que tinha uma demanda gigantesca para ele atender do lado de fora, as pessoas reclamando (...) então assim, era um lugar que me sentia até mal de estar, não tinha condições dele receber um aluno naquelas condições de trabalho" (RM3). 
“(...) chega um coordenador de uma Unidade querendo the sobrecarregar e não tem alguém ali, às vezes o preceptor não está com você, não tem quem the ajude a dizer que você é um residente, que você tem um número reduzido de pacientes, você não atende como o outro médico, por você ser residente você atende um menor número, para você desenvolver mesmo uma qualidade maior, e às vezes vem o coordenador, e aí quer exigir (...), pois é, e aí chega ele impondo, querendo que você atenda uma quantidade de pacientes " $X$ ", que não é a sua quantidade pela Residência, tudo isso influencia e vai desestimulando (...)" (RM4).

Nesse sentido, MASSUDA, et al. (2007), ao apresentarem a visão dos médicos residentes sobre a Residência Médica, consideram a necessidade de mudanças estruturais no funcionamento dos serviços que ofertam Programas de Residência e se configuram como campo de prática desses profissionais e argumentam que, "muitas vezes, o residente se insere no processo de trabalho não como um aprendiz, mas como 'tocador de serviço' ou 'mão-de-obra barata'."

Entretanto, essas dificuldades ainda fazem parte do rol de obstáculos a serem superados pelos Programas de Residência em Medicina de Família e Comunidade, não apenas no Estado do Ceará, mas no país como um todo. A esse respeito, a diretora do Departamento de Atenção Básica, da Secretaria de Atenção à Saúde, do Ministério da Saúde, Claunara Schiling de Mendonça, em entrevista à Sociedade Brasileira de Medicina de Família e Comunidade admite que o PSF, apesar de ser uma experiência consolidada no Brasil, conta ainda com um pequeno percentual de especialistas em Medicina de Família e Comunidade na composição das equipes de saúde da família, e considera que o Programa de Residência, eleito como a estratégia basilar para a formação desses profissionais ainda 
não é reconhecido "como um espaço de satisfação e realização do profissional médico", apontando como causas para a permanência dessa situação "as más condições para o trabalho - infra-estrutura, garantia dos insumos para exercer a integralidade do cuidado, número adequado de população sob sua responsabilidade, problemas apontados pelos profissionais nas equipes. Mas, principalmente, pela falta de exemplos durante seu processo formativo" (MENDONÇA, 2009).

E no que se refere a esse processo formativo, dois outros aspectos revelados pelas falas dos entrevistados, e que estão em estreita relação entre si, merecem destaque nessa análise. Primeiramente, muito embora tenha sido considerada de fundamental importância a figura do preceptor, é também extremamente necessário que a sua capacitação seja coerente com as necessidades do Programa de Residência, tanto no que diz respeito à sua formação na especialidade específica requerida pelo Programa, como no que tange à formação pedagógica para a função docente que irá desempenhar, o que vai influir diretamente na forma como são utilizadas as metodologias de ensino-aprendizagem adotadas pelos Programas de Residência. Assim, as falas dos residentes entrevistados apresentadas a seguir denotam dificuldades percebidas relacionadas a estas questões.

“a Residência era muito posto de saúde-dependente, se o posto de saúde fosse bom e o preceptor fosse bom, aquele residente iria se formar bem; se o posto de saúde fosse ruim e o preceptor não fosse tão bom, o residente muito provavelmente não iria ficar tão bom, então não formava os residentes uniformemente" (RM1) 
“(...) porque o preceptor... eu acho que ele tem que ter a prática, a vivência prática, e é isso que a gente sentia falta. (...) porque tem que ter preparação, você vai deixar um residente de cirurgia, sem ser com um cirurgião? Mas um médico de família pode ficar sem ser com um outro médico de família? Então a preceptoria realmente, não foi nada a contento, a gente é que foi atrás, buscando, vendo quem era que se adequava ao perfil, questionando, mas a gente terminou a Residência sem a preceptoria adequada, a gente era muito autodidata, na verdade" (RM2)

"(...) a Residência, ela era diferente para os residentes, vamos supor, um conteúdo que era dado mais fortemente por uns preceptores, outros preceptores talvez não fossem tão capacitados e não faziam essa abordagem como aqueles preceptores, então entre os meus colegas, uns aprenderam coisas que eu não aprendi, entendeu? Uns aprenderam a fazer alguns procedimentos ou a usarem algumas tecnologias em saúde, outros não, por quê? Porque o preceptor de um ensinava, o preceptor do outro não. Então teve alguns aspectos que eram diferentes dependendo do preceptor que você "pegasse" (RM3)

"Nós desse posto temos o privilégio de termos boas preceptoras. Quem está junto com a gente na prática mesmo são elas e elas estão bem preparadas. Existem postos que têm residentes que não têm preceptores. Alguns postos faltam alguns preceptores, por algum motivo acabaram desistindo ou então adoeceu, tirou licença, e ficou sem substituto. (...) Mas em relação a esse posto, a gente tem um privilégio" (RM4).

Conforme discutido anteriormente o trabalho de preceptoria requer profissionais com as competências necessárias, o que implica em estarem preparados para exercerem as funções clínicas e pedagógicas.

LOPES et al. (2009) tratando desse tema afimam que a necessidade de ampliar a formação de médicos de família e comunidade depara-se com a dificuldade de encontrar profissionais especialistas nesta área com a qualificação e a experiência para atuarem como preceptores de novos especialistas e superar a diversidade existente nos Programas de Residência Médica. 
Os autores prosseguem assegurando ser preciso que "os preceptores incorporem e passem a utilizar tecnologias de ensino-aprendizagem adequadas e que trabalhem com conteúdos que signifiquem na formação do médico de familia e comunidade, e não mais desenvolvam o ensino baseado apenas no bom senso ou habilidades pessoais", ou seja, o que eles estão propondo é o ensino baseado em competências e a utilização de metodologias significativas, no entanto o uso dessas abordagens metodológicas requer a formação adequada desses preceptores (LOPES et al., 2009).

No entanto, a legislação que trata da preceptoria nunca exigiu deles capacitação didático-pedagógica. O Decreto $N^{\circ} 80.281 / 77$ e a Lei № 6932/81 estabelecem que os preceptores devem ser "profissionais médicos de elevada qualificação ética e profissional"; enquanto que a Resolução CNRM № 04/78, no seu art. $5^{\circ}$, alínea "d" determina que eles devem ser "médicos portadores de certificados de Residência Médica da área ou especialidade em causa ou título superior, ou possuidores de qualificação equivalente, a critério da Comissão Nacional de Residência Médica", corroborada pelas Resoluções CNRM No $^{\circ}$ 02/2005, art. 23, alíneas "c", "d" e "e" e CNRM No 02/2006, art. 16 (BRASIL 1977; CNRM, 1978; 1981b; 2005; 2006).

Assim, a partir do que está posto na legislação que regula esse processo de formação, qualquer médico poderá assumir a função de preceptor, uma vez que, o próprio exercício profissional da medicina já incorpora essas exigências.

Como foi mencionado antes, existe uma inter-relação entre a adoção de currículos e metodologias de ensino-aprendizagem inovadores e 
a atuação dos preceptores/docentes, pois de nada adianta implantar projetos pedagógicos inovadores sem a adequada formação e participação da equipe docente; sendo assim, a capacitação desses profissionais tornou-se um desafio importante para as diversas funções demandadas por esses novos modelos educacionais, como referido por PERIM et al. (2009) ao discutirem sobre o desenvolvimento docente e a formação de médicos, constatam que:

\begin{abstract}
"Esse docente, na maioria das vezes médico, provavelmente formado pelo modelo hegemônico centrado no hospital, deverá atuar como educador na nova proposta de formar médicos. Deverá ter capacidade de preparar o estudante para aprender a aprender de forma a acompanhar a evolução do conhecimento; para interagir com os demais profissionais de saúde, atuando com competência em equipes multidisciplinares; para compreender a realidade do sistema único de saúde; e, mais do que isso, para refletir sobre ela, buscando atender às necessidades básicas de saúde dos usuários. Como fazer com que o docente mude sua postura profissional, acompanhando as inovações didático-pedagógicas? Como esperar que o docente atue na gestão de recursos humanos, na administração universitária, que promova a articulação entre ensino, serviços e a comunidade - enfim, que gerencie o processo de mudanças?" (PERIM et al., 2009, p. 72)
\end{abstract}

Logo, estratégias de capacitação devem ser buscadas, iniciativas como a da Sociedade Brasileira de Medicina de Família e Comunidade, que promoveu uma série de oficinas para capacitar preceptores de Medicina de Família e Comunidade, devem ser valorizadas, para que se possa suprir a carência de especialistas nessa área, cujas vagas nos Programas de Residência são ocupadas por médicos de outras especialidades, o que tem gerado muitas queixas por parte dos residentes, uma vez que a atuação do preceptor representa a forma de ensinar mais próxima do aluno, e estes 
querem ser acompanhados pelos médicos especialistas que teriam maior capacitação teórica e vivência prática em Medicina de Família e Comunidade.

Além dos problemas já citados, a não capacitação da equipe preceptor/docente compromete o desenvolvimento das metodologias de ensino-aprendizagem assumidas pelos Programas de Residência, ficando estas restritas à formulação teórica no desenho do currículo, sem, no entanto serem postas em práticas no desenvolvimento do Programa, como pode ser percebido nas falas dos entrevistados.

"as aulas teóricas não tinham um seguimento lógico de acontecer (...) eram aulas expositivas, (...) cerca de três horas de duração, mas que não tinham uma lógica, como eu estou dizendo, muitas vezes a gente chegava lá e não sabia nem que aula ia ser dada" (RM1).

“(...) a gente participava das aulas dos senviços. Por exemplo, se a gente tava rodando num senviço de clínica médica e tinha uma aula de asma, então, a gente ia assistir a aula de asma (...)" (RM2)

"Durante as aulas eles orientavam os textos (...) tinha bastante textos que eles deixavam disponíveis para a gente xerocar ou imprimir, eles mandavam por e-mail, as aulas eram todas mandadas também por e-mail" (RM3)

"Além disso, a gente tem uma aula semanal (...) que é administrada pelos preceptores ou pelos coordenadores da nossa Residência ou então por palestrantes convidados, que são pessoas também bem capacitadas em sua área" (RM4)

Logo, a partir da análise destas falas constata-se que quanto ao processo de implementação dos conteúdos não houve coerência entre os objetivos propostos e o processo de ensino-aprendizagem adotado no curso. Uma vez que a metodologia aplicada, conforme verificado nas falas, 
pautava-se na transmissão de um conjunto de informações descontextualizadas e desarticuladas, que não levava a uma reflexão. Não obstante todos os Programas de Residência terem afirmado em seus projetos que utilizariam metodologias ativas de aprendizagem, isso não foi a regra geral, e a utilização de aulas expositivas não favorece mudanças na posição dos residentes, de modo a levá-los a passar de uma atitude passiva, como receptáculos, para uma postura ativa, como sujeitos de seu próprio aprendizado.

Nesse sentido, MITRE et al. (2008, p. 2140) se referem a "necessidade de romper com a postura de mera transmissão de informações, na qual os estudantes assumem o papel de receptáculos passivos, preocupados apenas em memorizar conteúdos e recuperá-los quando solicitado - habitualmente, por ocasião de uma prova".

Para BOTTI e REGO (2010), "durante a residência, a aprendizagem deve ser significativa, com seus objetivos bem explícitos, para que possa motivar o residente".

No entanto, o que se percebe é que a influência do método tradicional de ensino, centrado no professor e nos conteúdos, ainda está muito presente na prática habitual dos profissionais que se propõem a serem educadores na área da saúde. Isso porque implementar novas metodologias de ensino-aprendizagem não é uma tarefa fácil, significa romper com estruturas fortemente arraigadas, o que acarreta uma brusca mudança, indo de formas tradicionais para metodologias ativas de aprendizagem, muitas vezes sem a prévia preparação de preceptores e residentes (CANUTO e 
BATISTA, 2009; MARIN et al., 2010).

Portanto, trata-se de um processo lento e contínuo, o que exige muita paciência e principalmente, a instituição de programas de educação permanente dos docentes/preceptores. Além disso, é de fundamental importância que o Programa de Residência tenha um currículo estabelecido e seguido, o qual deverá ser apresentado e discutido com os alunos, de modo que fiquem muito claros para eles quais são os objetivos a serem alcançados durante o processo de formação.

Um outro aspecto mencionado se refere à distribuição da carga horária do Programa de Residência em Medicina de Família e Comunidade, entre atividades na Unidade Básica de Saúde e em hospitais, quando apontam a existência de PRMFC que consomem $50 \%$ de sua carga horária, ou seja, todo o primeiro ano (R1), com atividades hospitalares.

Nessa concepção, tais Programas estão simplesmente promovendo a reprodução do modelo biomédico dentro da Unidade Básica de Saúde, e mais uma vez enfatizando a doença e não o doente, nem o ambiente em que ele vive e se relaciona. Por outro lado, deixam de ressaltar as ações de Atenção Primária à Saúde, distanciando o residente da compreensão de que uma equipe de Atenção Primária qualificada pode resolver de 85 a $90 \%$ dos problemas de saúde de uma comunidade.

Nesse sentido HARZHEIM (2009) afirma que:

"Para isto é fundamental que esta equipe atue tanto na promoção de saúde e prevenção de doenças, como também no atendimento de pessoas com doenças estabelecidas. 
Não é incomum encontrar equipes da Estratégia Saúde da Família que atuam como verdadeiros pronto-atendimentos, realizando consultas sem nenhuma ênfase sobre promoção de saúde e/ou prevenção" (HARZHEIM, 2009, p.2)

Deve-se ressaltar, entretanto, que a assistência médica curativa é componente importante das ações de atenção básica de saúde, e, portanto, não se nega a importância do atendimento médico a pessoas da comunidade que estejam doentes. E, além disso, deve ser enfatizado que a ocorrência de "verdadeiros pronto-atendimentos" não decorre apenas da formação e do interesse do profissional médico, mas é resultante de deficiências da própria oferta e estrutura dos serviços de saúde.

Como também afirma HARZHEIM (2009):

"Por outro lado, há equipes que crêem que seu trabalho é puramente de promoção e prevenção, deixando a atenção aos usuários doentes em segundo plano. Associado a isto, a dificuldade de acesso da população à equipe de Saúde da Família em caso de doença pode contribuir para falta de legitimidade da equipe frente à comunidade. $O$ equilíbrio adequado entre atividades promocionais, preventivas e curativas é variável, dependendo das necessidades em saúde de cada comunidade. Também depende das características de saúde e doença da população a necessidade de consultas com médicos especialistas focais, de atendimentos com outros profissionais da saúde, de procedimentos diagnósticos e terapêuticos e de internações hospitalares para que se obtenham bons resultados em saúde" (HARZHEIM, 2009, p.2-3) 


\section{Categoria II. Contribuição da Residência em Medicina de Família e Comunidade para a Prática do Médico de Família}

Conforme discutido exaustivamente ao longo desse estudo, a formação dos profissionais nos cursos de graduação da área da saúde tem demonstrado limitações quanto à sua formação básica, uma vez que a atual estrutura das Universidades ainda reproduz um modelo de trabalho na saúde que contempla atividades predominantemente curativas e reabilitadoras, não permitindo a integralidade da atenção. Essa realidade faz com que sejam necessários cursos de pós-graduação com capacitações especificas para os profissionais que desejam se inserir nos sistemas e serviços de saúde da rede pública, de modo a torná-los aptos a responderem às demandas de saúde da comunidade a que estão vinculados. Por isso, a Residência em Medicina de Família e Comunidade surge como uma proposta de formação do médico de família.

Assim, a análise das considerações feitas pelos profissionais, sujeitos da pesquisa, quanto à diferença existente entre os conhecimentos adquiridos na graduação e aqueles advindos do Programa de Residência denotam esta compreensão e possibilitam vislumbrar esta realidade. Ademais, nota-se, pelas declarações dos entrevistados, que a Universidade continua sendo uma instituição de ensino superior que usa a pedagogia de transmissão de conhecimento, basicamente de maneira verticalizada, e a organização do seu currículo por disciplinas negligencia o processo de 
ensino-aprendizagem e a interação do educador-educando, conforme expressam as falas.

"(...)com certeza, principalmente nas coisas próprias da Medicina de Família porque dentro da faculdade você aprende solto, você aprende solto a tratar um adulto, solto a tratar um idoso, solto a tratar uma criança, uma gestante, solto, mas sem integrar aquele conhecimento, sem ver que aquela gestante está inserida dentro de uma familia, que está dentro de uma comunidade, então isso me faltava para poder adequar" (RM1)

"(...) eu acho que essa que foi a principal diferença, da questão do procedimento que a gente tinha que executar, o atendimento do paciente, do cuidado, que eu não tive na faculdade, do cuidado longitudinal, de acompanhar o paciente um, dois anos, então, isso acrescentou bastante para mim, da Residência em relação à graduação" (RM2)

"Eu acho que são conhecimentos diferentes realmente, porque na faculdade você tem mais essa parte teórica, e você tem uma orientação mais para parte de tratamento mesmo. Na Medicina de Família você tem mais essa visão do paciente como um todo, de uma abordagem comunitária, familiar, de promoção e prevenção, e você vê mais a prática, você conhece a sua comunidade, então você está inserido dentro dela, você conhece os problemas da comunidade, você sabe que não adianta você passar uma receita e "tchau" paciente, se você não souber se realmente ele vai aderir, quais são os problemas que estão por trás daquela queixa, ele vai voltar para você. Então você tem que estar inserido no contexto da comunidade, no contexto familiar, para uma abordagem mais ampla desse paciente" (RM3)

“(...) na faculdade existem as aulas práticas, mas não é nada como estar na realidade, trabalhando num posto de saúde. A gente adquire aqui muito conhecimento prático mesmo, tanto de clínica como também de saúde da família, como fazer a prevenção, os métodos que a gente utiliza, os grupos, tudo isso a gente não vê muito na teoria, quando a gente está na faculdade, e mesmo quando eu passei no internato, pela Residência em Saúde da Família, como interna, o posto que eu estava nesse período não tinha grupos, esses grupos educativos que a gente desenvolve aqui no nosso posto e que na nossa realidade de faculdade 
a gente não vê isso, como é que desenvolve essas atividades educativas, é bem diferente." (RM4)

"Teve diferença, até porque você aprofunda mais, você vai com um olhar mais crítico quando você vai para a Residência. Você deixa de só de absorver. Quando você está na graduação tem muito essa idéia de só absorção, até pelo modelo de educação que a gente tem de só receber, ser receptivo. Na Residência você passa a ter um olhar mais reflexivo. É bem mais proveitoso para a formação (...)" (RM6)

Portanto, fica claro que, de acordo com a formação universitária vigente, a maioria dos profissionais que atuam no SUS ainda segue esse modelo curativista e fragmentado, e, consequentemente, na Estratégia Saúde da Família também, visto que apenas cerca de $6 \%$ dos médicos que trabalham nas equipes de saúde da família são especialistas em medicina de família e comunidade, enquanto que existem mais de 30 mil médicos atuando em Atenção Primária no Brasil (FALK, 2005; 2006).

Nesse sentido, HAQ et al. (1996) afirmam que:

"The quality of training for generalist physicians varies throughout the world. In many countries, generalist physicians are simply non-specialists, who receive limited to no training in the provision of primary care. Typically in these countries, medical students have little contact with ambulatory patients and limited instruction in primary care and prevention. As a result, these students fail to gain the skills necessary to function as competent family physicians. Today, individuals and organizations throughout the world are working to increase the relevance of medical education and practice. Physicians and policy makers have focused attention on training more primary care physicians to prove high-quality, cost-effective accessible, medical care" (HAQ et al, 1996, p. 352)

Desse modo, é premente a necessidade de mudanças significativas na gestão dos sistemas e serviços de saúde, nos processos de 
trabalho relacionados a essa área, como também na formação de recursos humanos demandados para estes serviços, sendo também historicamente reconhecida a forte resistência dos aparelhos formadores no sentido de mudarem as suas práticas educativas, que continuam formando profissionais que realimentam modelos assistenciais que não condizem com as atuais diretrizes dos SUS. Entretanto, isso não acontece apenas com o modelo de formação dos médicos, mas de todos os outros profissionais da saúde também (MORETO et al, 2008; SISSON, 2009).

Logo, é essencial investir na formação profissional que seja baseada e orientada para a comunidade e não se limite apenas a uma qualificação puramente técnica. Desse modo, um processo de formação para ser eficiente deverá considerar a importância da comunidade na definição de suas necessidades, uma vez que a atenção à saúde somente tem sentido quando responde às demandas dos usuários (SEVERINO, 2002).

Outro aspecto revelado pelas declarações dos entrevistados diz respeito à percepção deles quanto à contribuição do Programa de Residência em Medicina de Família e Comunidade para o aprendizado do trabalho em equipe. Os trechos abaixo conduzem à reflexão sobre a relação existente e necessidade do trabalho em equipe na Estratégia Saúde da Família.

(...) uma coisa que eu acho forte que a Residência me deu foi trabalhar em equipe, que eu não tinha na faculdade. A gente ia para aula, só os médicos, então a gente aprendia um pouco a trabalhar em equipe quando ia para o hospital, mas é uma equipe hospitalar, é diferente. Mas assim... de estar o dia-a-dia vivenciando uma equipe, estar com agente de saúde, estar com enfermeiro, estar com nutricionista conversando, discutindo, debatendo... Então isso a 
Residência realmente me trouxe, me acrescentou bastante (...) Eu acho que ela trás justamente a Equipe de Saúde da Família. Não tem como você estar trabalhando sozinho, porque se você estiver trabalhando sozinho, você não está fazendo Saúde da Família, você está fazendo uma outra coisa, às vezes meio "capenga". Então, a equipe te trás esse suporte. A Residência me ajudou bastante, porque ela me colocou frente a situações, que ocorrem no dia-a-dia e que você vai aprendendo a manejar, vai debatendo com a equipe. Então na hora que você conhece o dia-a-dia, que você está a frente daquele cotidiano, você vai na casa, vê a situação, você vê que o seu conhecimento, o seu raio de ação é limitado... aí você começa a sentir muito mais a necessidade do outro (...) Então eu acho que me sensibilizar, principalmente para a importância dos outros profissionais foi uma coisa importante da Residência para mim. (RM2)

"A medicina de família, ela basicamente por natureza, é um trabalho conjunto, você não trabalha sozinho, eu acho que é um grande diferencial até das outras especialidades médicas, porque como a gente conhece essas outras áreas e sabe que o nosso campo de ação é mais abrangente, a gente tem a ajuda de outros para estar contribuindo, eu acho que é o grande diferencial". (RM6)

"a gente faz a visita domiciliar junto com a nossa equipe de saúde da família e junto com a preceptora (...) não vai só o médico da equipe, vai o médico, a enfermeira, agente de saúde, o preceptor de Medicina de Família e a gente leva o NASF, que é o assistente social, que é o nutricionista, o terapeuta ocupacional, então a gente leva eles também para participar dessa visita, ela é multiprofissional, visando tentar melhorar aquela família, tentar diminuir a vulnerabilidade daquela família" (RM4)

Sem dúvida que um dos pilares da Estratégia Saúde da Família é o trabalho em equipe, e como afirma um dos entrevistados, atuar na Estratégia Saúde de Família não é um trabalho solitário; envolve a participação de várias categorias de profissionais, sendo, portanto multiprofissional e interdisciplinar, o que exige cooperação e complementaridade nas ações, requer discussão na tomada de decisão, que 
deve ser pactuada e a realização de planejamento constante, pressupondo responsabilidades mais compartilhadas entre os atores envolvidos.

Vale ressaltar, no entanto, que não é tarefa fácil estabelecer a harmonia e o diálogo diante de diferentes saberes e práticas entre os membros de uma equipe de saúde da família, e como afirmam FRANCISCHINI et al. (2008):

\begin{abstract}
"Reconhece-se a necessidade da conscientização da diversidade de conhecimentos e habilidades entre os membros da equipe e que é possível articular as ações desenvolvidas pelos diferentes profissionais no sentido de interagir entre si, ter compromisso ético, respeito com o outro e com a clientela, motivação, planejamento, responsabilidade, e, acima de tudo objetivos claros, possibilitando assim a construção de um projeto comum" (FRANCISCHINI et al., 2008, p. 28):
\end{abstract}

E acrescentam:

"O que leva a pensar que trabalhar em equipe é um desafio, onde cada membro desta deve estar consciente de que existe a necessidade de comunicação aberta, de uma prática democrática, que permita a cada integrante o exercício da prática individual, porém integrada, criativa e saudável, evitando assim a rotulação e deterioração das relações interpessoais. A conscientização dos membros pode se dar através de treinamento, mas é necessário garantir a educação permanente de todos os membros da equipe" (FRANCISCHINI et al., 2008, p. 28).

Portanto, a Residência em Medicina de Família e Comunidade desempenha um papel fundamental na capacitação dos médicos de família para o trabalho compartilhado com outros profissionais de saúde, ensinandoos a lidarem com a diversidade e a complexidade e a desenvolverem um 
espírito de equipe. Neste aspecto, existe um grande diferencial na atuação de um médico especialista em Medicina de Família e Comunidade dentro de uma equipe de saúde da família, em relação a outro profissional médico que não tenha essa capacitação específica.

Assim, na análise dos depoimentos dos entrevistados é possível verificar a percepção que eles têm de que a Residência em Medicina de Família e Comunidade é de fundamental importância para a formação dos profissionais que irão atuar nas equipes como médicos de família, conforme revelam as falas a seguir.

"(...) porque pôde me mostrar realmente o que era a Residência em Medicina de Família, e eu realmente confirmar o gosto que eu tinha por ela. (...) foi um Programa bom (...) é um Programa que está tentando melhorar e realmente formar um médico de família de qualidade" (RM1)

"(...) mas como [o curso de graduação] é um curso antigo, então a gente não tinha a prática na comunidade, a gente não praticava na comunidade, só tinha no hospital, a gente colocava a prática quando a gente ia no hospital, então era um público viciado, que já chegava com vários exames, com investigação complexas, geralmente eram doenças mais raras, então, por exemplo, no manejo de diabetes, de hipertensão, de doenças que são mais comuns a gente não tinha na graduação, de uma criança com pneumonia, de um idoso acamado e que foi isso o que a Residência me trouxe nessa minha vivência.(RM2)

"Eu acho o Programa muito importante, é essencial para o médico de saúde da família fazer uma Residência em Medicina de Família e Comunidade. Eu só queria deixar claro que a Residência em Medicina de Família é uma coisa muito válida. Se alguém me perguntar se vale a pena fazer, eu vou dizer que sim. Tanto é que eu estimulei já alguns colegas meus a fazer" (RM3) 
“(...) porque a gente sai da faculdade, apesar de hoje já ter uma visão mais ampliada do que é a saúde da família, mas a gente ainda sai muito 'verde', sem saber o que é a Medicina de Família. O que é que a gente faz? Qual é a proposta? A gente sai muito clínico, aquela visão clínica de tratar, de tratar, mas não tem aquela visão tão boa para a questão da prevenção. Então quando a gente faz a Residência abre muito essa visão. $E$ assim, facilita extremamente lidar depois no PSF" (RM4)

"E para fazer como é para ser, como é realmente a Medicina de Família, entender o que realmente ela é, só passando pela Residência para entender bem, ter uma visão mais ampliada, do que realmente é a saúde da família, e eu acho que seria interessante que todos os médicos que são do PSF, se eles tivessem a oportunidade de fazer a Residência, eu acho que seria interessante, a qualidade do serviço primário da rede pública iria melhorar bastante, não estou dizendo em termos quantitativos, eu digo em termos qualitativos, a gente ia poder ter uma resolutividade bem melhor" (RM4)

"Desde Cuba a gente aprende a Medicina de Família e Comunidade, desde o primeiro ano vai acompanhando, a gente tem essa matéria no currículo, e [a Residência] é uma coisa que eu achei interessante." (RM5)

"É importantíssimo, se a gente tivesse médicos de família na Estratégia, formados com Residência Médica na área, a gente teria uma Estratégia diferente. Eu digo porque a gente vê dentro da Estratégia Saúde da Família atualmente, cardiologistas, a gente vê intensivistas até, dentro da Estratégia, que aí quando chega uma coisa de criança encaminha, porque ali não era a área dele... 'E porque que eu vou ver?'... 'Passa' a criança. 'Não é para mim não!' Tem uns que até não atendem a determinados casos. Então, gente que eu conheço, que trabalha dentro da Estratégia (...) Eu acho que a gente teria, não só uma melhor Estratégia, mas também teríamos mais fixação do médico de família" (RM6)

Assim, diante dessas e de outras considerações que são apresentadas neste estudo, a partir da análise de trechos das entrevistas realizadas, pode-se perceber a relevância do Programa de Residência em Medicina de Familia e Comunidade para a formação do médico de família, 
que traduz em uma maior qualificação para a prática profissional.

Categoria III. Captação e Evasão da Residência em Medicina de Família e Comunidade: um dilema a ser enfrentado

A Residência Médica tem sido considerada como a melhor opção para formar médicos especialistas em todo Brasil, cuja conclusão Ihes dá o direito de exercerem sua especialidade, podendo divulgá-la amplamente. Assim, tão logo saem do curso de graduação, os profissionais buscam fazer uma Residência Médica, e se submetem a um processo seletivo, regulamentado pela Resolução CNRM N 008/2004, de 05 de agosto de 2004, que dispõe sobre o processo de seleção pública dos candidatos aos Programas de Residência Médica (CNRM, 2004b).

No Brasil, existem cerca de 2.600 programas de Residência Médica, oferecidos por 360 instituições, dentro das 53 especialidades reconhecidas no país; ao passo que estudo desenvolvido no Núcleo de Educação em Saúde Coletiva (NESCON), da Faculdade de Medicina, da Universidade Federal de Minas Gerais (UFMG) aponta que cerca de doze mil médicos se formam a cada ano nas universidades brasileiras (NESCON, 2010). Logo, a oferta de vagas para esses Programas é bem menor do que a quantidade de médicos que se forma a cada ano no país, tornando-as cada vez mais disputadas e provocando uma acirrada competição entre os 
recém-graduados, chegando ao ponto de existirem, inclusive, cursos de preparação para esta seleção.

Por isso, ao final do processo seletivo, em geral (pois em algumas especialidades há maior oferta do que procura), todas as vagas são preenchidas, ficando um número significativo de candidatos fora dos Programas de Residência. Todavia, isso não acontece com os Programas de Residência em Medicina de Família e Comunidade, cujas vagas nem sempre são preenchidas, e muitos dos que ingressam nesses Programas não completam o período de formação e o abandonam, condição observada em todo o país, inclusive no Estado do Ceará.

Portanto, essa tem sido uma grande preocupação no Brasil, posto que o sistema de saúde brasileiro necessita cada vez mais de médicos generalistas, resultando em uma situação inadmissivel, que se agrava pelo desinteresse dos acadêmicos e médicos recém-formados pelo estudo e prática generalista e pela atenção primária, sendo esta também uma situação preocupante nos países desenvolvidos.

DORSEY et al. (2003) analisando os resultados de uma pesquisa realizada nos Estados Unidos, verificaram um significativo decréscimo nas taxas de ocupação das vagas para os Programas de Residência em Medicina de Família, passando de 73\%, em 1996, para 47\%, em 2002. E, de acordo com GASPAR (2006), ainda nos Estados Unidos, os Programas de Residência que formam médicos generalistas têm ocupação de 50 a $60 \%$ das vagas ofertadas, e destas, $30 \%$ são abandonadas. Dentre os que concluem a Residência, $60 \%$ buscam outra especialidade, $21 \%$ referem que 
não voltariam a fazer esta especialidade, e 19\% afirmam que escolheriam outra profissão não médica.

As causas apresentadas para esse desinteresse dos médicos norte-americanos referem-se principalmente à remuneração e à sobrecarga de trabalho, diante do esforço adicional que se impõe para manter a integralidade do cuidado; se mostrando desproporcionais se comparadas à recompensa financeira obtida no trabalho na clínica centrada em procedimentos (MELLO et al., 2009).

Esses autores relatam ainda que na Inglaterra vem ocorrendo um crescente descontentamento entre os médicos de família ou general practitioners (GPs) daquele país, ao ponto de muitos deles pensarem em abandonar a prática generalista; enquanto que no Canadá verifica-se uma diminuição gradativa na preferência pela profissão de médico de família (MELLO et al., 2009).

Para enfrentar esse problema o governo brasileiro tem procurado formas de captação e incentivo aos profissionais médicos para atuarem na Estratégia Saúde da Família. Uma dessas iniciativas foi a instituição do Programa Nacional de Apoio à Formação de Médicos Especialistas em Áreas Estratégicas para o SUS (Pró-Residência), através da Portaria Interministerial $\mathrm{N}^{\circ} 1.001$, de 22 de outubro de 2009, que, segundo o Artigo $1^{\circ}$, da referida Portaria, tem como objetivo:

“(..) favorecer a formação de especialistas na modalidade residência médica em especialidades e regiões prioritárias, definidas, em edital próprio, observadas as demandas locais e regionais apresentadas pelos gestores do SUS, por meio de: a) Ampliação do número de vagas na modalidade Residência Médica e instituição de novos programas nos 
Hospitais Universitários Federais, Hospitais de Ensino, Secretarias Estaduais e Municipais de Saúde; b) Concessão de bolsas para educação pelo trabalho em saúde para apoiar Programas de Residência Médica (PRM); c) Cooperação técnica e apoio matricial por parte de instituições de reconhecida excelência e destaque na implementação de políticas públicas a Programas de Residência Médica (PRM) (...)" (BRASIL, 2009)

O Pró-Residência foi lançado pelos Ministérios da Saúde e Educação, com o apoio dos Conselhos dos Secretários Estaduais e Municipais de Saúde (CONASS e CONASEMS), com a meta de oferecer mil bolsas de estudo, em 2010, e outras mil, em 2011, para a formação na modalidade residência médica em especialidades e regiões prioritárias definidas pelos gestores do SUS.

Segundo o Ministério da Saúde, atualmente são oferecidas 1,7 mil vagas e, em 2011, esse número chegará a cerca de 3,7 mil, correspondendo ao aumento de $120 \%$ no número de vagas de ingresso nos programas federais. O programa receberá o investimento de $R \$ 24$ milhões, em 2010, e, $R \$ 48$ milhões, em 2011. A distribuição das bolsas será feita a partir da apresentação de propostas a dois editais lançados pela Secretaria de Gestão do Trabalho e da Educação em Saúde (SGTES/MS) e Secretaria de Educação Superior do MEC (SESu/MEC).

No entanto, as falas transcritas a seguir revelam uma outra compreensão acerca da bolsa de estudo como motivação dos profissionais na escolha desta especialidade, configurando-se inclusive como um fator que contribui para a evasão dos Programas de Residência em Medicina de Família e Comunidade. 
"Primeiro, porque o que o governo está fazendo é influenciar financeiramente as pessoas a fazerem a Residência em Medicina de Família e muita gente entra na Medicina de Família por causa desta bolsa e não por causa da Medicina de Família. A bolsa dos residentes que fazem Medicina de Família é praticamente o dobro da bolsa das outras Residências. E o dinheiro consegue sustentar a gente até certo ponto, depois o dinheiro não passa a ser mais o atrativo maior, você quer uma satisfação profissional, então eu acho que uma parte desiste por aî" (RM1)

“(...) Porque a bolsa da Medicina de Família ela tem um adicional, do Ministério da Saúde. (...) ela passa a ser mais cara, assim, passa a ser quase o dobro desse valor, três mil e seiscentos, diferente dos outros Programas, tem gente que vai pra lá por causa só da bolsa, fica um período... aí vai pensar." (RM6)

"Além também do problema das nossas bolsas, que infelizmente atrasa, é um problema que está melhorando esse ano, mas ano passado inclusive, nos passamos de dois meses sem receber absolutamente nada, ou seja, é difícil a pessoa que se formou se manter sem receber o seu salário, o que é justo, que é sua bolsa, que você está trabalhando para isso. Então, acaba que desestimula muitos residentes" (RM4)

O que se tem observado, no entanto, é o desinteresse dos profissionais médicos pelo trabalho na Atenção Primária à Saúde, e o conseqüente declínio da procura pela Medicina de Família e Comunidade, recaindo a escolha prioritariamente pelas subespecialidades clínicas e/ou cirurgicas, opção esta fortemente influenciada pelo poder da tecnologia e pelos desafios e exigências de uma sociedade em mudança, que se refletem na imagem da tecnologia e na perspectiva de maior prestígio em termos de cultura médica, sendo esta uma realidade que tem repercussões sobre as preferências profissionais dos atuais médicos, tanto assim que, nos Estados Unidos mais de $50 \%$ dos alunos de graduação em medicina não se 
interessam por disciplinas generalistas, e priorizam as especialidades

orientadas para os procedimentos técnicos, as quais apresentam melhor remuneração.

As colocações dos entrevistados, dispostas a seguir evidenciam, com transparência, essa discussão.

"Outra parte eu acho que desiste também porque o atrativo financeiro depois que você termina a Residência não é dos melhores, porque você faz uma Residência, ou seja, você se diferencia dos outros profissionais que não fazem, você se qualifica para trabalhar naquilo dali e a sua remuneração é igual a uma pessoa que nunca fez nenhuma Residência, nunca fez uma qualificação exata para trabalhar naquilo dali. E mesmo assim ainda é baixa se você for comparar com os outros. Porque dentro da Medicina de Família você não tem como ter outro emprego, se eu trabalho em hospital, eu tenho como ter um emprego de manhã e de tarde eu tenho consultório, mas na Medicina de Família são 40 horas, então você não tem como ter um consultório, como ter outra coisa, você é médico de família em tempo integral, então era para aquele salário suprir, ser pelo menos equiparado ao salário de outras pessoas que podem fazer duas coisas ao mesmo tempo. Quando na verdade o que a gente vê na prática é que o salário de um médico de família é igual ao salário de uma pessoa que trabalha num hospital 20 horas" (RM1)

"Eu atribuo ao mercado de trabalho, e eu acho que o mercado de trabalho não the diferencia, mesmo que seja para o PSF, tanto faz você ter uma Residência ou não. É diferente, se você é um cirurgião, se você tem um grau a mais, se for fazer um concurso, tem que ter cirurgia. Para fazer para estratégia em saúde da família, você não precisa ser médico de família, você pode ser qualquer coisa, o fato de você fazer uma Residência em Medicina de Família vai Ihe acrescentar no lado pessoal. Então para que fazer a Residência se aquilo ali não vai, talvez lhe trazer benefício no mercado de trabalho que uma outra Residência traria? Então o pessoal, às vezes, mesmo com vocação, como eu conheço vários que dizem: ah, eu gosto de medicina de família, mas e aí? Eu vou trabalhar, qual é a perspectiva? Vou ficar trabalhando a vida toda no Programa Saúde da Família? Eu não vou ser reconhecida, vou receber a mesma remuneração do colega que não é especialista, 
então, eu acho que é o reconhecimento mesmo da especialidade, é o campo de trabalho." (RM2)

"Eu acho que é porque quando a pessoa se propõe a fazer uma Residência de Clínica, Otorrino, Pediatria, ela precisa daquela Residência. Clínica não, mas serve como prérequisito. E ela precisa daquela Residência para exercer aquela especialidade. A Medicina de Família já não, você pode ser médico de família ser ter feito Residência em Medicina de Família. Você pode fazer uma especialização, você pode ter experiência, trabalhar como médico de família, apesar de não ter a especialização e depois prestar a prova de título. Em outras especialidades você até também pode fazer, mas é mais difícil, a pessoa geralmente, até mesmo pelo aprendizado, geralmente a pessoa faz a Residência Médica, é mais reconhecido também. A Medicina de Família como é uma especialidade nova, talvez o pessoal não tenha ainda entendido a real importância de você ter a Residência, até mesmo porque são oferecidas vagas para médico de família e nenhuma exige que a pessoa tenha a Residência em Medicina de Família" (RM3)

Esse tem sido um dos problemas apontados na literatura que trata

das causas da não procura pelos Programas de Medicina de Família e Comunidade ou da evasão deles. MELLO et al. (2009) apontam também esse razão, quando explicam que:

"Um dos motivos da baixa escolha da residência em MFC no Brasil é o fato de não ser necessária uma formação específica para atuar na especialidade, cujo principal cenário de trabalho se encontra na Estratégia de Saúde da Família" (MELLO et al., 2009, p. 467)

Entretanto, vale ressaltar que a opção que os médicos recémformados fazem por determinadas especialidades médicas tem sido objeto de estudo em diversos países, nos quais se verifica sempre o mesmo fenômeno, a escolha invariavelmente recai sobre os Programas de Residência Médica que oferecem especialidades mais complexas e são mais atrativas financeiramente. 
Portanto, diante de todas essas argumentações acerca da influência das questões financeiras na escolha da especialidade de medicina de família e comunidade, considera-se necessário que o governo procure não apenas incentivar o médico a entrar no Programa de Residência mediante o pagamento de uma bolsa de estudos atrativa financeiramente, percebe-se que isso não garante a sua permanência no Programa, tampouco na Estratégia Saúde da Família, e o investimento feito nesse residente seria inútil, já que o profissional poderá permanecer no Programa por certo período de tempo e depois sair para uma outra Residência ou se incorporar ao mercado de trabalho em outra especialidade. Aliás, esta é uma situação vivenciada no país que, apesar de bastante discutida ainda permanece sem alteração, pois os Programas de Residência Médica da rede pública do Sistema Único de Saúde ofertam bolsas de estudos para os residentes de todas as especialidades, financiadas pelo governo federal, no entanto, não há uma correlação destas com a necessidade de especialistas requerida pelo sistema de saúde, assim, muito desses profissionais têm sua formação financiada pelo setor público para exercerem suas atividades no setor privado, enquanto que o SUS continua com suas demandas não atendidas.

Portanto, faz-se necessário então, criar estratégias para a manutenção dos profissionais que ingressam nos Programas de Residência em Medicina de Familia e Comunidade e sua posterior inserção na Estratégia Saúde da Família, envolvendo aspectos relacionados ao próprio Programa de Residência Médica e a valoração da Atenção Primária à Saúde como área de atuação do profissional m. 
$\mathrm{Na}$ percepção de um entrevistado a carga horária de 60 horas de trabalho semanais seria um fator que dificulta a permanência do residente no Programa, de acordo com a fala seguinte.

A carga horária. A carga horária é maior, é diferente. Você estar só trabalhando, você atende mais rápido, você acaba terminando mais cedo, você tem mais tempo de fazer outras atividades, outros empregos. Então a carga horária eu acho que é um fator bem importante. $O$ fato de você ser residente, você ganhar menos do que se você estivesse trabalhando sem ser residente (...) Eu passei a trabalhar 60 horas, na verdade um trabalho-estudo. E aumentou a carga horária, mas para mim eu achava que compensava pelo aprendizado, mas muitas pessoas preferiam usar esse outro tempo das atividades da Residência em outros empregos, para ganhar mais. Então a carga horária, o fato da pessoa ter que correr atrás para sustentar a familia, essas coisas, porque você estando na Residência, você tem que se dedicar, você tem que estudar, você tem que preparar os casos clínicos, então isso é o que dificulta muitas vezes as pessoas a fazerem Residência, elas têm que correr atrás para ganhar dinheiro, por motivos diversos. (RM3)

Percebe-se nessa fala do entrevistado que a causa apresentada, em última análise, está ligada também a fatores financeiros, e certamente essa é uma grande preocupação dos profissionais nesse momento de suas vidas, os quais estão saindo da graduação e ingressando em um Programa de Residência, pois como foi relatado anteriormente, para muitos deles representa a entrada no mercado profissional, configurando-se como o primeiro emprego de suas vidas, muito embora tenham compromissos financeiros diferentes. Porém, no que se refere à carga horária dos Programas de Residência, esta é regulamentada pela Lei $N^{\circ} 6.932$, de 07 de julho de 1981, sendo igual para todas as especialidades médicas.

Além disso, os entrevistados expressaram pelas suas falas outras percepções acerca da evasão dos residentes, sendo estas mais relacionadas 
a problemas locais de estruturação dos Programas de Residência, como falta de infra-estrutura das Unidades de Saúde e ausência de preceptor para acompanhá-los, conforme pode ser observado nos trechos a seguir.

“(...) por causa desses problemas da Residência, (...) que aí, termina você tentando nadar contra a maré, você vai querendo que a Residência vá para frente, e a Residência às vezes não vai, que foi o que aconteceu comigo que quase desisti da Medicina de Familia (...) que inclusive aconteceu com minha turma... uma parte desistiu (...) (RM1)

"Primeiro, a falta de condições, de estrutura nos Postos. Segundo, às vezes a falta de um preceptor, às vezes você está ali numa Unidade e o preceptor está de licença e não tem um substituto, então você se sente só, e aí acaba não aprendendo como era para aprender, porque você está ali também com uma necessidade de aprender, de uma ajuda também para aprender teoria também, prática clínica e teoria" (RM4)

Estas dificuldades certamente eram mais contundentes no início da implantação dos Programas, principalmente com relação à presença do preceptor, uma vez que com a conclusão das turmas, novos preceptores foram formados, como pode ser observado na fala seguinte.

“(...) vários residentes, que foram ex-residentes dessa turma, passaram a ser preceptores" (RM3)

A incorporação desses especialistas no próprio Programa de Residência que os formou tem sido a maneira encontrada para garantir o fortalecimento desses Programas. Isso se verifica em Programas de Residência em Medicina de Família e Comunidade de outros Estados da federação, sendo que os egressos ou passam a compor equipes de 
coordenação e preceptoria ou vão criar novos Programas.

Quanto às dificuldades referentes à falta de infra-estrutura das Unidades de Saúde, realmente ainda continuam sendo grandes obstáculos, e essa questão leva à reflexão acerca da coerência defendida por TESTA (1992) e já discutida anteriormente, de que se deve dispor de estruturas coerentes com os propósitos estabelecidos.

Além do mais, os profissionais ao desenvolverem suas atividades de treinamento em serviço nessas Unidades de Saúde, sabem de antemão que serão estruturas semelhantes a essas que se constituirão seus postos de trabalho futuros, caso resolvam continuam na Estratégia Saúde da Família, e, isso certamente não será um fator motivador para tal opção.

Nesse sentido, CAMPOS e MALIK (2008) tratando sobre a questão da rotatividade dos profissionais no PSF afirmam que:

"Sobre as condições de trabalho, considera-se que a sobrecarga de trabalho das equipes de saúde da família, as dificuldades estruturais, como falta de medicamentos, materiais e retaguarda de outros níveis de atenção, além da insegurança gerada pela falta de capacitação dos profissionais para exercer a prática de generalista, levariam à alta rotatividade dos médicos" (CAMPOS e MALIK, 2008, p. 350).

Aliado a isso, pode-se perceber nos discursos dos profissionais entrevistados a percepção de situações de estresse e de desestímulo com o trabalho realizado diante das dificuldades enfrentadas.

(...) e você enfrenta muitas vezes muito mais problemas, porque você está falando de pessoas que não têm 
condições, você está indo dentro da casa daquele paciente, você está trabalhando com pessoas que, às vezes, não têm condições de comprar uma medicação, então se torna uma coisa muito mais frustrante para você (...) e você recebendo um salário igual a uma pessoa que está trabalhando 20 horas, num ambiente teoricamente, totalmente seguro e bom, como num consultório (...) Então eu acho que são fatores... que você pode desistir (...) (RM1)

(...) a gente quando chega na realidade são muitas as dificuldades que desestimulam, desestimulam mesmo, eu não tenho mais o mesmo estímulo de quando eu era R1, porque a gente vai passando por tantas coisas, tanta dificuldade, (...) às vezes eu fico um pouco desestimulada, com vontade de que acabe rápido, (...) tem momentos que em relação à própria comunidade a gente se desespera, porque é tanta dificuldade econômica, social, é tanto problema, tanto uso de drogas, que a gente fica assim, meu Deus o que é que eu posso fazer, me ajude, eu tenho horas que eu fico com vontade de chorar, chega um paciente chorando eu vou chorar junto, tem momentos que você fica em desespero sem saber como agir para tentar melhorar aquela situação daquela pessoa, daquela família, e assim, nesses momentos eu tenho vontade que acabe rápido, para tentar lidar menos com isso, mas assim, são altos e baixos, que tem durante a Residência, momentos que a gente está mais feliz, mais estimulado, tem outros que não, a dificuldade prevalece e a gente fica com vontade que acabe logo (...) (RM4).

Estudos acerca da satisfação no trabalho também são relatados

na literatura como fatores que influenciam a permanência de profissionais

em suas funções. CAMPOS e MALIK (2008) discutindo sobre essa questão

ponderam que:

"Muitos fatores tentam explicar por que os profissionais permanecem numa organização ou a deixam, mas a satisfação no trabalho talvez seja um dos fatores mais pesquisados em sua correlação com a rotatividade. A literatura considera que o principal fator que leva um funcionário a deixar uma organização é seu nível de insatisfação com a função que desempenha. $O$ descontentamento pode ser causado por qualquer um dos muitos aspectos que compõem o trabalho. A existência da correlação negativa entre satisfação no trabalho e 
rotatividade foi largamente estudada" (CAMPOS e MALIK, 2008, p. 352-53).

Ademais, os profissionais entrevistados evidenciaram a percepção de preconceitos por serem médicos de família, conforme as falas transcritas a seguir.

"ontem eu estava na UNIMED, eu fui ver o prontuário de uma colega minha que foi acidentada e aí a primeira coisa, sempre a mesma coisa: 'Qual é a sua especialidade?' E eu: 'médica de família.' 'Não, qual a SUA especialidade?' 'Sou médica de família, fiz Residência em Medicina de Família.' Então, sempre tem: 'Mas o que é isso?' Até porque é uma coisa nova, mas eu noto que ainda existe um preconceito em relação à especialidade, de ser médico de família, parece que é uma coisa meio de pobre para pobre, é médico de pobre. 'Você fez essa Residência pra atender pobre, o que é que você está fazendo aqui?' Porque a gente não tem ainda essa vivência do que é, porque a gente não tem campo, a gente não conquistou ainda os campos de trabalho na sociedade, que eu acho que a especialidade merece. Eu acho que é por conta disso que o pessoal acaba saindo logo, não se sente valorizado" (RM2)

Existe certo preconceito em relação à Medicina de Família, até mesmo da população em geral. Perguntam: 'Ah, você é médico de quê?' 'Ah, eu sou médico de família.' 'Mas sim, mas qual é a sua especialidade?' Mas, em relação às outras pessoas eu acho que também, porque queira ou não queira, a Medicina de Família ainda, porque ainda tem muito a crescer, é uma especialidade nova, mas ainda é muito voltada ao serviço público. Agora que os planos de saúde, que o serviço privado está começando a absorver esses profissionais. Então eu acho que é muito ligado ao preconceito mesmo da remuneração (...) Acho que é desconhecimento também da especialidade, ainda tem muito aquela coisa, agora mudou, os currículos da faculdade mudaram, da faculdade de Medicina, mas antes você tinha aquele currículo que era baseado em especialidades médicas mesmo." (RM3)

“(...) às vezes a gente escuta: 'o que é que faz um médico de família?' 'Vá ler, vá ler, que eu li, já fiz minha Residência, 
e agora você vai ler, para ser uma pessoa antenada no mundo.' Eu não me importo, tem gente que diz: 'Ah, você vai dizer que é o quê? Médica de família?' 'Sou, se for ao meu consultório tem lá na parede do meu consultório: Medicina de Família, eu faço consultório médico.' (...) existem propostas para os convênios de saúde, o problema é que ainda não entenderam, aí vão ler a respeito um dia $e$ vão saber que é importante." (RM6)

Desse modo, o panorama que envolve a permanência dos profissionais no Programa de Residência em Medicina de Família e Comunidade e após a conclusão, na Estratégia Saúde da Família apresenta complexos desafios que precisam ser enfrentados, definido estratégias de enfrentamentos desses problemas, sob o risco de o Programa passar a representar apenas um período de transição, pelo qual o profissional fica recebendo uma bolsa de estudos diferenciada e se preparando para ingressar em outro Programa de Residência. 


\section{CONCLUSÕES}

Os resultados deste estudo fornecem importantes subsídios para a análise dos Programas de Residência para formação do médico de família no Estado do Ceará, permitindo concluir, em uma visão mais abrangente, que:

- A formação dos profissionais de saúde, no caso em estudo, o médico, ainda é uma das problemáticas centrais para a consolidação da Estratégia Saúde da Família no Estado do Ceará.

- Apesar do esforço governamental no sentido de provocar mudanças nos aparelhos formadores, inclusive estabelecendo as Diretrizes Curriculares Nacionais para o Curso de Graduação em Medicina, os profissionais formados pelas Universidades, no âmbito da graduação e pósgraduação continuam sendo preparados para atuarem no modelo convencional, baseado nas especialidades, no ensino fragmentado e voltado para as doenças. Logo, é imprescindível que as escolas médicas estabeleçam as mudanças necessárias para fazer face à crescente demanda de capacitação desses profissionais, formando-os na lógica da atenção integral em saúde.

- Para trabalhar na Estratégia Saúde da Família o médico "deve ser" especialista em Medicina de Família e Comunidade, e não "preferencialmente generalista"; e, enquanto essa condição não for alcançada, deve existir um diferencial para os médicos que atuam na Estratégia e são especialistas em Medicina de Família e Comunidade, a fim 
de estimular a busca por essa formação específica e a manutenção desse profissional nas equipes de saúde da família; uma vez que isso representa condição essencial para garantir a implementação e o fortalecimento das atuais diretrizes da Atenção Básica e da Saúde da Família, não apenas no Estado do Ceará, mas em todo o país.

- O Programa de Residência em Medicina de Família e Comunidade é a modalidade de ensino de excelência para capacitação profissional e preparação do médico de família para atuar na Estratégia Saúde da Família, dada a sua condição de treinamento em serviço junto à comunidade, preenchendo as lacunas de conhecimentos oriundas da graduação. No entanto, dada a grande demanda apresentada pelo sistema de saúde faz-se necessário investir também em outras modalidades de formação. Além disso, deve-se estimular a criação e ampliação de PRMFC, a fim de melhorar o processo de formação desses especialistas.

Quanto às especificidades relativas aos Programas de Residência para formação do médico de família no Estado do Ceará, pode-se inferir que se trata de um processo em franca efetivação, sendo possível observar seus avanços, no entanto, verificam-se também elementos que ainda impedem a sua efetivação, aos quais se deve dar ênfase, mediante a utilização de estratégias de desenvolvimento de aspectos como: organização do Programa, em especial no que se refere à estruturação das Unidades de Saúde, adequação dos conteúdos aos objetivos de aprendizagem, capacitação da preceptoria e aderência dos residentes ao Programa, tendo no entanto, a convicção que é possível melhorar, pois nada do que foi 
detectado aqui se reveste em obstáculo intransponível.

- A criação de Programas de Residência para formação do médico de família no Ceará é bastante recente e sua execução ainda enfrenta alguns obstáculos devido ao processo de ajustes necessários até a sua consolidação. Nesse caso faz-se necessário seguir um processo de avaliação contínuo, como também uma revisão anual dos projetos desses Programas, a fim de observá-los à luz das experiências acumuladas durante os anos já decorridos.

- O desenho dos currículos dos Programas de Residência em Medicina de Família e Comunidade analisados reflete a tentativa de levar os profissionais a desenvolverem as competências necessárias ao desempenho do médico de família. No entanto, a execução destes Programas ainda não traduz efetivamente os propósitos estabelecidos nos seus currículos. Estes também devem ser avaliados sistematicamente para detectar os possíveis entraves à sua implementação. Percebe-se a necessidade do envolvimento dos residentes (atuais e potenciais alunos) durante o processo de elaboração do currículo destes Programas, como forma de torná-los mais participantes desse processo, despertando-lhes o interesse pelo seu aprendizado.

- Esses Programas de Residência propunham-se a utilizar metodologias ativas de ensino-aprendizagem, como PBL e Problematização. Entretanto, as estratégias educacionais empregadas reproduzem práticas educativas tradicionais, principalmente com a realização de aulas expositivas, nas quais os temas são abordados, sem uma participação 
efetiva dos residentes no processo de construção do conhecimento. Observa-se a necessidade de uma verdadeira mudança conceitual na prática docente, devendo, portanto, haver um programa de desenvolvimento dos docentes, para que estes possam ser capacitados na correta condução dos procedimentos metodológicos condizentes com a metodologia adotada pelo Programa de Residência.

- É significativa a não adesão dos profissionais aos Programas de Residência em Medicina de Família e Comunidade. Verifica-se que o esforço em captar os profissionais para o Programa não tem alcançado os resultados esperados. Percebe-se também que a falta de interesse dos profissionais por estes Programas decorre não apenas em virtude dos problemas locais, como falta de infra-estrutura nas Unidades de Saúde, capacitação da preceptoria, dentre outros; mas principalmente pelo fato de que o mercado de trabalho atual que se apresenta para esses profissionais, a estratégia Saúde da Família, não conseguiu estruturar a Atenção Primária no país até o momento; não conseguiu também apresentar uma proposta consistente de reconhecimento e de valorização dos profissionais que fizerem a opção para trabalhar na Saúde da Família, gerando muitas incertezas e instabilidades, pois não há uma legitimação dessa estratégia, uma vez que não se apresenta como um programa regular e estruturado. Portanto, trata-se de um problema macro, de reestruturação da própria estratégia da Saúde da Família, a fim de oferecer condições de trabalho adequadas, tanto do ponto de vista de infra-estrutura, como uma reformulação nas suas propostas de fixação dos médicos de família; caso 
contrário não se tornará atrativo para os profissionais fazer Residência em Medicina de Família e Comunidade.

Vale ressaltar que neste estudo a pesquisadora, que milita em defesa do SUS desde que esse foi criado, não teve a intenção de simplesmente apontar falhas e defeitos dos Programas de Residência analisados, longe disso, buscou sim, fazer um diagnóstico preciso da situação atual, para identificar os nós críticos que ainda têm impedido o pleno funcionamento de iniciativas tão necessárias à consolidação da Estratégia Saúde da Família; por acreditar ser essa a melhor altemativa para promover uma atenção humanizada e de qualidade, que atenda as necessidades de saúde da população. Considera ainda que, como diz a sabedoria divina, "Onde não há conselho fracassam os projetos, mas com os muitos conselheiros há bom êxito"*. Portanto, outros olhares podem trazer novas contribuições, somar esforços, para a melhoria desses Programas, concorrendo assim, para o seu aprimoramento.

\footnotetext{
"Bíblia Sagrada, Provérbios 15:22.
} 


\section{REFERÊNCIAS}

ALMEIDA, L. P. G. de; FERRAZ, C. A. Políticas de formação de recursos humanos em saúde e enfermagem. Revista Brasileira de Enfermagem. $v$. 61, n.1, p. 31-35, jan/fev. 2008.

ALMEIDA, H. G. G. de; FERREIRA FILHO, O. F. Educação permanente de docentes: análise crítica de experiências não sistematizadas. Revista Brasileira de Educação Médica, Rio de Janeiro, v. 32, n. 2, p. 240-247, jun. 2008.

ALMEIDA, M. J. de. Ordenação pelo SUS da formação de recursos humanos em saúde: contribuição da Rede UNIIDA para a regulamentação do inciso III, artigo 200 da Constituição Federal, Divulgação em Saúde para Debate, $n$. 12, p. 34-35, jul.1996.

ALVES, A. A. Residência médica - 60 anos: um pouco da história. In: Conselho Regional de Medicina do Estado do Rio de Janeiro. Manual do médico residente. $2^{\mathrm{a}}$ ed. rev. ampl. Rio de Janeiro: CREMERJ, 2007.

AMARAL, J. L. do. Recursos humanos para o SUS: opção pela articulação entre os profissionais de saúde, docente e discente, usuários e gestores, a CINAEM, os projetos UNI, os Conselhos de Saúde, a sociedade civil, Divulgação em Saúde para Debate, n. 12, p. 56-59, jul.1996.

AMES, E. E.; TRUCANO, L. A.; WAN, J. C.; HARRIS, M. H. Designing school health curricula: planning for good health, 2 ed. Dubuque: WCB. 1995. 241p.

ANDERSON, M. I. P.; RODRIGUES, R. D. Formação em medicina de família e comunidade. Cadernos ABEM. v. 4, p. 30-37, out. 2008.

ANDRADE, L. O. M.; BARRETO, I. C. H. C.; MARTINS, T.; AMARAL, M. I. V.; PARREIRAS, P. C. Escola de Formação em Saúde da Família Visconde de Sabóia: Três Anos Construindo a Tenda Invertida e a Educação Permanente no SUS. SANARE, ano V, n.1, p. 33-39, jan-fev-mar. 2004.

BARDIN, L. Análise de conteúdo. Lisboa: Edições 70. 1977. 226p.

BATISTA, N.; BATISTA, S. H.; GOLDENBERG, P.; SEIFFERT, O.; 
SONZOGNO, C. O enfoque problematizador na formação de profissionais de saúde. Revista de Saúde Pública. v. 39, n. 2, p.231-237. abr. 2005.

BATTEN, C.; TRAFFORD, V. Evaluation: an aid to institutional management. In: LOCKWOOD, G.; DAVIES, J. Universities: the management challenge, p. 285-310, Worcester: Billing \& Sons Ltd., 1985.

BELACIANO, M. I. O SUS deve aceitar este desafio: elaborar proposições para a formação e capacitação de recursos humanos em saúde, Divulgação em Saúde para Debate, n. 12, p. 29-33, jul. 1996.

BERBEL, N. A. N. A problematização e a aprendizagem baseada em problemas: diferentes termos ou diferentes caminhos? Interface Comunicação, Saúde, Educação. v. 2, n. 2, p. 139-154, fev. 1998.

BESSA, O.; PENAFORTE, J. (org.) Médico de família: formação, certificação e educação continuada. Conferências do Seminário internacional sobre saúde da família. Fortaleza: Escola de Saúde Pública do Ceará, 2002, 166p.

BLAISTEIN, N. M. La evaluacion en las residencias medicas municipales: clinica pediatrica del hospital Pedro de Elizalde, Educación Médica y Salud, OPAS/OMS, v. 27, n. 3, p. 376-399, julio/septiembre, 1993.

BLASCO, P. G. Medicina de família: ciência e arte com metodologia acadêmica. out. 2009. Disponível em:

http://www.pablogonzalezblasco.com.br/2009/10/30/medicina-de-familiaciencia-e-arte-com-metodologia-academical. Acesso em: 19 fev. 2010.

BLASCO, P. G.; LEVITES, M. R.; JANAUDIS, M. A.; MORETO, G.; RONCOLETTA, A. F. T.; BENEDETTO, M. A. C. De.; PINHEIRO, T. R. Family medicine education in brazil: challenges, opportunities, and innovations. Academic Medicine, v. 83, n. 7. p. 684-690, july. 2008.

BLOCH, C. Os profissionais de saúde: ampliando o campo de estudo, In: NUNES E D (Org.) As ciências sociais em saúde na América Latina: tendências e perspectivas, Brasília: OPAS, p. 307-319, 1985.

BOELEN, C. Medical education reform: the need for global action. Academic Medicine, v. 67, n. 11. p. 745-774. nov. 1992.

BÓGUS, C. M.; WESTPHAL, M. F.; FERNANDES, E. M.; POSSA, S. A reforma sanitária e os recursos humanos dos serviços locais de saúde: o caso de Vargem Grande Paulista, Educación Médica y Salud, OPAS/OMS, v. 29, n. 1, p. 20-31, enero/marzo, 1995. 
BOTTI, S. H. de O.; REGO, S. Processo ensino-aprendizagem na residência médica. Revista Brasileira de Educação Médica. v. 34, n. 1, p. 132-140; 2010.

BRASIL. Decreto $n^{\circ} 80.281$, de 05 de setembro de 1977, que regulamenta a Residência Médica, cria a Comissão Nacional de Residência Médica e dá outras providências. Diário Oficial da União, Brasília, DF, 06 set 1977. Seção 1, p. 11787.1977.

BRASIL. Constituição (1988). Constituição da República Federativa do Brasil, Brasília, DF: Senado, 1988.

BRASIL. Ministério da Saúde. Secretaria de Assistência à Saúde. Saúde da Familia: uma estratégia para a reorientação do modelo assistencial. Brasília, 1998.

BRASIL. Decreto $n^{\circ} 3.745$, de 5 de fevereiro de 2001, que institui o Programa de Interiorização do Trabalho em Saúde. Diário Oficial da União, Brasília, DF, 06 fev 2001. Seção 1, p. 2. 2001.

BRASIL. Ministério da Saúde. Portaria № 198, de 13 de fevereiro de 2004, que institui a Política Nacional de Educação Permanente em Saúde como estratégia do Sistema Único de Saúde para a formação e o desenvolvimento de trabalhadores para o setor e dá outras providências. Diário Oficial da União, Brasília, DF, nº 32/2004, Seção I. 2004a.

BRASIL. Ministério da Saúde. Política de educação e desenvolvimento para o SUS: caminhos para a educação permanente em saúde, Secretaria de Gestão do Trabalho e da Educação na Saúde. Departamento de Gestão da Educação na Saúde. Série C. Projetos, programas e relatórios, Brasília, 2004b.

BRASIL. Ministério da Saúde. Portaria No 1.143/GM, de 7 de julho de 2005, dispõe sobre o apoio aos Programas de Residência Médica em Medicina de Família e Comunidade por meio do Programa de Bolsas para a Educação pelo Trabalho. Diário Oficial da União, Brasília, DF, N 130, 08 jul 2005, Seção 1, p.30. 2005.

BRASIL. Ministério da Saúde. Saúde da família no Brasil: uma análise de indicadores selecionados: 1998-2005/2006 / Secretaria de Atenção à Saúde, Departamento de Atenção Básica. Brasília: Ministério da Saúde, 2008. 200p. (Série C. Projetos, Programas e Relatórios).

BRASIL. MEC / MS. Ministério da Educação. Ministério da Saúde. Portaria 
Interministerial $\mathrm{N}^{\circ} 1.001$, de 22 de outubro de 2009, que institui o Programa Nacional de Apoio à Formação de Médicos Especialistas em Áreas Estratégicas para o SUS (Pró-Residência), Diário Oficial da União, Brasília, DF, N ${ }^{\circ} 203,23$ out 2009.

BRASIL. Sistema de Informação da Atenção Básica (SIAB) e do Sistema de Cadastro Nacional de Estabelecimento em Saúde (SCNES). 2010a.

BRASIL. Ministério da Saúde. Manual operacional da fase 2 do projeto de expansão e consolidação da saúde da família PROESF. 2010-2013. Disponível em: http://dab.saude.gov.br/proesf/mo/mo_proesf_volume01.pdf. Acesso em: 19 fev. 2010. 2010b.

CAMPOS, C. V. de A.; MALIK, A. M. Satisfação no trabalho e rotatividade dos médicos do Programa de Saúde da Família. Revista de Administração Pública: Rio de Janeiro. v. 42, n. 2, p. 347-368, mar./abr. 2008.

CAMPOS, F. E. de.; AGUIAR, R. A. T. de. A expansão da atenção básica nas grandes cidades e a especialização em saúde da família como estratégia para sua viabilidade. In: Cadernos RH Saúde / Ministério da Saúde, Secretaria de Gestão do Trabalho e da Educação na Saúde. v. 3, n. 1 (mar. 2006) -. Brasília: Ministério da Saúde, 2006.188p.

CAMPOS, F. E. de.; GIRARDI, S. N. Caracterização dos programas de residência de medicina preventiva e social no Brasil, In: Ensino da saúde pública, medicina preventiva e social no Brasil, Rio de Janeiro: Abrasco, p. 41-57, jun. 1984.

CANUTO, A. M. M.; BATISTA, S. H. S. da S. Concepções do processo ensino-aprendizagem: um estudo com professores de medicina. Revista Brasileira de Educação Médica. v. 33, n. 4, Rio de Janeiro. out./dez. 2009.

CARAPINHEIRO, G. Saberes e poderes no hospital: uma sociologia dos serviços hospitalares. $2^{\mathrm{a}}$ ed. Porto-Portugal: Afrontamento, 1993.

CASE, S. M.; SWANSON, D. B. Constructing written test questions for the basic and clinical sciences, Philadelphia: National Board of Medical Examiners - NBME, 115p., 1996

CASTRO, V. S. de; NÓBREGA-THERRIEN, S. M. Residência de medicina de família e comunidade: uma estratégia de qualificação. Revista Brasileira de Educação Médica. Rio de Janeiro. v. 33. n. 2. p. 211-220; 2009.

CECCIM, R. B.; FEUERWERKER, L. C. M. O quadrilátero da formação para a 
área da saúde: ensino, gestão, atenção e controle social. PHYSIS: Revista de Saúde Coletiva, Rio de Janeiro, v. 14, n. 1. p. 41- 65, 2004.

CFM - Conselho Federal de Medicina. Resolução CFM No 1.232/86, de 11 de outubro de 1986, que reconhece a Medicina Geral Comunitária como especialidade médica para efeito de registro de qualificação de especialistas nos Conselhos de Medicina. 1986.

CFM - Conselho Federal de Medicina. Resolução CFM no 1.634/2002, de 11 de abril de 2002, que dispõe sobre convênio de reconhecimento de especialidades médicas firmado entre o Conselho Federal de Medicina (CFM), a Associação Médica Brasileira (AMB) e a Comissão Nacional de Residência Médica (CNRM). Diário Oficial da União, Brasília, DF, 29 abr 2002, seção I, p. 81. 2002.

CHIAVENATO, I. Recursos humanos, São Paulo: Atlas, 4ª Ed., 1997.

CHRISTÓFARO, M. A. A organização do sistema educacional brasileiro e a formação na área da saúde. In: SANTANA, J. P.; CASTRO, J. C. (orgs.). Capacitação em desenvolvimento de Recursos Humanos de Saúde CADRHU. Brasília (DF): Ministério da Saúde/ OPAS; 1999.

CIAMPO, L. A. del.; RICCO, R. G.; DANELUZZI, J. C. Residência médica em medicina geral e comunitária. Proposta de um programa de formação de médicos generalistas. Revista Brasileira de Educação Médica: Rio de Janeiro. v. 27, n. 3, set/dez. 2003.

CNE. Conselho Nacional de Educação. Câmara de Educação Superior. Resolução CNE/CES N ${ }^{\circ} 4$, de 7 de novembro de 2001, que institui Diretrizes Curriculares Nacionais do Curso de Graduação em Medicina. Diário Oficial da União, Brasília, DF, 09 nov 2001. Seção 1, p. 38. 2001.

CNRM. Comissão Nacional de Residência Médica. Resolução CNRM Nº 04/78, que dispõe sobre as normas para que os certificados gozem de validade nacional, os Programas de Residência Médica. Diário Oficial da União, Brasília, DF, 09 nov 1978.

CNRM. Comissão Nacional de Residência Médica. Resolução CNRM No 07/81, de 12 de junho de 1981, que inclui o Programa de Residência Médica em Medicina Geral Comunitária entre as especialidades médicas credenciáveis como Programa de Residência Médica. Diário Oficial da União, Brasília, DF, 17 jun 1981, Seção 1, p. 11.436. 1981a. 
de julho de 1981, que dispõe sobre as atividades do médico residente e dá outras providências. Diário Oficial da União, Brasília, DF, 09 jul 1981. 1981b.

CNRM. Comissão Nacional de Residência Médica. Resolução CNRM Nº 004/2003, de 23 de dezembro de 2003, que dispõe sobre as especialidades com acesso direto e com pré-requisito.

CNRM. Comissão Nacional de Residência Médica. Resolução CNRM N ${ }^{\circ}$ 005/2004, de 08 de junho de 2004, que dispõe sobre os serviços de preceptor/tutor dos programas de Residência Médica. Diário Oficial da União, Brasília, DF, 11 jun 2004, Seção I, p. 19. 2004a.

CNRM. Comissão Nacional de Residência Médica. Resolução CNRM No 008/2004, de 05 de agosto de 2004, que dispõe sobre o processo de seleção pública dos candidatos aos Programas de Residência Médica. 2004b.

CNRM. Comissão Nacional de Residência Médica. Resolução CNRM N 02/2005, de 07 de julho de 2005, que dispõe sobre a estrutura, organização e funcionamento da Comissão Nacional de Residência Médica. Diário Oficial da União, Brasília, DF, 14 jul 2005, seção 1, p.59/61. 2005.

CNRM. Comissão Nacional de Residência Médica. Resolução CNRM N 02/2006, de 17 de maio de 2006, que dispõe sobre requisitos mínimos dos Programas de Residência Médica e dá outras providências. Diário Oficial da União, Brasília, DF, nº 95, 19 mai 2006, seção 1, p. 23-36. 2006.

CUTOLO, L. R. A. Estilo de pensamento em educação médica: um estudo do currículo do Curso de Graduação em Medicina da UFSC. 2001. 227f. Tese (Doutorado em Educação). Universidade Federal de Santa Catarina, Centro de Ciências da Educação. Florianópolis, SC.

CYRINO, A. P.; CYRINO, E. G. Integrando comunicação, saúde e educação: experiência do UNI - Botucatu, Interface - comunicação, saúde, educação / Núcleo de comunicação da Fundação UNI, Botucatu, SP: Fundação UNI, v.1, n.1, p.157-168, ago, 1997.

CYRINO, E. G.; TORALLES-PEREIRA, M. L. Trabalhando com estratégias de ensino-aprendizado por descoberta na área da saúde: a problematização e a aprendizagem baseada em problemas. Cadernos de Saúde Pública, Rio de Janeiro, v. 20, n. 3. p. 780-788, mai-jun, 2004.

DELUIZ, N. O modelo das competências profissionais no mundo do trabalho e na educação: implicações para o currículo. Boletim Técnico do SENAC. Rio de Janeiro. v. 7, n. 3, p. 3-25. cap. 1. 2001. 
DE SETA, M. Transformando a educação profissional: o ensino no departamento de formação profissional para o sistema de saúde, Vox poli, Rio de Janeiro: FIOCRUZ, n. 9, jul/ago/set/2000.

DESLAURIERS, J-P.; KÉRISIT, M. O delineamento da pesquisa qualitativa. In: POUPART, J.; DESLAURIERS, J-P.; GROULX, L-H.; LAPERRIËRE, A.; MAYER, R.; PIRES, A.P. A pesquisa qualitativa: enfoques epistemológicos e metodológicos. Tradução de Ana Cristina Nasser. Petrópolis, RJ: Vozes, 2008 (Coleção Sociologia) pt. II. p. 127-153.

DIETEL, R. J.; HERMAN, J. L.; KNUTH, R. A. What does research say about assessment?, North Central Regional Educational Laboratory - NCREL, Oak book, 1991, http://www.ncrel.org/sars/areas/stw_esys/4assess.htm.

DORSEY, E. R.; JARJOURA, D.; RUTECKI, G. W. Influence of controllable lifestyle on recent trends in specialty choice by US medical students. JAMA. v. 290, p. 1173-1178. 2003.

DUPRET, L. M. A LDB e a PRAXIS - ensino médio e educação profissional, Vox poli, editorial, Rio de Janeiro: FIOCRUZ, n. 9, jul/ago/set/2000.

EDLER, F. C. De olho no Brasil: a geografia médica e a viagem de Alphonse Rendu. História, Ciências, Saúde. Manguinhos, v. VIII, supl., p. 925-43, 2001.

FALK, J. W. A especialidade medicina de família e comunidade no Brasil: aspectos conceituais, históricos e de avaliação da titulação dos profissionais. 194f. [Tese]. Universidade Federal do Rio Grande do Sul, Porto Alegre (RS), 2005.

FALK, J. W. Os títulos de especialista. Rev Bras Med Fam e Com. Rio de Janeiro v. $2 \mathrm{n}^{\circ} 7$ editorial. p.162-164. out / dez 2006.

FARIAS, E. R.; STEIN, A. T.; HOFFMANN, J. E. Os egressos da residência de medicina de família e comunidade do centro de saúde-escola Murialdo, 19762000. Boletim da Saúde. Porto Alegre. v. 18, n.1, jan/jun. 2004.

\section{FEUERWERKER, L. C. M. Mudanças na educação médica e residência} médica no Brasil. São Paulo: Hucitec/Rede Unida, 1998, 190p.

FEUERWERKER, L. C. M. A construção do trabalho em rede entre os projetos UNI, Vox poli, Rio de Janeiro: FIOCRUZ, n. 10, jan/fev/mar. 2001a. Opinião. 
FEUERWERKER, L. C. M. A formação de médicos especialistas e a residência médica no Brasil. Saúde em Debate, Rio de Janeiro, v. 25, n. 57, p. 39-54, jan./abr. 2001b.

FEUERWERKER, L. C. M. Além do discurso de mudança na educação médica: processos e resultados. São Paulo: Hucitec; 2002.

FEUERWERKER, L. C. M.; LIMA, V. V. Os paradigmas da atenção á saúde e da formação de recursos humanos, In: BRASIL, Ministério da Saúde.

Políticas de recursos em saúde. Brasília: Ministério da Saúde, p.167-178. 2002.

FONTANELLA, B. J. B.; RICAS, J.; TURATO, E. R. Amostragem por saturação em pesquisas qualitativas em saúde: contribuições teóricas.

Cadernos de Saúde Pública, Rio de Janeiro, v. 24, v. 1, p. 17-27, jan, 2008.

FRANCISCHINI, A. C.; MOURA, S. D. R. P.; CHINELLATO, M. A importância do trabalho em equipe no programa saúde da família. Investigação. v. 8, n. 13, p. 25-32, jan/dez. 2008.

FRANKLIN C., J. Educação superior: conceitos, definições e classificações. Brasília: Instituto Nacional de Estudos e Pesquisas Educacionais, 2000. 54p.

FREIRE, P. 2005. Pedagogia do Oprimido. Rio de Janeiro, Paz e Terra.

GALLO, E.; VAITSMAN, J.; CAMPOS FILHO, A. C. Gestão inovadora e cultura organizacional: ferramentas para a qualidade nos serviços públicos de saúde, In: COSTA, N. do R.; RIBEIRO, J. M. (Org.) Políticas de saúde e inovação institucional: uma agenda para os anos 90 , Rio de Janeiro: Secretaria de Desenvolvimento Educacional/ENPS/FIOCRUZ, 196p. 1996.

GARRAFA, V. Saúde $x$ educação ou saúde + educação, Divulgação em Saúde para Debate, n. 12, jul/1996. Editorial.

GIL, A. C. Como elaborar projetos de pesquisa. $4^{\text {a }}$ ed., 8. reimp., São Paulo: Atlas, 2006. 175p.

GIRARDI, S. N.; CARVALHO, C. L.; ARAÚJO, J. F.; FARAH, J. M.; WAN DER MAAS, L.; CAMPOS, L. A. B. de. Índice de escassez de médicos no Brasil: estudo exploratório no âmbito da atenção primaria. Disponível em http://www.obsnetims.org.br/cd2/pt/pro/mesa3/M3\%20-\%20T1.doc. Acesso em: 19 fev. 2010.

GODOY, A. S. Introdução à pesquisa qualitativa e suas possibilidades. 
Revista de Administração de Empresas. São Paulo, v. 35, n. 2, p. 57-63, mar/abr 1995.

GRONLUND, N. E. Assessment of student achievement, 6 ed., Allyn and Bacon, 230p., 1998.

GÜNTHER, H. Pesquisa qualitativa versus pesquisa quantitativa: essa é a questão? Psicologia: teoria e pesquisa. v. 22, n. 2, mai-ago, 2006.

HAQ, C.; VENTRES, W.; HUNT, V.; MULL, D.; THOMPSON, R.; RIVO, M.; JOHNSON, P. Family practice development around the world. Oxford University Press. Family Practice. v. 13, n. 413. p. 351-356, 1996

HARZHEIM, E. Atenção primária na saúde (APS). In: BRASIL. Ministério da Saúde. Ciclo de debates sobre redes regionalizadas de atenção à saúde: desafios do SUS. Texto referência. Brasília - DF, 10 de março de 2009. Disponivel em:

http://www.opas.org.br/informacao/UploadArq/ciclo_debates_texto_referenci al.pdf. Acesso em: 25 jul. 2010.

HORNBURG, N.; SILVA, R. da. Teorias sobre currículo: uma análise para compreensão e mudança. Revista de divulgação técnico-científica do ICPG. v. 3, n. 10, - jan.-jun./2007. Disponível em:

http://www.scribd.com/doc/520266/TEORIAS-SOBRE-CURRICULO. Acesso em: 19 fev. 2010.

JANAUDIS, M. A.; BLASCO, P. G.; HAQ, C.; FREEMAN, J. Formando médicos para a medicina de família e comunidade. Revista Bioética. 15 (1).p. 27-36. 2007.

KISIL, M. Uma estratégia para a reforma sanitária: a iniciativa UNI, Divulgação em Saúde para Debate, n. 12, p. 5-14, jul/1996.

LAGUNA, J. A. La modernizacion del cientificismo y el arcaismo nacional actual: el caso de la formacion medica en el Peru, Educación Médica y Salud - a) capacitacion avanzada en desarrolo de recursos humanos - b) experiencias de trabajo en las americas, OPAS/OMS, v. 26, n. 2, p. 51-67, abril/junio, 1992.

LIMA, J. C. de S. A residência médica: articulação entre a prática e o ensino. 2008. 181p. Tese (Doutorado em Saúde Coletiva) - Instituto de Medicina Social, Universidade do Estado do Rio de Janeiro. Rio de Janeiro.

LIMA, V. V.; RIBEIRO, E. C. de O. Desafios na construção de novos modelos 
pedagógicos nos cursos de enfermagem e de medicina. Londrina: Olho Mágico. v.9, n.1, p. 45-48, jan/abr. 2002.

LINN, R. L.; GRONLUND, N. E. Measurement and assessment in teaching, 7. ed. Merrill, 560p., 1995.

LOPES, J. M. C.; FERNANDES, C. L. C.; CURRA, L. C. D.; MATTOS, L. F. C. Manual da oficina para capacitar preceptores em medicina de família e comunidade. Florianópolis: Sociedade Brasileira de Medicina de Família e Comunidade, 2009. 184p.

MACHADO, J. L. M.; CALDAS JR, A. L.; BORTONCELLO, N. M. F. Uma nova iniciativa na formação dos profissionais de saúde, Interface - comunicação, saúde, educação / Núcleo de comunicação da Fundação UNI, Botucatu, SP: Fundação UNI, v.1, n.1, p.147-156, ago/1997.

MACHADO, M. H. et al. Os médicos no Brasil: um retrato da realidade, Rio de Janeiro: Fiocruz, 244p, 1997.

MACIEL FILHO, R.; BRANCO, M. A. F. Rumo ao interior: médicos, saúde da família e mercado de trabalho. Rio de Janeiro: Editora Fiocruz; 2008. 205p.

MADAUS, G. F.; KELLAGNAN, T. Curriculum evaluation and assessment, In: Handbook of research on curriculum, New York: Macmillan, p. 119-154, 1992.

MAGZOUB, M. E.; SCHMIDT, H. G. A taxonomy of community-based medical education. Academic Medicine. v. 75, n. 7, p 699-707. jul/2000.

MALIK, A. M. Avaliação, Qualidade, Gestão... para trabalhadores da área de saúde e outros interessados. São Paulo: SENAC, 1996. 38p.

MAMEDE, S. Aprendizagem baseada em problemas: características, processos e racionalidade. In: MAMEDE, S. (Org.); PENAFORTE, J. (Org.); SCHMIDT, H.; CAPRARA, A.; TOMAZ, J. B.; SA, H. I. do. Aprendizagem baseada em problemas: anatomia de uma nova abordagem educacional. Fortaleza: Hucitec. cap. 1. p. 27-48. 2001. 232p.

MARCONI, M. de A.; LAKATOS, E. M. Fundamentos de metodologia científica. $6^{a}$ ed., São Paulo: Atlas, 2005. 315p.

MARIANO, R. E. M.; SILVA, M. G. C. da. O processo seletivo para a residência médica do sistema único de saúde no Estado do Ceará. In: JORGE, M.S.B.; SAMPAIO, H.A.C. (Org.). Construção do conhecimento 
em saúde coletiva: políticas públicas e diversidades. 1 ed. Fortaleza: Ed. INESP/EdUECE, 2001. p. 249-260.

MARIANO, R. E. M.; SILVA, M. G. C. da. O processo de avaliação na formação do profissional de saúde. In: SILVA, M.G.C.; JORGE, M.S.B. (Org.). Construção do saber em saúde coletiva: transição epidemiológica $e$ diversidades. 1 ed. Fortaleza: Ed. INESP/EdUECE, 2002. p. 348-358.

MARIANO, R. E. M.; SILVA, M. G. C. da. Educação médica: modelo de saúde x formação profissional. In: Conselho Regional de Medicina do Estado do Ceará (CREMEC). (Org.). Concurso de monografias / Prof. Dalgimar Beserra de Menezes. 1 ed. Fortaleza: Expressão, 2006. p. 75-103.

MARIN, M. J. S.; LIMA, E. F. G.; PAVIOTTI, A. B.; MATSUYAMA, D. T.; SILVA, L. K. D. da; GONZALEZ, C.; DRUZIANI, S.; ILIAS, M. Aspectos das fortalezas e fragilidades no uso das metodologias ativas de aprendizagem. Revista Brasileira de Educação Médica. v. 34, n. 1, p. 13-20. 2010.

MARSIGLIA, R. G. Relação ensino/serviços: dez anos de integração docente assistencial (IDA) no Brasil, São Paulo: Hucitec, 1995, 118p.

MASSUDA, A.; CUNHA, F. M. da; PETTA, H. Residência Médica: contribuições dos médicos residentes ao debate. Rev Assoc Med Bras:. v. 53. n. 2. p. 95-107. 2007. Editorial.

MEDICI, A. C.; GIRARDI, S. N. Emprego, remuneração de pessoal e produtividade em saúde: um balanço da literatura recente, Divulgação em Saúde para Debate, n. 14, p. 38-43, ago/1996.

MELLO, G. A.; DEMATTOS, A. T. R.; SOUTO, B. G. A.; FONTANELLA, B. J. B.; DEMARZO, M. M. P. Médico de família: ser ou não ser? Dilemas envolvidos na escolha desta carreira. Revista Brasileira de Educação Médica. v. 33, n. 3, p. 475-482; 2009.

MENDES, E. V. As políticas de saúde no Brasil nos anos 80: a conformação da reforma sanitária e a construção da hegemonia do projeto neoliberal, In: E. V. (Org.) Distrito sanitário: o processo social de mudanças das práticas sanitárias do sistema único de saúde, São Paulo-Rio de Janeiro: Hucitec/Abrasco, 3 ed., p.19-91, 1995.

MENDES, E. V. Uma agenda para a saúde, São Paulo: Hucitec, 1996, 300p.

MENDES, E. V. Os grandes dilemas do SUS: tomo I. Salvador, Bahia: Casa da qualidade editora. 2001. 114p. 
MENDES, E. V. A atenção primária à saúde no SUS. Fortaleza: Escola de Saúde Pública do Ceará, 2002, 92p.

MENDONÇA, C. S. de. Entrevista concedida a Sociedade Brasileira de Medicina de Família e Comunidade. 28/05/2009. Disponível em: http://www.sbmfc.org.br/default.asp?site_Acao=mostraPagina\&Paginald $=11 \&$ mNoti_Acao=mostraNoticia\&noticiald=61. Acesso em: 25 jul. 2010.

MERCADO, F. J.; BOSI, M. L. Introdución. Notas para un debate. En: BOSI, M. L.; MERCADO, F. J. Investigación cualitativa de los servicios de salud. Lugar editorial: Buenos Aires, p. 29-60. 2006.

MERCADO-MARTINEZ, F.J. O processo de análise qualitativa dos dados na investigação sobre serviços de saúde. In: BOSI, M. L. M.; MERCADO, F. J. (org.) Pesquisa qualitativa de serviços de saúde. Petrópolis, RJ: Vozes. 2004. p. $137-174,607$ p.

MESQUITA, W. Residência Médica: em busca da qualidade, Diálogo médico, São Paulo: Roche, a. 14, n. 7, out. 1999.

MISSAKA, H.; RIBEIRO, V. M. B. A preceptoria na formação médica: subsídios para integrar teoria e prática na formação profissional - o que dizem os trabalhos nos congressos brasileiros de Educação Médica. s.d. Disponível em: www.foco.fae.ufmg.br/viienpec/index.php/enpec/viienpec/paper/.../706. Acesso em: 19 fev. 2010.

MITRE, S. M.; BATISTA, R. S.; MENDONÇA, J. M. G. de; PINTO, N. M. de M.; MEIRELLES, C. de A. B.; PORTO, C. P.; MOREIRA, T.; HOFFMANN, L. M. A. Metodologias ativas de ensino-aprendizagem na formação profissional em saúde: debates atuais. Ciência e Saúde Coletiva. v. 13, supl. 2. p. 21332144. dez. 2008.

MOREIRA, V. O método fenomenológico de Merleau-Ponty como ferramenta crítica na pesquisa em psicopatologia. Psicol. Refl. Crít., Porto Alegre, v. 17, n.3, p. 447-456, 2004.

MORETO, G.; BENEDETTO, M. A. C. de; RONCOLETTA, A.; LAMUS, F.; GONZÁLEZ, P. La educación médica y la propuesta "Salud para todos": la Declaración de Alma-Ata treinta años después. Cuadernos de Medicina en Investigación y Salud. a. 2, v. 2, n. 2. Chía-Colombia, p. 109-119. noviembre. 2008.

MOROSINI, M. V. G. C. Modelos de atenção e a saúde da família. MOROSINI, M. V. G. C.; CORBO, A. D'A. (orgs.) Rio de Janeiro: 
EPSJV/Fiocruz. 240 p. (Coleção Educação Profissional e Docência em Saúde: a formação e o trabalho do agente comunitário de saúde, 4). 2007.

NEBOT ADELL, C.; ROSALES ECHEVARRIA, C.; BORRELL BENTZ, R. M. Desarrollo de competencias en atención primaria de salud. Revista

Panamericana Salud Publica, Washington, v. 26, n. 2, aug. 2009. Disponível em: http://www.scielosp.org/scielo.php?pid=S1020-

$49892009000800011 \&$ script=sci_arttext. Acesso em: 30 jun. 2010.

NOGUEIRA, R. P. Estabilidade e flexibilidade: tensão de base nas novas políticas de recursos humanos em saúde, Divulgação em Saúde para Debate, n. 14, p. 18-22, ago.1996.

NOGUEIRA, R. P. Pessoal de saúde: a discussão teórica e a produção científica sobre o tema. In: NUNES ED (Org.), As ciências sociais em saúde na América Latina: tendências e perspectivas, Brasília: OPAS, p. 391-408, 1985.

NOGUEIRA-MARTINS, L. A.; JORGE, M. R. Natureza e magnitude do estresse na Residência Médica, São Paulo: Escola Paulista de Medicina, 2000.

NUNES, E. D. As ciências sociais nos planos de estudo de graduação e pósgraduação, In: NUNES ED (Org.), As ciências sociais em saúde na América Latina: tendências e perspectivas, Brasília: OPAS, p. 427-452, 1985.

NUNES, E. D. Pós-graduação em Saúde Coletiva no Brasil: histórico e perspectivas. PHYSIS: Rev. Saúde Coletiva, Rio de Janeiro, v. 15, n. 1, p. 13-38, 2005.

OMS - Organização Mundial da Saúde. Declaração de Alma-Ata, relatório da conferência internacional sobre cuidados primários de saúde, OMS/UNICEF, Alma-Ata-URSS, set. 1978.

OMS - Organización Mundial de la Salud. Sistemas de educación continua: prioridad al personal de salud de distrito, Serie de informes técnicos 803 , Ginebra: OMS, 55p., 1990

OPAS - Organização Pan-Americana da Saúde/ OMS. Renovação da Atenção Primária em Saúde nas Américas. Documento de posicionamento da OPAS. ago. 2005.

PARKHOUSE, J. Continuing education of health personal and its evaluation, 
Helsinki: WHO Regional Committee for Europe, n. 33, 25p., 1979.

PERIM, G. L.; ABDALLA, I. G.; AGUILAR-DA-SILVA, R. H.; LAMPERT, J. B.; STELLA, R. C. de R.; COSTA, N. M. da S. C. Desenvolvimento docente e a formação de médicos. Revista Brasileira de Educação Médica. v. 33. supl.1. Rio de Janeiro. 2009.

PIERANTONI, C. R.; VARELLA, T. C.; FRANÇA, T. A formação médica: capacidade regulatória de estados nacionais e demanda dos sistemas de saúde. In: Cadernos RH Saúde / Ministério da Saúde, Secretaria de Gestão do Trabalho e da Educação na Saúde. v. 3, n. 1 (mar. 2006) -. Brasília: Ministério da Saúde, 2006.188p.

POLIGNANO, M. V. História das políticas de saúde no Brasil: uma pequena revisão. In: CURY, G. C; POLIGNANO, M. V; ALVES, A. L. Cadernos do internato rural: textos de apoio, 2001.

POPE, C.; MAYS, N. Pesquisa qualitativa na atenção à saúde. Tradução de Ananyr Porto Farjado. 2. ed. Porto Alegre: Artmed, 2005. 118p.

QUINTANA, P. B.; ROSCHKE, M. A. C.; RIBEIRO, E. C. de O. Educación permanente, proceso de trabajo y calidad de servicio en salud, In: Educación permanente de personal de salud, Série Desarrollo de Recursos Humanos, n. 100, Washington: OPAS/OMS, p. 33-61, 1994.

RAGGIO, A.; GIACOMINI, C. H. A permanente construção de um modelo de saúde, Divulgação em Saúde em Debate, v. 44, n.16, p. 9-16, dez. 1996.

RANGEL, M. L; VILABÔAS, A. L. Rede Unida: breve histórico, concepção, organização e estratégias de ação, Divulgação em Saúde para Debate, $n$. 12, p. 15-18, jul/1996.

RIBEIRO, E. .C de O.; MOTTA, J. I. J. Educação permanente como estratégia na reorganização dos senviços de saúde, Divulgação em Saúde para Debate, n. 12, p. 39-44, jul/1996.

RICHARDSON, R. J. e col. Pesquisa social: métodos e técnicas. 3. ed. São Paulo: Atlas, 1999. 334p.

RODRIGUÉZ, M. I. Las innovaciones educativas en la formación de personal de salud en México dentro del contexto de las transformaçiones ocurridas en América Latina, Educación médica y salud, OPAS/OMS, v. 29, n. 1, p. 3249, enero/marzo, 1995. 
ROONEY, A. L.; VAN OSTENBERG, P. R. Licenciamento, acreditação e certificação: abordagens à qualidade de senviços de saúde, Série de aperfeiçoamento sobre a metodologia de garantia de qualidade, Bethesda: Center for Human Services, USAID, 1999.

ROSENBERG, L. Aspectos pedagógicos da residência médica, In: Requisitos mínimos de um programa de residência médica: competências em medicina preventiva e social, São Paulo: Cadernos Fundap, 1992.

ROVERE, M. R. Gestion estrategica de la educacion permanente en salud, In: Educacion permanente de personal de salud, In: Educación permanente de personal de salud, Série Desarrollo de Recursos Humanos, n. 100, Washington: OPAS/OMS, p. 63-106, 1994.

ROWNTREE, D. Assessing students: how shall we know them?, 6. ed. London: Kogan Page, 273p., 1997.

SACRISTÁN, J. G. O currículo: uma reflexão sobre a prática. Tradução de Ernani F. da Fonseca Rosa. 3. ed. Porto Alegre: ArtMed. 2000.

SANTANA, J. P. de; CHRISTÓFARO, M. A. C. Educação, Trabalho e Formação Profissional em Saúde. NESP/CEAM/UNB. Núcleo de Estudos de Saúde Pública. Programa de Políticas de Recursos Humanos de Saúde POLRHS. 2002. Disponível em: nesp.unb.br/polrhs/.../edc_trab_form_prof_

em_saude.htm. Acesso em: 19 fev. 2010.

SANTANA, J. P. de; GIRARDI, S. N. Recursos humanos em saúde: reptos atuais, Educación Médica y Salud, OPAS/OMS, v. 27, n. 3, p. 341-399, julio/septiembre, 1993.

SAVIANI, N. Currículo e trabalho pedagógico: prescrições políticas, prática negociada. Texto referente à exposição na Oficina Temática do $10^{\circ}$ Congresso do SINPRO Minas - Sindicato dos Professores de Minas Gerais, 31 de maio de 2008. Disponivel em: www.sinprominas.org.br/imagensDin/arquivos/361.doc. Acesso em: 19 de fev. 2010.

SBMFC - Sociedade Brasileira de Medicina de Família e Comunidade. [homepage na internet]. Florianópolis: Disponível em: http://www.sbmfc.org.br/ Acesso em: 19 fev. 2010.

SCHRAIBER, L. B. Educação médica e capitalismo: estudo das relações educação e prática médica na ordem social capitalista. Rio de Janeiro: Hucitec-Abrasco, 1989, 133p. 
SCHRAIBER, L. B. Pesquisa qualitativa em saúde: reflexões metodológicas do relato oral e produção de narrativas em estudo sobre a profissão médica. Revista de Saúde Pública, v. 29, n. 1, p. 63-74. 1995.

SCHRAIBER, L. B. Ética e subjetividade no trabalho em saúde, Divulgação em saúde para debate, n. 12, p. 45-50, jul. 1996.

SCHRAIBER, L. B; NEMES, M. I. B. Processo de trabalho e avaliação de serviços em saúde, São Paulo: Cadernos Fundap, São Paulo, n. 19, p. 106121, 1996.

SCHRAIBER, L. B; PEDUZZI, M. Tendências e possibilidades da investigação de recursos humanos em saúde no Brasil, Educación Médica y Salud, OPAS/OMS, v. 27, n. 3, p. 295-313, julio/septiembre, 1993.

SEEGMÜLLER, E. F.; GIELOW, R.; BEHRENS, M. A. LIMA JUNIOR, E. Formação médica: uma proposta diante das demandas da sociedade. Experiência da Pontifícia Universidade Católica do Paraná-PUCPR. Tuiuti: Ciência e Cultura, n. 39, p. 9-22, Curitiba, 2008.

SEVERINO, A. J. Educação e universidade: conhecimento e construção da cidadania. Interface - Comunicação, Saúde, Educação. v. 6, n.10, Botucatu. Fev. 2002.

SILVA, J. D. M. Análise das características e do desempenho dos candidatos ao processo seletivo à residência médica do Sistema Único de Saúde do Estado do Ceará para ingresso em 1997, Fortaleza: IOCE/SEAD, 1997, 68p.

SILVA, C. H. Murialdo: história e construção na saúde coletiva do Rio Grande do Sul. Escola de Saúde Pública do Rio Grande do Sul. Boletim da saúde. v. 16, n. 2, p. 105-115. jul/dez. 2002.

SILVA, T. T. da. Documentos de identidade: uma introdução às teorias do currículo. 2. ed. $9^{a}$ reimp. Belo Horizonte: Autêntica. 2005. 156p.

SILVA, M. G. C. da. Observatório médico: crônicas e ensaios do cotidiano. Fortaleza: Edições UECE, 2007. 144p.

SILVA, L. M. V; FORMIGLI, V. . LA. Avaliação em Saúde: Limites e Perspectivas. Cadernos de Saúde Pública, v. 10, n.1, p.80-91, jan/mar, Rio de Janeiro, 1994.

SISSON, M. C. Identidades profissionais na implantação de novas práticas 
assistenciais. Revista Brasileira de Educação Médica. Rio de Janeiro. v. 33. supl. 1. 2009.

SOBRAL, D. T. Desenvolvimento de habilidades de aprendizagem: estudod dos efeitos de uma experiência. Revista Brasileira de Educação Médica. Rio de Janeiro, v .24, $n^{\circ} 2$, p. 49-54. maio/set. 2000.

SOUZA, P. G. de; RANGEL, M. Avaliação: um impasse na educação médica, Revista Brasileira de Educação Médica, v. 27, n. 3, p. 213- 222, set/dez, 2003.

TEIXEIRA, C. F; PAIM, J. S. Políticas de formação de recursos humanos em saúde: conjuntura atual e perspectivas, Divulgação em Saúde para Debate, n. 12, p. 19-23, jul/1996.

TEIXEIRA, M.; MACHADO, M. H.; MOYSES, N.; VIRGINIA, S. R. Trabalho e gestão em saúde: algumas considerações no contexto do SUS, In: COSTA, N. do; RIBEIRO, J. M. (Orgs.) Políticas de saúde e inovação institucional: uma agenda para os anos 90, Rio de Janeiro: Secretaria de Desenvolvimento Educacional/ENPS/FIOCRUZ, 196p., 1996.

TESTA, M. Pensar em saúde. Porto Alegre: Artes Médicas-Abrasco.1992.

TURATO, R. E. Tratado da metodologia da pesquisa clínico-qualitativa: construção teórico-epistemológica, discussão comparada e aplicação nas áreas da saúde e humanas. Petrópolis, RJ: Vozes, 2003.

TURATO, R. E. Métodos qualitativos e quantitativos na área da saúde: definições, diferenças e seus objetos de estudo. Revista de Saúde Pública. v. 39, n.3, p. 507-514, 2005.

VANNUCHI, M. T. O.; CAMPOS, J. J. B. de. A metodologia ativa na Residência em Gerência do Curso de Enfermagem da UEL. Cogitare Enferm. v. 12, n. 3. p. 358-364. jul/set. 2007.

VUORI, H. A. Qualidade da Saúde. Divulgação em Saúde para Debate. n. 3, p.17-25, fev, 1991.

WIERS, R. W.; VAN DE WIEL, M. W. J.; SÁ, H. L. C.; MAMEDE, S.; TOMAZ, J. B.; SCHMIDT, H. G. Design of a problem-based curriculum: a general approach and a casa study in the domain of public health. Taylor \& Francis Ltd.: Medical Teacher. v. 24, n. 1. p. 45-51. 2002. 


\section{APÊNDICES}


APÊNDICE I - Roteiro para entrevistas com os residentes e exresidentes dos Programas de Residência em Medicina de Família e Comunidade

1. Qual a sua opinião sobre o Programa de Residência que você está cursando (ou cursou)?

2. Qual a diferença entre os conhecimentos adquiridos na graduação e na Residência em Medicina de Família e Comunidade (RMFC)?

3. Qual a sua expectativa de aplicabilidade no seu local de trabalho dos conhecimentos adquiridos?

4. Como você poderia descrever as situações vivenciadas durante o curso e aquelas presentes em sua prática diária?

5. Em que a Residência em Medicina de Família e Comunidade the ajudou a trabalhar em uma equipe do PSF?

6. Qual a sua opinião acerca da organização da Residência que você está cursando (ou cursou), quanto aos seguintes aspectos:

- Ordenação dos conteúdos;

- Adequação dos conteúdos aos objetivos;

- Definição dos objetivos;

- Carga horária total;

- Qualidade e organização do material didático;

- Carga horária diária;

- Carga horária para atividades práticas;

- Compatibilidade entre objetivos e necessidades de aprendizagem;

- Qualidade das instalações.

7. Qual a sua opinião acerca da equipe docente?

8. E sobre as avaliações realizadas durante o Programa?

9. Quais os fatores que influenciaram a sua escolha pela Residência em Medicina de Família e Comunidade?

10. A que você atribui a evasão dos residentes da Residência em Medicina de Família e Comunidade?

11. Você teria algo mais a acrescentar sobre o Programa de Residência em Medicina de Família e Comunidade que você está cursando (ou cursou)? 
APÊNDICE II - Roteiro para entrevistas com os coordenadores dos Programas de Residência em Medicina de Família e Comunidade

1. Há quanto tempo este Programa de Residência foi criado?

2. Há quanto tempo você coordena este Programa?

3. Quais os objetivos desse Programa de Residência?

4. Em que foi baseado o currículo do Programa de Residência que você coordena?

5. Como foi desenhado o currículo deste Programa de Residência?

6. Qual a estrutura curricular?

7. Qual a carga horária total? E de atividades teóricas? E práticas?

8. Onde são desenvolvidas as atividades práticas?

9. Como está estruturado o sistema de avaliação do Programa?

10.Você gostaria de acrescenta algo mais acerca do Programa de - Residência que você coordena? 
APÊNDICE III - Termo de Consentimento Livre e Esclarecido para os médicos residentes

Você está sendo convidado(a) como voluntário(a) a participar da pesquisa: "Análise dos Programas de Residência para formação do médico de família no Estado do Ceará".

A JUSTIFICATIVA, OS OBJETIVOS E OS PROCEDIMENTOS: O motivo que nos leva a estudar os programas de formação do médico de família, na modalidade de residência é conhecer os projetos pedagógicos destes Programas e verificar a estrutura curricular destes cursos, suas diferentes disciplinas e organização interna, como forma de avaliar a coerência entre a base cognitiva que apóia a prática destes profissionais e sua adequação ao perfil do profissional requerido para a atuação no PSF. $O$ objetivo desse projeto é caracterizar os Programas de Residência existentes no Estado do Ceará, para formação do médico de família. Os procedimentos de coleta de dados serão da seguinte forma: você está convidado a participar de uma entrevista, para sabermos a sua satisfação com o programa cursado, bem como, solicitamos que você responda a um questionário, com perguntas fechadas para podermos caracterizar o perfil do médico residente em saúde da família. A fim de podermos analisar com mais detalhes a sua participação neste projeto, solicitamos a sua autorização para gravarmos a entrevista.

DESCONFORTOS E RISCOS E BENEFÍcIOS: Você não será submetido a qualquer desconforto ou risco, e sua participação, na entrevista, no preenchimento do questionário será totalmente voluntária.

GARANTIA DE ESCLARECIMENTO, LIBERDADE DE RECUSA E GARANTIA DE SIGILO: Você será esclarecido(a) sobre a pesquisa em qualquer aspecto que desejar. Você é livre para recusar-se a participar, retirar seu consentimento ou interromper a participação a qualquer momento. A sua participação é voluntária e a recusa em participar não irá acarretar qualquer penalidade ou perda de benefícios.

$\mathrm{O}$ (s) pesquisador(es) irá(ão) tratar a sua identidade com padrões profissionais de sigilo. Os resultados da pesquisa serão enviados para você e permanecerão confidenciais. Seu nome ou o material que indique a sua participação não será liberado sem a sua permissão. Você não será 
identificado(a) em nenhuma publicação que possa resultar deste estudo. Uma cópia deste consentimento informado será arquivada no Curso de Doutorado Interinstitucional no Estado do Ceará da Faculdade de Saúde Pública da Universidade de São Paulo e outra será fornecida a você.

\section{CUSTOS DA PARTICIPAÇÃO, RESSARCIMENTO E INDENIZAÇÃO POR} EVENTUAIS DANOS: A participação no estudo não acarretará custos para você e não será disponível nenhuma compensação financeira adicional

\section{DECLARAÇÃO D(O)A PARTICIPANTE: Eu,}

fui informada (o) dos objetivos da pesquisa acima de maneira clara e detalhada e esclareci minhas dúvidas. Sei que em qualquer momento poderei solicitar novas informações e motivar minha decisão se assim o desejar. O professor orientador Dr. Eurivaldo Sampaio de Almeida e o(a) professor(a) co-orientador(a)

certificaram-me de que todos os dados desta pesquisa serão confidenciais. Também sei que caso existam gastos adicionais, estes serão absorvidos pelo orçamento da pesquisa. Em caso de dúvidas poderei chamar a estudante Rita Erotildes Maranhão Mariano, o professor orientador Dr. Eurivaldo Sampaio de Almeida ou o(a) professor(a) co-orientador(a) no telefone (85) 3272.6923 ou o Comitê de Ética em Pesquisa da Faculdade de Saúde Pública da Universidade de São Paulo, sito à Av. Dr. Arnaldo, 715, Cerqueira César - São Paulo, SP.

Declaro que concordo em participar desse estudo. Recebi uma cópia deste termo de consentimento livre e esclarecido e me foi dada a oportunidade de ler e esclarecer as minhas dúvidas.

\begin{tabular}{clc}
\hline Nome & Assinatura do Participante & Data \\
\hline Nome & Assinatura do Pesquisador & Data \\
\hline Nome & Assinatura da Testemunha & Data
\end{tabular}


APÊNDICE IV - Termo de Consentimento Livre e Esclarecido para os coordenadores dos Programas de Residência

Você está sendo convidado(a) como voluntário(a) a participar da pesquisa: "Análise dos Programas de Residência para formação do médico de familia no Estado do Ceará".

A JUSTIFICATIVA, OS OBJETIVOS E OS PROCEDIMENTOS: O motivo que nos leva a estudar os programas de formação do médico de família, na modalidade de residência é conhecer os projetos pedagógicos destes Programas e verificar a estrutura curricular destes cursos, suas diferentes disciplinas e organização interna, como forma de avaliar a coerência entre a base cognitiva que apóia a prática destes profissionais e sua adequação ao perfil do profissional requerido para a atuação no PSF. O objetivo desse projeto é caracterizar os Programas de Residência existentes no Estado do Ceará, para formação do médico de família. Os procedimentos de coleta de dados serão da seguinte forma: como momento inicial do processo de coleta de informações, necessitamos conhecer os Programas de Residência para formação dos médicos de família existentes no Ceará, e solicitamos sua colaboração em participar de uma entrevista, na qual buscaremos conhecer melhor o Programa sob sua coordenação. A fim de podermos analisar com mais detalhes o conteúdo dos dados coletados, quando da sua participação, solicitamos a sua autorização para gravarmos a entrevista.

DESCONFORTOS E RISCOS E BENEFícIOS: Você não será submetido(a) a qualquer desconforto ou risco, e sua participação nesta entrevista será totalmente voluntária.

GARANTIA DE ESCLARECIMENTO, LIBERDADE DE RECUSA E GARANTIA DE SIGILO: Você será esclarecido(a) sobre a pesquisa em qualquer aspecto que desejar. Você é livre para recusar-se a participar, retirar seu consentimento ou interromper a participação a qualquer momento. A sua participação é voluntária e a recusa em participar não irá acarretar qualquer penalidade ou perda de benefícios.

$\mathrm{O}$ (s) pesquisador(es) irá(ão) tratar a sua identidade com padrões profissionais de sigilo. Os resultados da pesquisa serão enviados para você e permanecerão confidenciais. Seu nome ou o material que indique a sua participação não será liberado sem a sua permissão. Você não será 
identificado(a) em nenhuma publicação que possa resultar deste estudo. Uma cópia deste consentimento informado será arquivada no Curso de Doutorado Interinstitucional no Estado do Ceará da Faculdade de Saúde Pública da Universidade de São Paulo e outra será fomecida a você.

\section{CUSTOS DA PARTICIPAÇÃO, RESSARCIMENTO E INDENIZAÇÃO POR} EVENTUAIS DANOS: A participação no estudo não acarretará custos para você e não será disponível nenhuma compensação financeira adicional

\section{DECLARAÇÃo DO(A) PARTICIPANTE: Eu,}

fui informada (o) dos objetivos da pesquisa acima de maneira clara e detalhada e esclareci minhas dúvidas. Sei que em qualquer momento poderei solicitar novas informações e motivar minha decisão se assim o desejar. O professor orientador Dr. Eurivaldo Sampaio de Almeida e o(a) professor(a) co-orientador(a)

certificaram-me de que todos os dados desta pesquisa serão confidenciais. Também sei que caso existam gastos adicionais, estes serão absorvidos pelo orçamento da pesquisa. Em caso de dúvidas poderei chamar a estudante Rita Erotildes Maranhão Mariano, o professor orientador Dr. Eurivaldo Sampaio de Almeida ou o(a) professor(a) co-orientador(a) de Ética em Pesquisa da Faculdade de Saúde Pública da Universidade de São Paulo, sito à Av. Dr. Arnaldo, 715, Cerqueira César - São Paulo, SP.

Declaro que concordo em participar desse estudo. Recebi uma cópia deste termo de consentimento livre e esclarecido e me foi dada a oportunidade de ler e esclarecer as minhas dúvidas.

\begin{tabular}{cll}
\hline Nome & Assinatura do Participante & Data \\
\hline Nome & Assinatura do Pesquisador & Data \\
\hline Nome & Assinatura da Testemunha & Data
\end{tabular}




\section{Rita Erotildes Maranhão Mariano}

Rita Erotildes Maranhão Mariano possui graduação em Odontologia pela Faculdade de Odontologia da Universidade Federal do Ceará (1981) e Mestrado em Saúde Pública pela Universidade Estadual do Ceará (2001), e está cursando o Doutorado Interinstitucional em Saúde Pública, pela Universidade de São Paulo. Exerceu atividades gerenciais na Secretaria da Saúde de Fortaleza, como Diretora da Divisão de Vigilância e Assisténcia à Saúde (DVAS) do Distrito Sanitário I (1992) e como Coordenadora das Unidades de Saúde Luis Costa (1988) e Pio XII (1993). Atualmente exerce a funçāo de assessora técnica no Centro de Educação para as Profissōes de Saúde da Escola de Saúde Pública do Ceará ESP.CE. Tem ampla experiência na área de Saúde Pública, com ênfase em Metodologia da Pesquisa Científica e em Educação para as Profissōes de Saúde, com atuação na elaboração de programas educacionais e no desenvolvimento de currículo baseado em competências; na avaliação da formacāo profissional: na producäo de material didático e na elaboração e desenvolvimento de cursos de educação à distância. Possui experiência também em atividades docentes de capacitação em cursos de especialização e em treinamentos de pessoal e de facilitação de grupos tutoriais em metodologias inovadoras de ensino (PBL), nas áreas de gestão de sistemas de saúde (politicas de saúde, planejamento, administração e avaliação em saúde)

(Texto informado pelo autor)

Última atualização do currículo em 05/04/2010

Endereço para acessar este CV:

http://lattes.cnpq.br/1522069858761574

Certificado

Certericado

$05 / 04 / 10$

\section{Dados pessoais}

Nome Rita Erotildes Maranhão Mariano

Nome em citações MARIANO, Rita Erotildes Maranhão

bibliográficas

Sexo Feminino

Endereço profissional Escola de Saúde Pública do Ceará.

Av. Antonio Justa. 3161

Meireles

$60165-090$ - Fortaleza. CE - Brasil

Telefone: (85) 31011418 Fax: (85) 31011418

URL da Homepage: htto://www.esp.ce.gov.b

Formação acadêmica/Titulação

2006

Doutorado em andamento em Interinstitucional em Saúde Pública (DINTER)

Universidade de Säo Paulo, USP. Brasil.

Título: Análise dos Programas de Residència para formação do médico de familia no Estado do Ceara

Orientador: Eurivaldo Sampaio de Almeida.

Palavras chave: Formação Protissional; Avaliação na Formação Profissional em Saúde; Programa Saúde da

Familia; Política de Recursos Humanos; Residência Médica.

1999 - 2001 Mestrado em Saude Pública (Conceito CAPES 3)

Universidade Estadual do Ceará, UECE, Brasil.

Título: O processo seletivo da Residência Médica do Sistema Unico de Saude do Ceará. em 2000 organizacão.

execução e mensuracão dos resultados, Ano de Obtenção: 2001

Orientador: Marcelo Gurgel Carlos da Silva

Bolsista do(a): Fundação Cearense de Apoio ao Desenvolvimento Cientifico e Tecnológico.

Palawas-chave: Educação Profissional em Saúde; Avaliação na Formação Profissional em Saude: Processo Seletivo: Residência Médica.

Grande área: Ciências da Saude : Area: Saúde Coletiva : Subárea: Saúde Pública / Especialioade: Educação Para As Protissôes de Saúde.

Grande área: Ciências Humanas / Área: Educação / Subárea: Tópicos Especificos de Educacăo i Especialidade:

Educação Permanente.

Grande área: Ciências Humanas / Área: Educação / Subárea: Ensino-Aprendizagem : Especielidade: Avaliaçāo da Aprendizagem.

Setores de atividade: Formação Permanente e Outras Atividades de Ensino, Inclusive Educação A Distáncia e

Educacão Especial: Políticas. Planejamento e Gestảo em Saúde: Outro.

1999 - 2000 Especializacão em Saude Pública

Universidade Estadual do Ceará, UECE, Brasil.

1995 - 1996 Especialização em Gestäo de Sistemas Locais de Saúde . Carga Horária: 760h:

Escola de Saúde Pública do Ceará

Tituio: Açóes Preventivas em Saude Bucal: Fatores que influenciam a atuaçầo dos profissionais no Cistrito

Sanitario I- Fortaleza -Ce.

Orientador: Silvia Mamede Studart Soares.

Bolsista do(a): Fundação Cearense de Pesquisa e Cultura. . .

1977-1981 Graduaçâo em Odontologia

Uitiversidade Federal do Ceará, UFC, Brasil. 


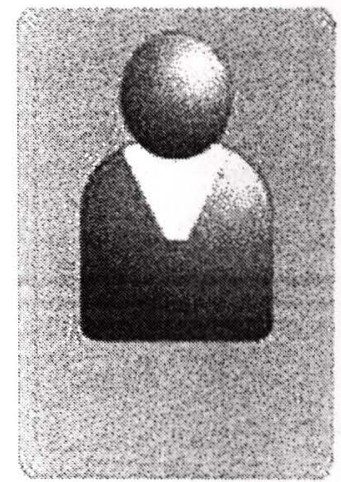

\section{Eurivaldo Sampaio de Almeida}

possui graduação em Medicina pela Universidade do Pará (1963) , especialização em III Curso de Especialização Em Planejamento do Set pela Universidade de São Paulo (1970) , doutorado em Saúde Pública pela Faculdade de Ciências Médicas e Biológicas de Botucatu (1974), ensino-fundamental-primeiro-grau pelo Colégio Moderno (1950) , ensino-fundamental-primeirograu pelo Colégio Moderno (1954) e ensino-medio-segundo-grau pelo Colégio Moderno (1957) Atualmente é professor titular da Universidade de São Paulo. Tem experiência na área de Saúde Coletiva. Atuando principalmente nos seguintes temas: SUS, Norma Operacional Básica.

(Texto gerado automaticamente pela aplicação CVLattes)

Última atualização do currículo em 06/08/2010

Endereço para acessar este CV:

http://lattes.cnpq.br/9508773475748684

Certificade

pelo autor em

$06 / 08 / 10$

\section{Dados pessoais}

Nome Eurivaldo Sampaio de Almeida

\section{Nome em citações ALMEIDA, E. S.}

bibliográficas

Sexo Masculino

Endereço profissional Universidade de São Paulo, Faculdade de Saúde Pública, Departamento de Prática de Saúc Avenida Doutor Arnaldo, 715

Cerqueira César

01246-904 - Sao Paulo, SP - Brasil

Telefone: (11) 30617792 Fax: (11) 30883283

URL da Homepage: http://www.tsp.usp.br

\section{Formação acadêmica/Titulação}

1995 Livre-docência

Universidade de São Paulo, USP, Brasil.

Título: Contribuição à Implantação do SUS: Estudo do Processo com a Estratégia Norma Ope 01/93, Ano de obtenção: 1995.

Palavras-chave: SUS; Norma Operacional Básica.

Grande área: Ciências da Saúde / Área: Saúde Coletiva / Subárea: Saúde Pública.

1964 - 1974 Doutorado em Saúde Pública

Faculdade de Ciências Médicas e Biológicas de Botucatu.

Título: Abordagem Sistêmica, como Base do Planejamento em Saúde. Aplicação em uma Rt de Obtenção: 1974

Orientador: Reinaldo Ramos.

1970 - 1970 Especialização em III Curso de Especialização Em Planejamento do Set . Universidade de Sâo Paulo, USP. Brasil.

1958 - 1963 Graduação em Medicina Universidade do Pará.

1955 - 1957 Ensino Médio $\left(2^{\vee} \mathrm{grau}\right)$. Colégio Moderno.

1951 - 1954 Ensino Fundamental ( $1^{\circ}$ grau) Colégio Moderno.

1946 - 1950 Ensino Fundamental (1\% grau) Colégio Moderno. 